\title{
Exploring the instrumental and reactive violence dichotomy in the offences of violent psychopaths
}

\author{
By \\ Jane Flynn
}

\begin{abstract}
A thesis
submitted to Victoria University, Wellington in fulfilment of the requirements for the degree of Master of Science in Forensic Psychology
\end{abstract}

Victoria University, Wellington

April 2013 


\begin{abstract}
In the literature acts of violence are often divided into two dichotomous subtypes: instrumental and reactive violence. The two types of violence are considered to be underpinned by different theoretical paradigms, social learning theory and frustration aggression. This division, although widely criticised and lacking conceptual clarity, appears to be generally accepted in scientific literature. This exploratory study used multidimensional scaling and cluster analysis to see how violence characteristics co-occur in the offences of seriously violent psychopathic offenders; and whether the co-occurrence of offence variables could be explained by the instrumental and reactive dichotomy. The study also explored whether instrumental and reactive violence characteristics differentiate primary and secondary variants of psychopathy, with the hypotheses that primary psychopaths would show more instrumental features in their violence and secondary psychopaths show more reactive features. Findings show that violence characteristics do no co-occur as a mutually exclusive dichotomy and that rather, many violent acts have mix of reactive and instrumental characteristics, reflecting a dimensional rather than a dichotomous structure. This in turn suggests that act specific theories may not be necessary to describe different types of violence. Contrary to prediction, psychopathic subtypes did not differ on violence characteristics.
\end{abstract}




\section{Acknowledgements}

There are a great number of people to thank who helped the creation of this thesis. Firstly thank you to my supervisors; Dr. Devon Polaschek, for her support, guidance, and (apparently infinite) patience, and Dr. Marc Wilson for everything statistical. Thanks also to Victoria University, Wellington Scholarships.

A big thank you also goes to everyone in the "Cellular Psychology" lab, for reading through so many pages of this thesis with good humour, and even better suggestions, even when it was a complete mess; also for the help with kitten and puppy naming.

A special mention goes to Emma, my partner in crime during this process, thank you for the shopping trips, the exercise tips, and generally for being an awesome person to have in the same boat as me.

I would like to thank the New Zealand Department of Corrections for making this research possible and to the staff at Wellington Psychological Services who allowed me to undertake my research alongside them and were unfailingly friendly and welcoming despite the intrusion.

I would like to thank all my friends - thanks for all your help with this thesis, but mostly thanks just for keeping me sane. Special thanks to Paula for being a great friend, a big help, and a fantastic office mate. Thanks to my family - Mum, Pere, Andrew, and Tissy - for always being there. Most of all to Greg who has supported and encouraged me throughout this - I cannot thank you enough. 


\section{Contents}

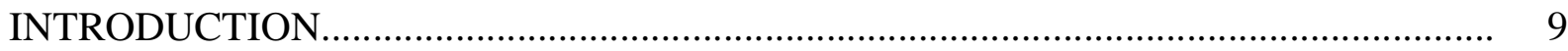

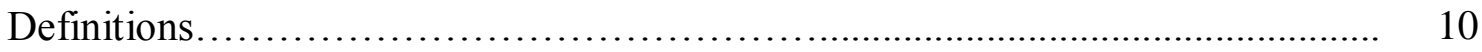

History of the distinction between instrumental and reactive violence.............. 10

Other dichotomies........................................................................ 15

Literature review .......................................................................... 16

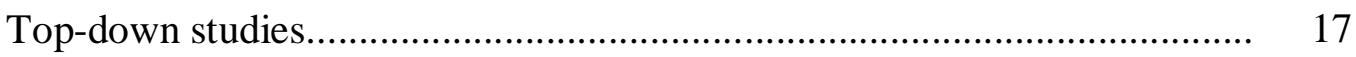

Findings from top-down studies....................................................... 18

Limitations of top-down studies ............................................................ 20

Criterion contamination...................................... 20

Conceptual inconsistency................................ 21

Subtyping violent acts and actors in the same way............... 23

General comments on the top-down studies.......................... 24

Bottom-up studies................................................ 24

Findings from the bottom-up studies............................... 26

General comments on the bottom-up studies......................... 27

The theory of instrumental and reactive violence.............................................. 29

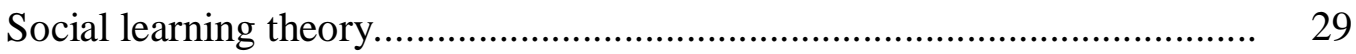

Criticisms of social learning theory................................. 29

Frustration-aggression................................................................ 30

Cognitive neo-association theory.......................................................... 30

Criticisms of FA and cognitive neo-association theory................. 31

Evidence against a two theory model of violence................................................ 32

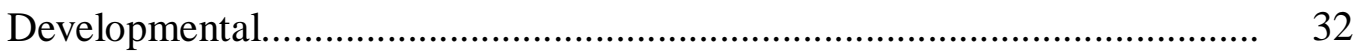

Adult versatility .................................................. 33 


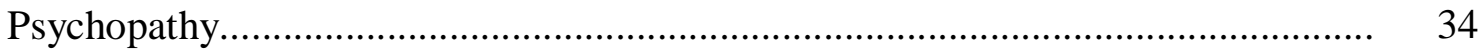

History of the primary and secondary variants of psychopathy.................. 35

Literature review................................................................................ 36

Variants of psychopathy.................................................................. 36

Psychopathy and violence subtypes............................... 37

Aims of the current studies............................................................................ 40

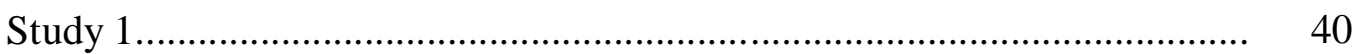

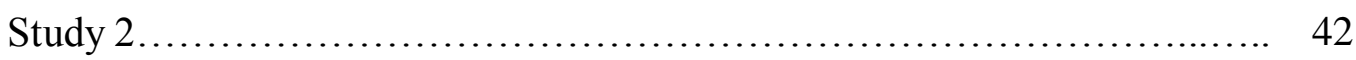

\section{STUDY 1}

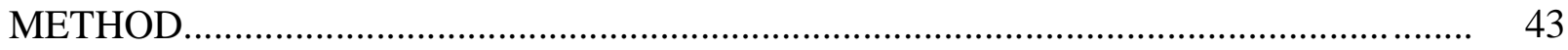

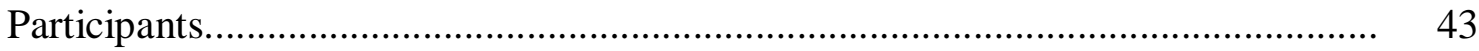

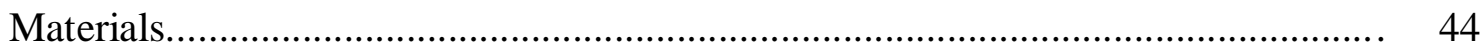

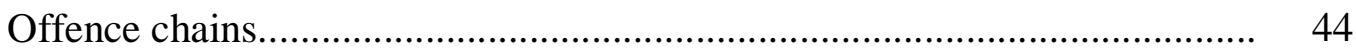

Instrumental and reactive coding scheme............................................ 44

Coding scheme variables................................... 45

Revisions to the coding scheme................................ 48

Inter-rater reliability......................................... 49

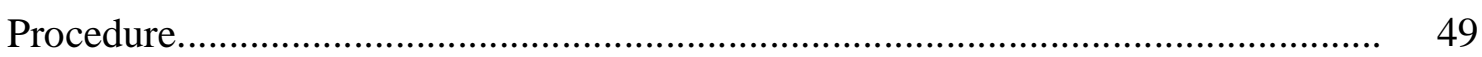

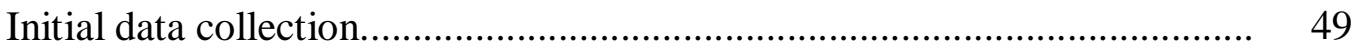

Data preparation for analysis.......................................................... 49

Data analytic strategy........................................................................ 51

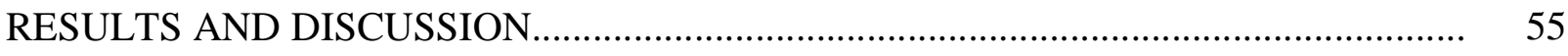

Multidimensional scaling results for all variables............................................ 55

Discussion of multi-dimensional scaling results............................................. 57

Reactive violence variables................................................................... 57 
Instrumental violence variables................................... 58

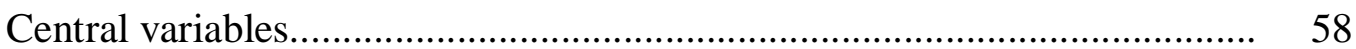

Dimensions....................................................... 59

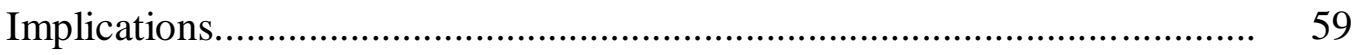

Goals do not differentiate subtypes of violence.................. 60

Provocations do not differentiate subtypes of violence............. 62

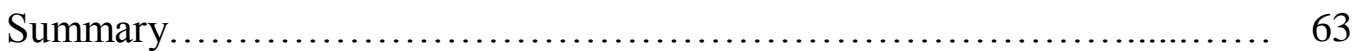

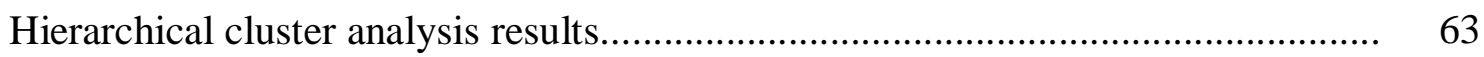

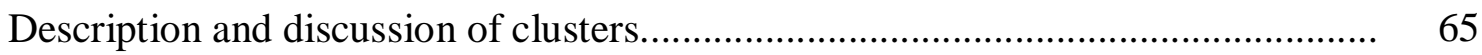

Cluster one: instrumental violence................................ 65

Cluster two: premeditated violence.................................. 66

Cluster three: goal driven reactive violence............................ 68

Cluster four: expressive violence................................. 71

Discussion of hierarchical cluster analysis results.......................................... 72

Underlying affective dimension.................................... 73

Exploratory proximal variables.................................. 75

Evidence for the automatic and controlled processing confound............ 76

Evidence for the typology in previous literature........................ 77

Summary................................................... 78

MDS and HCA results for offence variables................................... 79

Discussion of offence only factors................................................................. 80

\section{STUDY 2}

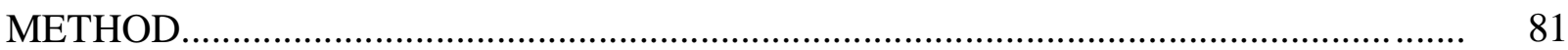

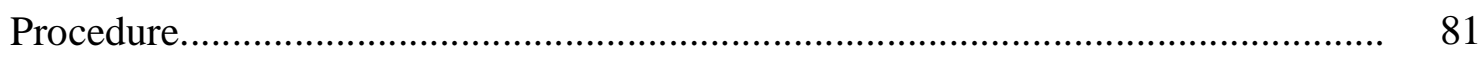

Primary and secondary psychopath variants....................... 82 
Data analytic strategy............................................. 83

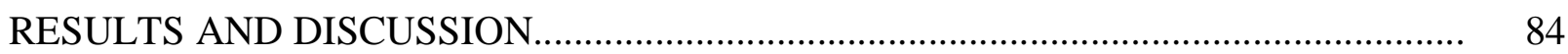

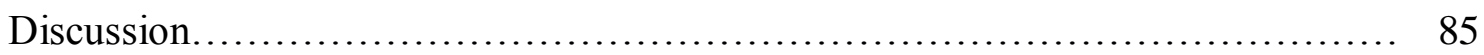

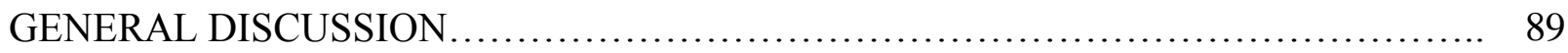

Theoretical implications............................................... 92

Applications............................................................ 94

Limitations and future research............................................. 98

Other comments on future research............................... 101

Conclusion......................................................... 102

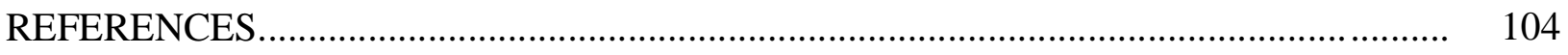

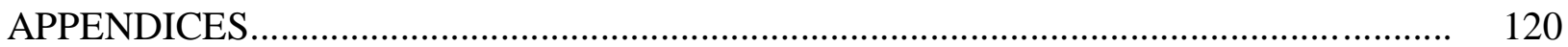

Appendix A- Overview of the main dichotomous distinctions.................... 120

Appendix B-Operationalisations of instrumental and reactive violence variables.... 123

Appendix C-Correlates of instrumental and reactive violence....................... 126

Appendix D-Coding Guide for Violent Incidents (Cornell, 1996)................ 128

Appendix E-Instrumental and Reactive Coding Scheme....................... 135

Appendix F-Watson and Tellegen's Two-Factor Structure of Affect............... 144

Appendix G-Variables used in MDS analysis............................. 145

Appendix H- Dendrogram output for HCA............................... 150 


\section{LIST OF TABLES}

Table 1. Theoretical characteristics of reactive and instrumental violence

Table 2. Outline of the variables used in the coding scheme of the current study.

Table 3. Motives in predatory and dispute related violence (Clarke \& Felson, 1993, p 105) 61

Table 4. Cluster scores for primary and secondary variants.......................... 84

Table 5. Individual variable response frequencies.................................... 85

\section{LIST OF FIGURES}

Figure 1. The MDS scalogram "map"

Figure 2. Hierarchical cluster analysis solution for all variables........................ 64

Figure 3. MDS output and HCA cluster solution for offence variables................... 80 


\section{Introduction}

The word "violence" has many connotations. Armed robbery, domestic battery, and a bar room brawl are all violent offences, yet they are performed in very different ways and for different purposes (Ramirez, 2010). Violence is clearly heterogeneous in both form and function. Mutually exclusive subclasses, or dichotomies, have been developed to make sense of the heterogeneous nature of violence. The differentiation between reactive and instrumental violence is one dichotomy of violence that has dominated the scientific literature for many years. Examining violence subtypes could have both theoretical and practical implications, as according to Kempes, Matthys, de Vries, and van Engeland (2005) different types of violence stem from different sources; produce different emotional, cognitive and behavioural consequences; and have different implications when diagnosing, preventing or treating offenders.

Violence subtyping may be of particular importance in regard to a particular class of offender: psychopaths. Psychopaths, as measured in this study by the Psychopathy ChecklistRevised (PCL-R; Hare, 2003) and Psychopathy Checklist-Screening Version (PCL-SV; Hart, Cox, \& Hare, 1995), are a group that is highly overrepresented within prisons. Studies indicate that between that anywhere $15-30 \%$ of inmates meet diagnostic criteria for psychopathy (Lilienfield \& Arkowitz, 2007). It has been hypothesised (Fontaine, 2007) that psychopaths are also heterogeneous in form, and divide into primary and secondary variants. As such, instrumental and reactive violence characteristics may differentiate these variants. If subtypes of psychopaths can be differentiated by violence type, it could have prognostic value. The current exploratory study examines both the characteristics of violent offences, with particular regard to the instrumental and reactive dichotomy, as well as the relationship of offence types to the variants of psychopathy. 
The introduction is broken into four sections. Firstly, aggression and violence are defined. Secondly, the instrumental and reactive violence subtypes are explored in more detail. In particular the different ways the instrumental and reactive dichotomy of violence have been conceptualised in the scientific literature (Decker, 1996) are considered; the relevant literature is critiqued; and finally the theory and aetiology thought to underlie the two types of violence is considered. The third part of the introduction will consider psychopathy, with particular reference to the primary and secondary psychopathy variants, and how these may be associated with different behavioural correlates in violence enactment. Lastly, the aims of the current study will be outlined.

\section{Definitions}

For this study the definition of aggression and violence as outlined by Gilbert and Daffern (2010) has been used:1) aggression represents behaviour, not an emotion or attitude; 2) there is an intention to cause harm to the victim; 3) there is some type of aversive consequences that occur to the victim; 4) the victim is a living being; 5) the victim is motivated to avoid the harm; 6) violence represents an extreme form of aggression which involves an attempt to carry out serious physical harm, or threat of serious physical harm occurring.

\section{History of the distinction between instrumental and reactive violence.}

Scientific literature (e.g., Bandura, 1973; Feshbach, 1964; Geen, 2001) has long differentiated between reactive and instrumental subtypes of violence. The subtypes hypothetically represent two mutually exclusive forms of violence, which it is thought all violence can be divided into. Instrumental and reactive violence theoretically have different characteristics associated with them, as outlined in Table 1. Reactive violence is considered to be an angry, unplanned act with the goal of harming another person (Bushman \& Anderson, 2001; Vitaro, Barker, Boivin, Brendgen, \& Tremblay, 2006). In contrast, 
instrumental violence is a "cold-blooded" act where the primary goal is to obtain some reward (e.g., money) rather than to inflict harm (Bushman \& Anderson, 2001; Fontaine, 2007; Vitaro et al., 2006).

Table 1.

Theoretical characteristics of reactive and instrumental violence

Reactive Instrumental

$\begin{array}{lll}\text { Antecedent } & \text { Provocation } & \begin{array}{l}\text { Perceived chanc } \\ \text { outcome }\end{array} \\ \text { Intention } & \begin{array}{l}\text { Impulsive; immediate; in } \\ \text { reaction to }\end{array} & \text { Premeditated }\end{array}$

Affect Anger; loss of control No anger

Function Cause harm, or without goal Achieve goals

Note: from Merk, de Castro, Koops, and Matthys (2005); Cima and Raine, (2009); Meloy, (2006)

The history of the distinction begins, it seems, with Buss (1961) who in The Psychology of Aggression defined "angry" (reactive) violence as behaviour that is reinforced by watching victims suffer, and instrumental violence as behaviour that is reinforced by the normal reinforcements of everyday life (e.g., money, status and the like). Buss (1982) referring to his 1961 work states: "Frustration usually leads to angry [reactive] violence, this helps put the frustration-aggression hypothesis in proper perspective" (p. 20). Buss assumed that reactive violence is underpinned by the theory of frustration-aggression, and occurs when the aggressor is angry and vents his anger by inflicting pain on a victim; but such violence, since it is not reinforced by acquisition of a reward, is, in Buss's view, less likely to occur than is instrumental violence. 
Feshbach (1964) proposed a similar distinction: while the primary aim of hostile (reactive) violence is to do harm, instrumental violence serves as a vehicle toward achieving other goals. In making these points, Buss (1961) and Feshbach (1964) not only established the dichotomy that scientific literature still adheres to, but also outlined the two underlying theoretical paradigms: the frustration-aggression hypothesis (Dollard, Doob, Miller, Mowrer, and Sears, 1939; Berkowitz 1962, 1969) to explain reactive violence and social learning theory (Bandura, 1973, 1978) to explain instrumental violence. There has, it seems, been no further theoretical advance since to explain the distinction between instrumental and reactive violence.

Since its inception, the dichotomy of instrumental and reactive violence has been criticised on several grounds. Importantly, Bushman and Anderson (2001) argued that the distinction between reactive and instrumental violence oversimplifies a highly complex behaviour with multiple motivations and that the dichotomy has such limited validity that it is “time to pull the plug”' (Bushman \& Anderson, 2001, p. 278).

Possibly because of the weakness of the underlying theory (discussed later), many conceptual problems are seen with the traditional operationalisation of instrumental and reactive violence that is outlined in Table 1 . Firstly many violent acts cannot easily be dichotomised. Hartup and deWitt (1974) noted that, as defined by Buss (1961) and Feshbach (1964), both reactive and instrumental characteristics may occur in the same act. Secondly, harm is rarely the only goal of reactive violence; authors including Bandura (1973) have questioned whether any specific motivation to only do harm actually exists. It is also considered that instrumental aggressors may want to harm their victims (Woodworth \& Porter, 2002). Relatedly, it has been argued that insofar as reactive and instrumental violence are both directed toward specific goals, both can be considered instrumental (Felson, 2009). Chambers (2006), for one, found in her study that offences that were committed in a reactive 
manner often displayed an instrumental goal, such as appearing "tough" (p. 67) or reducing threat. Thirdly, reactive acts can be carried out long after anger has passed or an offender may aggress in anger with the instrumental belief that their violence will pay off (Berkowitz, 1993). Lastly, instrumental acts may seem unplanned or automatic because the behaviour is so learned and ingrained (Felson, 2009; Bushman \& Anderson, 2001).

A general criticism also made is that the dichotomy does not take into account temporal shift in form and function of violent acts (e.g., Card \& Little, 2006; Ramirez, Rodríguez, \& Manuel, 2003), for example an instrumental robber may react with violence if the victim is not compliant. Furthermore, the dichotomy takes violent offending out of context. Proximal factors of offending such as relationships, financial stress, drug abuse, are rarely considered even though they are important precipitants to violence (Zamble \& Quinsey, 1997).

A lack of theoretical clarity regarding the instrumental/reactive distinction means that there is disagreement regarding which variables are most important in characterising each type of violence: put simply, it is unclear what each form of violence should actually look like. There are, for example, several overlapping variations on the concept of reactive violence. Berkowitz $(1989,1993)$, in his definition, emphasises the provocation aspect of reactive violence: reactive violence is primarily a hostile response to a perceived attack. Other scholars (Cornell, Warren, Hawk, Stafford, Oram \& Pine, 1996; Woodworth \& Porter, 2002) emphasise a highly emotional response as characteristic of reactive violence. Third, Barratt (1991) and Bushman and Anderson (2001) contend that impulsivity is the hallmark of reactive violence. Similarly, instrumental violence has received varying types of emphasis. For instance, Bushman and Anderson (2001) emphasise the degree to which aggression is premeditated or planned as the most important component of instrumental violence. Other 
scholars (Feshbach, 1964; Cornell et al., 1996) emphasise the aspect of being goal-driven or having clear non-injurious goals as the ultimate aim.

It is necessary for researchers to agree upon operational definitions of violence and its subtypes for it to be of practical use (Parrott \& Giancola, 2007). A typology that is useful must classify offences into groups that are actually different (Hair \& Black, 2010).

As a result of the complexity of instrumental and reactive categorisation, a proposed solution is to consider instrumental and reactive violence as a single dimension (Woodworth \& Porter, 2002), with each type of violence located at opposite ends of a continuum. This would help accommodate the overlap of violence characteristics that occurs between the two types of violence. Alternatively, it is sometime considered that the two types of violence are two separate dimensions, and that most individuals will be either high or low on both dimensions (Walters, 2008).

Bushman and Anderson (2001) also propose a refinement to the dichotomy. They suggest a definition of violence which considers both proximate and ultimate goals. The proximate goal is the immediate intention to do harm, and the ultimate goal is the goal achieved by doing harm. The ultimate goal of assault, for example, may be to enhance status or seek revenge, rather than simply cause harm (the proximate goal). The use of proximate and ultimate goals still allows for discussion of instrumental and reactive violence, but can accommodate acts where there are both reactive and instrumental violence characteristics. Similarly, the social interaction theory (Tedeschi \& Felson, 1994) interprets all aggressive behaviour as ultimately instrumental, in that every act has a goal separate from the goal of harm. Harm is a necessary feature of violence, but never the primary goal, from this perspective. 


\section{Other dichotomies}

In the study of aggression dichotomies of violence similar to that of instrumental and reactive have also been proposed, these include: expressive (hostile) versus instrumental violence (e.g., Bandura, 1973; Hartup \& deWitt, 1974; Kingsbury, Lambert, \& Hendrickse, 1997); impulsive versus premeditated violence (e.g., Barratt \& Slaughter, 1998); proactive versus reactive violence (e.g., Crick \& Dodge, 1996; Dodge \& Coie, 1987; Cornell et al., 1996); dispute related versus predatory violence (Clarke \& Felson, 1993), predatory versus affective violence (Meloy, 2006); annoyance motivated versus incentive motivated violence (Zillmann, 1979); and self-preserving versus need-promoting violence (Toch, 1969). Although the above terms are often used interchangeably, these different dichotomies actually describe overlapping but conceptually different violent offence pathways.

These different dichotomies are defined by offence characteristics that are meant to co-vary in a systematic way (Appendix A contains a description of the most common dichotomies, and the variables which are considered to characterise them). This concurrence of variables makes two assumptions. First it is assumed that within each type of violence, the characteristics that define that specific type will co-occur with one another with regularity (e.g., in reactive violence one would expect anger to co-occur with a lack of planning), this is known as consistency. Secondly, the characteristics of one type are assumed not to co-occur with the characteristics of another type (anger, for example, should not also be seen during instrumental violence); this is known as differentiation (Canter, 2000). However, as with the instrumental and reactive dichotomy, these assumptions are usually not met, as there is overlap in the characteristics used to differentiate the types of violence. If there is overlap between what are meant to be mutually exclusive dichotomies, the validity of the dichotomy becomes questionable. 
An example of this overlap, and the difficulties involved in subtyping violence, is illustrated when considering the question of how to classify a violent act which appears thoughtless to the observer. Instrumental violence is usually seen as thoughtful, where costs and benefits are considered before acting, so it is unlikely that this act would be categorised as such. But frequent use of violence, even instrumental, can become automated so it may appear thoughtless (Bushman \& Anderson, 2001). Reactive violence is usually seen as thoughtless, so this category may be chosen, however people sometimes consider various courses of action and decide that an angry outburst is the best way to achieve what they want. In this way the violence may not be as thoughtless as it appears. It is also unclear exactly how much thought is required before an act becomes thoughtful or planned. Many violent acts may be reasonably assigned to more than one category, this compromises any practical worth of subtyping, as it is hard to know how to best categorise a single act.

\section{Literature review}

It is often stated (e.g., Meloy, 2006; Cima \& Raine, 2009) that there is much evidence and support for the instrumental and reactive dichotomy of violence. But despite the common usage of the various dichotomies in scientific literature, studies which look at instrumental and reactive subtypes do not tend to find these pure types of violence in adult forensic populations.

Violence subtype studies are typically designed in one of two ways. One design methodology involves assigning violent acts to reactive and instrumental groups based on preconceived notions about the behavioural characteristics of each type (e.g., that reactive is impulsive and instrumental violence is planned) and then look for differences, such as levels of psychopathy, between the groups (top-down studies). Other studies follow an atheoretical design to investigate how certain variables measured in a sample cluster together, and 
whether this clustering process uncovers instrumental and reactive subtypes (bottom-up studies).

Top-down studies. Top-down studies will be illustrated with reference to three particularly influential studies, which all aimed to test the validity of the distinction between instrumental and reactive violence: Cornell et al. (1996); Woodworth and Porter, (2002); and Tapscott, Hancock, and Hoaken, (2012). Each study claims to find support for the instrumental and reactive dichotomy with reference to differential external correlates.

The studies by Cornell et al. (1996) examined the relationship between psychopathy and type of violence in 106 male offenders from a medium-security state prison and 50 violent offenders referred for pre-trial examination. The studies looked to distinguish instrumental from reactive offenders on violence characteristics as well as offender psychopathy levels. Similarly, the purpose of the study by Woodworth and Porter (2002) was to examine differences between 125 psychopathic and non-psychopathic individuals in the instrumentality or reactivity of their homicidal offences. Taking a different approach, Tapscott et al. (2012) looked at the frequency of reactive versus instrumental violent offending of 71 violent male offenders. The authors also tested the hypothesis that reactive violent offences would be more severe (i.e., cause physical injury) than instrumental violent offences. Increased severity of violence was considered evidence that offenders were reinforced by harm doing during reactive violence (Berkowitz, 1993), therefore providing support to the hypothesis that the frustration-aggression theory (Dollard et al., 1939) underlies reactive violence.

Each of the above studies began by coding offence descriptions for instrumental and reactive features using a coding scheme or a broad definition of instrumental and reactive violence prepared for this purpose (see Appendix B for an overview of the variables coded in these, and other, studies). For Cornell et al. (1996), the predominance of one type of offence 
(instrumental or reactive) over the other in the overall offending history of an offender was used to define the offender as predominantly instrumental or predominantly reactive. However, in the studies by Woodworth and Porter (2002) and Tapscott et al. (2012) the predominance of instrumental or reactive features in a single offence was used to group the offences as purely reactive, reactive/instrumental, instrumental/reactive or purely instrumental.

Findings from top-down studies. Cornell et al., (1996) found that offenders who had committed at least one act of instrumental violence over their offence histories were relatively more psychopathic than offenders who had no history of instrumental violence. Woodworth and Porter (2002) similarly found a significant relationship between type of homicide and psychopathy. Specifically, Woodworth and Porter found that psychopathic offenders were far more likely to have used primarily instrumental violence (93.3\%), compared with non-psychopathic offenders who were more likely to have committed primarily reactive violence (51.6\%). Tapscott et al. (2012), found that, as predicted, reactive offences were more severe than instrumental offences.

Regarding the frequency of instrumental versus reactive violence and the offence characteristics associated with each type, Cornell et al. (1996) discovered that of correctional offenders, approximately $53 \%$ were classified as predominantly reactive, and $47 \%$ were classified as predominantly instrumental. Among violent pre-trial offenders, $60 \%$ were classified as reactive, and $40 \%$ as instrumental. It must be emphasised that that predominance is not the same as exclusivity. In fact, to deal with mixed violence histories, a double standard was put in place in the coding scheme of Cornell. Essentially, if an offender had any previous instrumental violence they were characterised as "instrumental" (p. 785). However, the utility method of grouping is questionable given that "most, if not all, of the offenders with a history of instrumental violence also had a history of reactive violence" (Cornell et al., 1996, p. 785). 
Reactive offenders conversely could not have any instrumental offences in their offending histories.

Cornell et al. (1996) concluded that no single offence characteristic posed an absolute distinction between the two types of violence, as "crimes appear to have elements of both" (p.785). Although instrumental violence was often premeditated, unprovoked, and coldblooded — as traditionally conceptualised — it could also be opportunistic, escalated by provocation (i.e., if the provocation occurred after the violence was initiated), and accompanied by arousal (e.g., anxiety). This finding speaks against a clear distinction between reactive and instrumental violence, and their use as a dichotomy to describe violence. Cornell et al. also found that the single best characteristic to differentiate instrumental violence from reactive was a clear goal such as robbery.

Among incarcerated homicide offenders Woodworth and Porter (2002) found that approximately $36 \%$ of the offences were classified as "primarily reactive" and $56 \%$ as "primarily instrumental" and 8\% were unclassifiable (p.440). An analysis of the contribution of three separate dimensions (affect, instrumental gain, and impulsivity) thought to underlie the degree of instrumentality of the groups, revealed that although these dimensions were partially interrelated, they each contributed unique variance to the instrumental/reactive coding scheme. However when the three dimensions were entered into a regression analysis concurrently, only impulsivity was a predictor of instrumental and reactive ratings.

The results of Tapscott et al. (2012) provided more encouraging evidence for a dichotomy of violence than those of Woodworth and Porter (2002). Of the 188 violent offences that could be coded, 64 were purely reactive, 4 were reactive-instrumental, 10 were instrumental-reactive, and 110 were purely instrumental. Like the findings of Woodworth and Porter the findings of Tapscott et al. echo the thinking of Buss (1961) that instrumental offences may be more common. Tapscott et al. (2012) concluded that "The general 
conclusion is that reactive and instrumental violence are indeed distinguishable. Few realworld acts of violence could not be dichotomised as reactive or instrumental" (p.216).

Limitations of the top-down studies. It is worth making a note of some of the limitations of the above mentioned research. These are the problems of: criterion contamination; conceptual inconsistency; and using the instrumental/ reactive dichotomy to classify offenders. These will be discussed in turn.

Criterion contamination. To measure the instrumental and reactive behaviours, Cornell (1996) developed a coding system: The coding guide for violent incidents. The first rating attempted to make the distinction between instrumental and reactive offences through a "global" rating based on the rater's overall evaluation of the incident (p.2). Then the remaining eight secondary rating dimensions were used to assess specific characteristics of violence of the offenders' most recent offence only. These characteristics were: planning, goal directedness, provocation, anger, victim injury, victim relationship, intoxication and psychosis. Most of the secondary characteristics were assumed to relate to instrumental or reactive violence in specific ways. For example, high levels of planning and goal directedness define instrumental crimes whereas the offender's perceived provocation and high arousal are features of reactive violence.

It is important in this kind of research that any external variables used to validate group differences are not the same as the variables used to create the instrumental and reactive groups in the first place. In the study by Cornell et al., (1996) the relationship between global ratings (used to group instrumental and reactive offenders) and the secondary characteristic were analysed to clarify the offence characteristics that were or were not linked to the instrumental-reactive distinction. However, the secondary characteristics were not independent of the original instrumental-reactive ratings; in fact many of the criteria were the same, for example the presence of a goal. So the finding by Cornell et al. that the presence of 
a goal could be used to classify violence as instrumental is not surprising given that that is how instrumental violence had been defined in the study.

Conceptual inconsistency. All the authors discussed here began their research with preconceived notions about how instrumental or reactive offences should look so that offences could be grouped by these characteristics. However in each of these studies there are differences in the way instrumental and reactive violence are conceptualised and defined. The empirical basis for these different models of instrumental and reactive violence is not stated. This lack of conceptual clarity suggests a lack of solid theory underlying the instrumental reactive dichotomy which would help to make clear which violence characteristics should cooccur in instrumental and reactive violence. The weaknesses of the underlying theories is made more evident by the fact that both Tapscott et al. (2012) and Cornell et al. (1996) tie instrumental and reactive aggression explicitly to social learning theory and frustration aggression respectively, and yet have quite distinct conceptualisations of what the subtypes of violence should look like.

Cornell et al. (1996) operationalised instrumental violence as violence that was goaldriven and required planning. Reactive violence was defined by an absence of planning or goals, rather it was considered to be a response to provocation. In contrast to Cornell et al., in Woodworth and Porter's (2002) coding scheme, instrumental violence included both violence committed as a means to achieve an external goal (e.g., to acquire money) and also violence committed where harm was the intent of the act (e.g., revenge, acts of sadism). Interestingly in other research (e.g., Douglas, 2010; Tapscott et al., 2012) violence with harm as the central goal was considered clearly reactive. But in this study the goal of harm was no longer important in distinguishing between subtypes. This change by Woodworth and Porter fundamentally altered how the dichotomy was conceptualised and reflects the problems mentioned earlier with the use of harm as a goal to differentiate reactive from instrumental 
violence; that is, it may not be true that reactive violence always has harm as it primary goal, or that instrumental offenders do not want to harm their victims.

Tapscott et al. (2012) also made a fundamental change to the definition of instrumental violence. Consistent with Cornell et al. (1996), Tapscott et al. emphasised that reactive violence has no goal other than harm, while instrumental violence is goal driven; however Tapscott et al. differed from both Cornell et al. and Woodworth and Porter (2002), by removing premeditation as a requirement for instrumental violence. For example, if an offender robbed the victim, the offence was coded as purely instrumental, regardless of whether the act was planned in advance or whether it was opportunistic. These differences allowed for instrumental violence to be automatic.

This change by Tapscott et al. (2012) underscores a problem with the use of planning to define instrumental violence: instrumental acts may seem unplanned because the behaviour is so learned and ingrained (Felson, 2009). According to Anderson and Bushman (2001) instrumental-reactive dichotomy is confounded with the automatic-controlled information processing dichotomy. They consider that reactive violence is defined as being automatic (i.e., unreasoned, impulsive, uncontrollable, and spontaneous) and instrumental violence is defined as being controlled (i.e., reasoned, calculated, and premeditated); but these definitions do not account for the fact that some obviously reactive violence has many controlled features (e.g. responding aggressively only when target is unarmed), and instrumental violence may appear automatic when practised often. This point echoes the work of Todorov and Bargh (2002) who describe studies showing that repeated use of aggression-related concepts (i.e., through exposure to aggression-related events) can result in individual differences in both the perception of others', as well as in one's own, behaviour. Simply put, exposure to aggression and use of violence can make violence an automatic behaviour. 
Another way of looking at the above mentioned confound, and using the terminology of Megargee $(1966 ; 1979)$, is that that experience with violence in the chronically under controlled is confounded with loss of control in the chronically over controlled, as both may lead to violence which appears automatic or impulsive. In an attempt to understand how a formerly non-violent person can engage in acts of extreme violence, Megargee developed a theory of aggression that proposes two types of violent individuals: over-controlled and under-controlled personalities. The over controlled personality type requires intense provocation in order to act violently as they are inhibited against violent behaviour. However, once the threshold of control is breached, the resulting act of violence is extreme. Undercontrolled personality types, by contrast, have a lower tolerance level and little self-control in conflict situations. Compared to individuals with over-controlled personality, the undercontrolled personality offenders act violently more often, yet less severely.

Subtyping violent acts and violent actors in the same way. Also seen in the study by Cornell et al. (1996) is the use of the instrumental and reactive dichotomy of violence to classify offenders. Some researchers argue that instrumental and reactive violence types indicate different emotional, cognitive and behavioural correlates (see Appendix C) of the perpetrators (Merk, de Castro, Koops, \& Matthys, 2005) and that the distinction has implications for diagnosis, prevention, and intervention of those who perpetrated the offences. Tapscott et al. (2012) for example, suggest that individuals with different proportions of instrumental versus reactive violent offences may benefit from alternative courses of treatment (p.214). However this tendency to use the instrumental/reactive dichotomy as though it applies to offenders rather than offences is problematic. The definition of instrumental and reactive violence clearly refers to specific offence behaviours, but grouping offenders in this way suggests that the instrumental and reactive violence types are correlated to distinct and consistent personality traits (Vitaro \& Brendgen, 2005). 
However, classifying offenders as instrumental or reactive, in fact, makes very little sense given that most recidivist offenders "appear to use violence for many different purposes determined by the situation" (Chambers, 2006, p.58) and that most findings suggest that individuals use both kinds of violence (e.g., Cornell et al.,1996; Woodworth and Porter, 2002).

General Comments on top-down studies. What is immediately clear from the studies reviewed above is that even by starting with preconceived notions we cannot find a clear instrumental - reactive dichotomy of violence. There is always a mixing of the instrumental and reactive types both over offence histories (Cornell et al., 1996) and in individual offences (Woodworth \& Porter, 2002; Tapscott et al., 2012). The fact that most people have a history of both offence types, and that "no one offence characteristic is synonymous with instrumental or reactive violence" is evidence against the usefulness of the dichotomy. This finding illustrates the arguments by Bushman and Anderson (2001) that it is often not possible to definitively conclude whether an aggressive act is reactively or instrumentally motivated.

The level of support these studies provides for the existence of clear dichotomous subtypes is arguable. However, some support for the instrumental and reactive groups may be seen in the differential relationship of psychopathy (Cornell et al., 1996; Woodworth \& Porter, 2002) and violence severity (Tapscott et al., 2012) to the subtypes present.

Bottom-up studies. The second group of studies from Ohlsson and Ireland (2011), Kockler, Stanford, Nelson, Meloy, and Sanford, (2006), and Tkatchouk (2006) have all taken an exploratory approach to the problem of subtyping violence, and have allowed the data to co-vary as it will, to see if the traditional instrumental/reactive dichotomy is found. These studies, on the whole, have provided little support for the idea of two discrete subtypes of 
violence. The below studies looked at offence characteristics rather than person traits, and were selected for their use of adult forensic samples.

In support of the position that subtyping violence may be useful, but that pure forms of violence rarely exist (Block \& Block, 1992), the research by Kockler et al., (2006) tested models of violence in a convenience sample from a forensic state hospital $(n=86)$. Similarly, Ohlsson and Ireland (2011) looked at 206 medium security adult male prisoners to examine aggression motivation, and explore whether the dichotomy of reactive and proactive (instrumental) motivation exists in extreme samples. In a corresponding study stemming from the criminal profiling literature, Tkatchouk (2006) undertook research to see how offence and offender variables cluster together. An attempt was made to classify 550 stranger homicide offenders into a number of groups that were statistically different with respect to offence behaviours and offender characteristics.

The three studies all began by gathering variables relevant to violence and aggression, and used these to group their research samples into clusters of similar types of offences or offenders. Kockler et al. (2006) administered a self-report measure of impulsive and premeditated aggression: the Impulsive/Premeditated Aggression Scale (IPAS; Stanford, Houston, Mathias, Villemarette-Pittman, Helfritz, Conklin, 2003) and used scores on this measure to group their sample by undertaking an exploratory principal components analysis (PCA) on the 30 items of the IPAS. Ohlsson and Ireland (2011) used a similar method, collecting individual scores on completed Aggression Motivation Questionnaires (Ireland, 2008), then conducting a Principal Component Analysis (PCA) on the items of this questionnaire to group the sample. Tkatchouk (2006) took a different approach and used two clustering processes (Wards and K-Means) to cluster 56 offence and offender behaviour variables. The solutions provided by the two analyses were then cross-tabulated. Clusters 
produced under Ward's method which remained together under K-Means were labelled stable clusters and retained.

Findings from the bottom-up studies. The study by Kockler et al. (2006) produced two main findings. Firstly, a factor analysis on the IPAS yielded two factors which broadly looked like the conceptualisations of impulsive and premeditated aggression. Data on the IPAS suggested that $34(40 \%)$ participants could be classified as predominately premeditated aggressive and $51(60 \%)$ could be classified as predominately impulsive aggressive. The second finding was that the scales which comprised the two factors were significantly intercorrelated $(r=.40, p<.01)$. According to the authors the findings from this study provided empirical support for the bimodal classification of aggression.

Instead of uncovering two types of offence motivation as hypothesised, Ohlsson and Ireland (2011) found the presence of four aggression functions: provocation (to defend self and others, being provoked), social recognition (gaining or maintaining a reputation), positive outcome (believing violence would have a positive outcome or using violence because it has worked in the past) and pleasure (sadism). Anger was related to all core aggression motives, which may suggest anger is of limited importance in subtyping violence despite it often being used to define reactive aggression. This is notable as it relates to another criticism of the instrumental and reactive dichotomy that has been put forward: reactive acts of violence can be carried out long after anger has passed, or an offender may aggress in anger with the instrumental belief that their violence will pay off (Berkowitz, 1993). Ohlsson and Ireland state that: "it may be reasonable to deduce from the results that an exclusive reactiveproactive distinction was not found and that instead aggression in forensic populations may be explained better by a concept of mixed motives" (p.284).

The results of Tkatchouk (2006) revealed nine stable clusters. The variables that were coded included: crime scene information (11 variables), offender's behaviour before, during, 
and after the commission of the crime (20 variables), victim characteristics (25 variables), and offender's background characteristics (physical, social, sexual, and history; 20 variables).

General comments on the bottom up studies. Again the main finding from these studies appears to be that the reactive/instrumental dichotomy of violence is insufficient. The study by Kockler et al. (2006) appears to support the dichotomy; however, the high intercorrelation between the instrumental and reactive constructs that was found is problematic. One of the major criticisms levelled at the dichotomy of instrumental and reactive subtypes is that, as with the Kockler et al. study, a strong correlation between the two forms of violence is often seen (e.g., Crick \& Dodge, 1996; Dodge \& Coie, 1987; Hubbard et al., 2002, Woodworth \& Porter, 2002; Cornell et al., 1996). Specifically, it is the strength of the relationship between reactive and instrumental violence has been a primary focus of the controversy. Empirical studies show consistently strong correlations between reactive and instrumental violence within adult populations (e.g., $r=.74$, Cima, Tonnaer, \& Lobbestael, 2007; $r=.70$, Ostrov \& Houston, 2008). These correlations imply that that the two subtypes of violence tend to co-occur with an individual and within an aggressive act (Merk et al., 2005) and so may not be able to be usefully separated. This correlation is of concern because, if instrumental and reactive violence are not independent of one another, a dichotomy does not exist and subtyping violence is unlikely to be useful (Merk et al., 2005).

Neither the findings of Ohlsson and Ireland (2011) not those of Tkatchouk (2006) provide evidence for an instrumental and reactive dichotomy. It is interesting to note that the offence characteristics did not clearly dichotomise in the study by Tkatchouk. Clusters described variously as reactive, opportunistic, planned, unplanned, economically motivated and unclear were found, suggesting again that the classification of offences may be more complex than a dichotomy would suggest. The findings of Ohlsson and Ireland, similarly do not support the instrumental and reactive distinction, rather they demonstrate how valuable 
information can be lost if behaviour motivation is not expanded beyond the "rather crude reactive-proactive distinction" (Ohlsson \& Ireland , 2011, p.284). The results of Ohlsson and Ireland (2011) and Tkatchouk (2006) both suggest a "more comprehensive framework is required for forensic samples, one that moves away from a simple dichotomy" (Ohlsson \& Ireland 2011 p. 285)”.

This lack of a clear dichotomy in the findings is probably not surprising as it is not always obvious when a violent action belongs to a specific category. Frequently, many acts of violence arise from unclear and multiple motives. For example, Greenberg (as cited in Felson, 2004) found that employees who thought they were underpaid punished their employer through the act of theft: a mix of instrumental and reactive goals driven by anger. Even violence which starts out as clearly instrumental or reactive may change. Weinshenker and Siegel (2002) linked animal and human research on violence, and found that within one violent event motives may switch between reactive and instrumental. Weinshenker and Siegel suggest that "individuals displaying [instrumental] violence may shift to [reactive] aggression when the victim is in physical contact with the aggressor... it is possible that the reverse sequence may take place” (p. 243).

While there is evidence that there are a number of variables which may distinguish violence into different types (e.g., affect, planning, provocation etc.), evidence also seems to suggest that these violence characteristics can be mixed and matched during an act of violence, rather than existing only in opposition to each other, i.e., neither consistency or differentiation occur in regards to the variables the are meant to characterise instrumental and reactive violence. Given this mixing of violence characteristics, it is hard to know how violence should be classified as instrumental or reactive, or why. 


\section{The theory of instrumental and reactive violence}

As mentioned previously, two separate theoretical paradigms have consistently been used to explain reactive and instrumental violence. Social learning theory (SLT) has been thought to explain instrumental violence (Bandura, 1973, 1978), which is thought to be driven by positive outcome and efficacy expectancies for offending behaviours. In comparison, reactive violence is understood from the framework of the frustration-aggression hypothesis (Berkowitz, 1989; Dollard et al., 1939) and is thought to be underpinned by poor social-emotional adjustment and hostile attribution biases for aggression. However if real world violence cannot be dichotomised, which the cited evidence suggests it cannot, the same theoretical principles should be able to explain all violent behaviour. In this section each paradigm will be considered in turn, and then the evidence for requiring separate theories to explain the instrumental and reactive violence distinction will be assessed.

Social learning theory. Bandura's (1978) social learning theory focuses on the social influences in the development of an individual. In regard to violence, the theory suggests that instrumental violence can be learned vicariously when rewarding consequences are observed to be associated with the aggressive behaviour of others; this provides incentive to engage in similar behaviour (Tapscott et al., 2012). There has been empirical support for SLT, in particular from Bandura's studies with children who demonstrated increased violence when it had been modelled (Bandura, Ross, \& Ross, 1963) and especially when the modelled violence had been rewarded (Bandura, 1965).

Criticisms of social learning theory. Social Learning Theory is considered the most psychologically complete theory of human behaviour (Hollin, 1989), however while the SLT model explains the development of offending behaviour, it says little about the role of cognitions in the acquisition of antisocial behaviour (Hollin, 1989). SLT has also been criticised as it may ignore factors such as emotion and personality (the internal context of an 
individual) in favour of the external learning context. Feldman (1993) suggested that the links between social learning and biological, family and social precursors of offending need to be worked out more fully, to explain why some children are more likely to become offenders than others.

Frustration-aggression. According to the frustration-aggression theory originally conceived by Dollard et al. (1939), individuals possess an internal drive to behave aggressively and this drive is activated when there is interference in goal directed activity (frustration). Only the aggressive acts are capable of reducing the instigation to aggress; violence therefor is seen as cathartic.

As originally proposed, the frustration-aggression hypothesis held that (a) aggression is always based on frustration and (b) frustration always leads to aggression (Dollard et al. 1939), propositions that are not always true (Robarchek, 1977). The reformulation of the frustration-aggression theory advanced by Berkowitz $(1962,1969)$ was less narrowly defined. Berkowitz argued that aversive events in general (e.g., pain, depression, fear etc.) as well as frustration, lead to violence. Berkowitz (1962) proposed that every frustration increases anger, and that anger may be the primary inborn reaction to goal interference. The connection between frustration and aggression seems to be, for Berkowitz, an innate response sequence, where anger is an inevitable response to frustration, which in turn may lead to aggression and violence.

Cognitive neo-association theory. The cognitive neo-association Theory (Berkowtiz, 1998) subsumes the earlier frustration-aggression hypothesis. The theory provides a causal mechanism to explain why aversive events increase aggressive behaviour.

Cognitive neo-association theory states that negative feelings and experiences are the main causes of anger and angry aggression. The theory assumes that cues present during an aversive event become associated with the cognitive and emotional responses triggered by the 
event (Anderson \& Bushman, 2001). Negative affect produced by unpleasant experiences, such as depression, pain, crowding, or provocations automatically stimulates associated aggressive thoughts, memories, expressive motor reactions, and physiological responses that have become linked together. These responses in turn stimulate anger (Anderson \& Bushman, 2002). The likelihood that an angry person will act aggressively depends on his or her interpretation of the motives of the people involved.

Criticisms of frustration-aggression and cognitive neo-association theory. Frustrations do not always cause aggressive actions. The body of research has on the whole been unsuccessful at clarifying the nature of the relationship between a frustrating event and an aggressive outcome. There have been a variety of cases where a frustration arising in interpersonal interaction produces not anger, but rather fear. Moreover, the behavioural response to this frustration is not necessarily aggression but rather a variety of coping mechanisms directed toward dealing with the perceived threat and the fear it evokes (Robarchek, 1977).

The catharsis hypothesis is considered to be largely discredited and empirically false (Bushman, 2002; Rameriz 2010). Research into the cathartic effect of violence has generally shown that catharsis does not reduce negative affect or aggressive feelings (Geen, 2001). Bushman (2002) describes a study where subjects who hit a punching bag proceeded to aggress towards the confederate even more than those who did not do the catharsis activity. The results from this research demonstrate that, in the Bushman's words, "venting to reduce anger is like using gasoline to put out a fire-it only feeds the flame" (p.729).

Suggesting an innate drive to aggress appears to be unnecessary to explain why reactive violence occurs. It may only provide one example of why an offender may be motivated to act in these situations (Robarchek, 1977). Nor does frustration-aggression appear to be a specific explanation of reactive violence; even if we take frustration- 
aggression at face value there is no clear reason why a response to goal blocking should use specifically reactive violence to relieve the situation. The frustration-aggression hypothesis is simply too broad and sweeping.

Generally, cognitive neo-association is seen as having better explanatory power than the frustration-aggression hypothesis, but still runs into the problem that violence need not arise from negative affect. Cognitive neo-association has also been criticised for overgeneralising the impact of negative social environments on an individual. This criticism is from Tedeschi and Felson (1994) who state: "the assumption that there is an automatic relationship between aversive stimuli and reactive aggression ignores the important role of the parties involved and why they support a violent response in a given situation context" (p.368). Put simply, individuals and their own personal contexts of learning, attitudes and attributes are largely ignored. Cognitive neo-association theory and the frustration-aggression hypothesis both largely overlook the role of learning in violence enactment, even though it is clear that learning at the very least shapes what violence looks like, if not why it comes about (Patrick \& Zempolich, 1998).

\section{Evidence against a two theory model of violence}

Developmental. Many empirical studies have considered that there are separate aetiological pathways for instrumental and reactive violence (e.g., Dodge, Lochman, Harnish, Bates \& Pettit, 1997). However, given that the evidence suggests that offenders use both forms of violence (Cornell et al., 1996), it seems that if there is a developmental pathway for each type of violence, it is most likely that these pathways do, or can, co-occur in the same offenders.

In her thesis Van’t Klooster (2011) looked at the developmental pathways of seriously violent male offenders. Her findings suggested much developmental similarity between these offenders. The men interviewed predominantly came from homes where drug use, violence, 
and other forms of abuse were prolific. Violence directed at and witnessed by the sample at an early age led to violence becoming a learnt behaviour. As men, the lessons were taken with them into the adult lifestyles, resulting in drug use, gang memberships and domestic violence being common. While a change in violence was seen over time (e.g., increasing complexity of goals with age), both reactive and instrumental kinds of violence were seen in all the individuals.

The conclusion from Van't Klooster (2011) was that early development provides the scaffolding upon which future lifestyle is based; such as through introduction to antisocial associates, learnt behaviours, and life changing events. Lifestyle directly influences goal directed violence behaviour, with drug use, antisocial relationships and boredom often leading to an increase in violence. The thesis suggests that offenders come from similarly violent backgrounds, where violence is learned, but they are versatile in whether they chose to use instrumental or reactive violence. Common offender backgrounds may lead to the fluid use of both forms of violence in ways that cannot be captured by the instrumental and reactive typology.

Adult versatility. Specialisation of offenders refers to the tendency of an offender to commit an offence of a particular type, for example robbery, burglary, or assault (Miller \& Lynam, 2006). Despite a common belief in offender specialisation, evidence suggests that this belief is a myth perpetuated by television rather than reality. Evidence instead supports the view that that the majority of offenders are criminally versatile (Simon, 1997). In studies by Paterson and Braiker (as cited by Simon, 1997) and in a study by Simon (1997) half of the samples admitted a variety of criminal offending in the lead up to imprisonment. Between $1 \%$ (Simon, 1997) and 10\% (Paterson and Braiker, as cited by Simon, 1997) could be referred to as specialists, in the sense that one type of offence was commonly repeated, but even then these offenders still committed other sorts of offences. 
If the offenders and the offences do not differentiate clearly, either during development or in the types of violence acts they commit it is unlikely that we need specialist theories for each form of violence. Separate aetiologies and underlying mechanisms are simply not necessary to explain violence. Put simply this versatility and variability of offenders, and the lack of evidence for discrete, unmixed, subtypes of violent offences, suggests that a general causal process is capable of explaining much of the variation in violent crime.

\section{Psychopathy}

Psychopathy is a constellation of relatively distinctive personality traits such as callousness, manipulativeness, egocentricity, impulsivity, and a need for stimulation (Cleckley, 1941; Hare, 1991) as well as a history of early, pervasive antisocial behaviour. The term psychopath is usually used as though it denotes only a single type of person; this person usually fits into the conceptualisation of psychopathy made popular by Cleckley (1941). In his seminal work The Mask of Sanity (1941) Cleckley marked the start of the conception of psychopathy as a particular type of antisocial, emotionless and criminal character. Cleckley believed that a psychopathic person was someone who is outwardly a perfect mimic of a normally functioning person, but is masking a fundamental lack of normal personality, genuine emotion or conscience. However, far from all psychopaths being cold, calculating, "Clecklian" individuals, the term "psychopathy" may, in fact, be a label applied to a very diverse group of individuals who display significant trait differences (Poythress \& Skeem, 2006). For example individuals with similarly high scores on commonly used measures of psychopathy appear to differ markedly from one another in emotional stability. To make sense of the differences between those who meet the criteria for psychopathy, prior taxonomies have suggested a distinction between primary and secondary psychopathy (e.g., Karpman, 1948; Lykken, 1995). Primary psychopaths are said to exhibit traits such as lack of 
remorse, lack of empathy, and shallow emotions. Secondary psychopaths, conversely, experience more anxiety, impulsivity, and attachments to others.

The Psychopathy Checklist-Revised (PCL-R; Hare, 2003) is considered the "gold standard" in the assessment of psychopathy among incarcerated offenders (Fulero, 1995). The checklist is based partly on the conceptualisation of psychopathy by Cleckley (1941) of a psychopath as an individual who is callous, unemotional, self-centred, and charming, but to the world displays a facade of excellent overall mental health.

As measured by the PCL-R, psychopathy encompasses both affective/interpersonal traits, known as Factor 1 characteristics on the PCL-R (e.g., glibness and superficial charm, pathological lying, lack of remorse, and shallow affect) as well as Factor 2 characteristics associated with a chronically antisocial and unstable lifestyle (e.g., a need for stimulation, impulsivity, lack of realistic goals, and promiscuity). Secondary psychopaths are reportedly characterised by greater anxiety and negative affectivity, a higher level of substance abuse, and lower scores on PCL-R Factor 1 than primary psychopaths (Blackburn, 1998).

History of the primary and secondary variants of psychopathy. The case for variants of psychopathy primarily stem from the work of Karpman (1941, 1948a, 1948b) who initially proposed the split of primary and secondary types. Karpman (1948b) suggested that on the surface both subtypes display the same symptoms: they both "lie, cheat and swindle; they are irresponsible and unreliable; seemingly have no feeling or regard others....they seem not to profit by experience, repeating the same blunders over and over again” (p.475). But that on closer inspection, that the majority of these people's psychopathic behaviour stems from, and is secondary to, other underlying clinical conditions (Karpman, 1948a). The remaining minority of psychopaths do not have underlying conditions, so psychopathy is their primary disorder. 
Karpman (1941) specified that secondary psychopaths are more hot-headed or impulsive and under certain conditions display signs of empathy, love, guilt and a need for affection. Primary psychopaths are void of these emotions and are at the core cold, calculating, hedonistic, egotistical and selfish. Karpman hypothesised that secondary psychopathy arose out environmental circumstance, while primaries were born with this affective deficit. For this reason it is considered that secondary psychopaths will be more amendable to treatment efforts. Primary psychopaths conversely are not treatable since there is simply no underlying cause to work with.

\section{Literature review}

Variants of psychopathy. Several cluster analytic studies have derived subtypes with characteristics consistent with the theoretical conceptualisations of primary and secondary psychopathy. Blackburn (1975), using the Minnesota Multiphasic Personality Inventory (MMPI), found evidence for two groups of impulsive, under socialised criminals among patients at a high-security British psychiatric hospital: one with low anxiety, and one with high levels of anxiety and greater proneness to guilt. Henderson (1982) replicated these findings, again using the MMPI, among violent offenders. Wales (1995), using the Millon Clinical Multiaxial Inventory (MCMI), found two clusters of offenders with psychopathic traits among referrals to a forensic psychiatric service. Both scored high on the antisocial, narcissistic, and histrionic scales of the MCMI. However, the first psychopathic cluster was relatively free of additional pathology, whereas the second cluster exhibited high scores on scales measuring schizoid, avoidant, dependent, and passive-aggressive traits.

Using model-based cluster analysis on the PCL-R and trait anxiety scores for 124 inmates with histories of serious violent offences, Skeem, Johansson, Andershed, Kerr, and Louden (2007) found two clusters which paralleled the primary and secondary distinction. Compared to primary psychopaths, secondary psychopaths had significantly higher trait 
anxiety and lower PCL-R scores. Secondary psychopaths also manifested more borderline personality features, poorer interpersonal functioning (e.g., irritability, withdrawal, lack of assertiveness), more symptoms of major mental disorder, poorer clinical functioning, and a trend toward greater potential treatment responsivity, than did primary psychopaths.

These studies and others like them (e.g., Blackburn, Logan, Donnelly, \& Renwick, 2008; Swogger, Walsh, \& Kosson, 2008; Swogger \& Kosson, 2007) provide support for the proposition that psychopaths can be divided into groups consistent with how the primary and secondary variants of psychopathy have been conceived (Skeem, Polaschek, Patrick, \& Lilienfeld, 2011).

Psychopathy and violence subtypes. Given their propensity toward violence in general, as well an association with impulsivity and poor behavioural controls, the use of reactive violence may not be unexpected from the criminal psychopath. However, most commonly, a general relationship between instrumental violence and psychopathy is cited, for example Cornell et al. (1996), state that that "because of their insensitivity to social, moral, or emotional prohibitions against violence, psychopaths may be more willing to engage in violent behaviour for instrumental purposes" (p. 784).

A number of studies have investigated the relationship between type of violence and psychopathy. However, the results of these studies have sometimes been confusing and there is disagreement about the extent to which the instrumental-reactive distinction is useful in differentiating the violence committed by psychopathic individuals versus non-psychopathic individuals.

Williamson, Hare, and Wong (1987) examined the nature of the violent offences in a group of 101 Canadian offenders. They found that psychopathic offenders frequently were motivated by material gain or revenge ( $45.2 \%$ compared with $14.6 \%$ of the non-psychopaths) and did not appear to have been in a state of heightened emotional arousal at the time of the 
violent act, all of which is suggestive of instrumental violence. In contrast, non-psychopathic offenders appeared to have experienced more emotional arousal during their crimes: $31.7 \%$ of the non-psychopaths exhibited strong emotional arousal - such as jealousy, rage, or a heated argument during their offence - compared with $2.4 \%$ of the psychopaths. This arousal is suggestive is reactive violence.

Cornell et al. (1996) found that, across their criminal histories, psychopaths (as classified using the PCL-R) were more likely to have committed instrumental violence than non-psychopaths (who were more likely to have committed reactive violence). However it is noted by Cornell and colleagues that possibly no offender in their sample had a purely instrumental offending career. Similarly, Woodworth and Porter (2002) found psychopathic offenders were significantly more likely, to have used primarily instrumental violence (93.3\%), compared with non-psychopathic offenders who were more likely to have committed primarily reactive violence $(51.6 \%)$ when committing stranger homicides; although the psychopathic group did have other reactive offences in their offence histories.

Dempster, Lyon, Sullivan, and Hart (1996) investigated the institutional files of 75 adult male violent offenders participating in an inpatient treatment program. Although psychopaths were found to have committed more instrumental violence, they also had displayed impulsive behaviour in the context of their offences. Based on these findings, Hart and Dempster (1997) concluded that even if psychopathic individuals commit more instrumental crimes, they may be "impulsively instrumental" (p.227). Woodworth and Porter (2002) also suggest that psychopaths may have "selective impulsivity" (i.e., choosing to be impulsive; p.443), due to their apparent versatility in the use of both instrumental and reactive violence. It is likely, then, that psychopaths can and do engage in both forms of violence.

There is some evidence that instrumental violence is related to the Factor 1 features of psychopathy, whereas reactive violence is more associated with the Factor 2 characteristics 
(e.g., Patrick \& Zempolich, 1998), but again the evidence is mixed. Several studies have provided support for a relationship between PCL-R Factor 1 (affective/interpersonal) and instrumental violence (e.g., the forensic sample in Cornell et al., 1996; Vitacco, Neumann, Caldwell, Leistico, \& Van Rybroek, 2006; Woodworth \& Porter, 2002). However some studies have found no support for the theoretical relationship between Factor 1 and instrumental violence (correctional sample in Cornell et al., 1996). Similarly, several studies indicated an association between PCL Factor 2 (social deviance/antisocial behaviour) and instrumental violence (correctional and forensic samples in Cornell et al., 1996; Camp, Skeem, Barchard, Lilienfeld, \& Poythress, 2013). However, one study suggested no such association (Woodworth \& Porter, 2002), and one study suggested a negative association (Vitacco et al., 2006). This suggests the relationship between type of violence and psychopathy is hazy at best.

It is thought that one of the ways the primary and secondary variants of psychopathy may differ is in the type of violence they use. It has been suggested (e.g., Falkenbach, 2004) that primary psychopathy will have a stronger association with instrumental violence and secondary psychopathy with reactive violence (Skeem, Poythress, Edens, Lilienfeld, \& Cale, 2003). As well as distinguishing primary and secondary psychopaths generally, Karpman (1948a) also differentiated the two subtypes in terms of reactivity, suggesting: “... the true [primary] psychopath ...often coolly and deliberately plans his actions...” (p.528). Patrick and Zempolich (1998) similarly noted that “'. . .aggression in the 'pure,' [primary] psychopath is more likely to be appetitively oriented (i.e., 'instrumental') than defensively motivated', (p.313). The literature examining this relationship is, however, extremely sparse.

One study which looks at the association between violence subtypes and psychopathy subtypes is the thesis of Falkenbach (2004) who, as a validation of primary and secondary psychopathy theories, compared subclinical clusters analogous to the primary and secondary 
psychopathy subtypes on measures of aggression. Falkenbach hypothesised that the prototypical primary and secondary groups would differ significantly in the types of aggression that they manifested, with instrumental aggression being more prevalent in the cluster with primary traits. To this end a study was conducted on a non-forensic adult sample (96 college students) who described acts of aggression. These acts were rated as instrumental or reactive using an adapted version of the rating scale developed by Cornell et al. (1996). The students were clustered on measures of aetiology (Behavioural Activation System and Behavioural Inhibition System; Gray, 1985), psychopathy (Levenson's psychopathy measure; Levenson, Keihl, \& Fitzpatrick, 1995) and anxiety (State Trait Anxiety Inventory; Speilberger, Gorsuch \& Lushene, 1970) to look for primary and secondary "like" psychopathy subtypes. Four clusters emerged, two of the clusters were representative of subclinical primary and secondary psychopathy and the other two represented nonpsychopathic groups.

It was found that there was a positive association between psychopathic traits and violence types. Specifically, the prevalence of combined instrumental/reactive aggression was nearly three times higher in the Primary-Psychopathic-like-traits cluster than in the Secondary-Psychopathic-like traits cluster. Falkenbach (2004) concluded that her results support the existence of sub-clinical subtypes of psychopathy that resemble, in meaningful ways, primary and secondary clinical variants.

\section{Aims of the current studies}

Study 1. The current research is an exploratory study analysing violent offenders' narrative accounts of their violence ("offence chains") to see how offence variables considered important to the instrumental and reactive violence dichotomy (e.g., affect, planning, and goals) co-occur in the offences of seriously violent psychopaths. This will 
effectively "make sense" of how different types of violence manifest; and whether this presents us with a clear dichotomy

As the lack of conceptual clarity surrounding the dichotomy means it is not known with certainty what violence characteristics should be associated with each type of violence, this study will explore the consistency and differentiation of violence characteristics in offence chains. The study will investigate whether variables characteristic of instrumental and reactive violence identified from previous literature co-occur in a way suggested by previous conceptualisations of violence subtypes (i.e., a dichotomy), or else will establish what kind of groups, dimensions or themes might emerge from the co-occurrence of the variables (see Table 1 for an outline of variables characteristic of instrumental and reactive violence according to previous literature). The research also aims to investigate differentiation: whether the characteristic variables of one type of violence (i.e., instrumental or reactive), do not co-occur with the characteristic variables of another type. A descriptive analysis of the findings will be provided.

The overall purpose of this study is to determine whether these theoretically distinct subtypes of violence can be differentiated from one another in the offences of convicted adult violent offenders. The purpose is also to provide a more sophisticated and accurate description of violence, which both improves upon previous operationalisations of the instrumental and reactive dichotomy (see Appendix B) and overcomes methodological limitations in the violence subtyping research: such as assuming the co-occurrence of offence characteristics. The study also adds to the surprisingly limited pool of instrumental and reactive research which has studied forensic populations.

By coding for several violence-related variables associated with the instrumental reactive dichotomy, and examining the relationships between these variables, it can be seen whether instrumental and reactive violence can be validly distinguished in an adult forensic 
population. This in turn relates to whether or not different underlying theories are necessary to describe violent acts. Due to the exploratory nature of this study, there are no specific hypotheses.

Study 2. Secondly, the study will explore if psychopaths are heterogeneous in regard to offending style and type. According to Karpman (1941), on the surface, both primary and secondary variants display the antisocial behaviour typical of psychopathy. However, the surface behaviour of secondary psychopaths is caused by an underlying emotional problem such as anxiety or depression, whereas primary psychopaths have very little underlying emotion and are egotistic and selfish at the core. Secondary psychopaths possess an affective disturbance marked by underlying symptoms of depression and anxiety, whereas primary psychopaths suffer no such symptoms because they lack the innate capacity. Due to these differing traits thought to underlie primary and secondary psychopathy, there is reason to suppose that these two variants may show different forms of violence. In particular, primary psychopaths are thought to have a stronger association with the variables linked to instrumental violence and secondary psychopaths are considered to be associated with reactive violence.

There is a dearth of literature on the question of whether there is a relationship between violence types and psychopathy variants. Consequently the current research will consider the primary and secondary variants of psychopathy that have been suggested in the literature, and examine whether there is evidence for their theoretical links with different forms of violence. Specifically it will investigate whether the subtypes of primary and secondary psychopaths differ in the instrumentality/reactivity of their violent offence characteristics. Significant differences in types of violent behaviour will support the validity of psychopathy variants. It is hypothesised that given their emotional detachment, primary psychopaths may be more inclined to show instrumental violence characteristics in an effort 
to obtain an extrinsic reward, while secondary psychopaths may be more prone to display reactive violence characteristics.

\section{Method Study 1}

Approval was sought and granted by Victoria University Wellington School of Psychology Ethics Committee (SOPHEC) and the New Zealand Department of Corrections before data coding commenced.

\section{Participants}

The data were coded from archival sources. The sample $(N=112)$ consisted of male violent offenders who had participated in Te Whare Manaakitanga's (TWM) treatment programme for high-risk violent offenders at Rimutaka Prison, Wellington, between 1998 and 2011. The men had spent an average of 28.57 months in treatment $(S D=9.49)$ with $76.8 \%$ completing the treatment programme. The men in the sample were all incarcerated for violent offences including assault, aggravated robbery and murder. They were generally assessed to be at a high risk of re-imprisonment; the average estimated likelihood of returning to prison over five years following release was $67 \%^{1}(S D=18.97)$. The offenders had been assessed for psychopathic personality, prior to this study, with either the PCL-R (Hare, 2003) or Psychopathy Checklist: Screening Version (PCL-SV; Hart, Cox, \& Hare, 1995), and had all met the cut-off scores for psychopathy: PCL-SV scores $(\geq 18)$ or PCL-R scores $(\geq 30)$.

Of the sample $69 \%$ of the sample identified as Maori, $20 \%$ as European/Pakeha, and $11 \%$ as another ethnicity. The mean age for the men was 32 years $(S D=7.54)$, with a range from 20-60 years old.

Selection of offenders was dependent upon two criteria, firstly the existence of a sufficiently detailed 'offence chain' narrative, and secondly, previous assignment to a

\footnotetext{
${ }^{1}$ Based on the New Zealand Department of Corrections' actuarial risk assessment tool, the Risk of reConviction X Risk of re-Imprisonment model (RoC*RoI; Bakker, O’Malley, \& Riley, 1998). The RoC*RoI measure was developed for the New Zealand Department of Corrections to assist in the accurate prediction of an offender's risk of conviction and likelihood of re-imprisonment (Department of Corrections, 2004).
} 
primary or secondary psychopathy cluster based on Millon Clinical Multiaxial Inventory III scores (MCMI-III; Millon, 1997).

\section{Materials}

Offence chains. The archival data was available in the New Zealand Department of Corrections treatment records for offenders who had participated in a high intensity rehabilitation programme at Te Whare Manaakatanga. The Department of Corrections gave permission to use archival offence chains from the offenders' treatment files. An 'offence chain' is a narrative either written by, or recorded in the offenders' own words. The offence chain provides a detailed description of a single offence from the offenders' perspective, including pre, during, and post-offence characteristics (e.g., use of alcohol/drugs, relationship to the victim, whether a weapon was used). The offence chains are created during an assessment phase of participation in the rehabilitation programme.

The offence chains needed to be of a subjectively reasonable quality to be coded for instrumental and reactive violence features. Any that did not have enough information to code 17 of the 19 categories in the coding scheme, or were illegible, were removed from the sample.

Instrumental and reactive coding scheme. A coding scheme was developed in order to explore the relationship between instrumental and reactive violence variables by systematically identifying and recording the offence characteristics present in the described offence.

Before creating a coding scheme to capture the offence variables assumed to be associated with instrumental or reactive violence, it was necessary to understand how these had been coded in the past. Due to the nature of the current study, the use of previous coding schemes was limited to those that were aimed at capturing features of violent behaviour rather than character traits, and that could be applied to written archival information. With 
few exceptions, the publicly available coding schemes that matched these criteria were based on the coding scheme created by Cornell (1996; see Appendix D). Cornell's coding scheme has provided the basis for the coding schemes of Woodworth and Porter (2002); Falkenbach, Poythress, and Creevy (2008); Vitacco, Neumann, and Wodushek, (2008); Douglas (2010); and Camp et al. (2013), and is similar to those of Chase, O’Leary, and Heyman (2001) and Tapscott et al. (2012). These coding schemes have all measured similar variables traditionally associated with the distinction between instrumentality and reactivity (e.g., planning, anger, provocation).

Coding scheme variables. As there were preliminary models and theory on which to base the coding of the current study, a table of the relevant coding schemes was created (see Appendix B); which both lists the variables coded in the past as relating to either reactive or instrumental violence, and outlines how they had been operationalised. This table became the basis of a new coding scheme for this study. As many variables as possible from these past schemes were used in the new coding scheme, however there were some variables that were excluded from the new coding scheme as the offence chains did not provide the relevant information (e.g., Psychosis).

Previous schemes have operationalised instrumental and reactive violence in various and inconsistent ways. In the coding scheme for the current study no assumptions were made about what variables defined either instrumental or reactive violence, therefore the scheme was as inclusive as possible when capturing information. The coding scheme included a range of offence characteristics and these were defined and operationalised broadly so as not to miss any information that may be relevant. These broader operationalisations were reflected in the levels and categories which could be selected under each variable. For example while many previous coding schemes (e.g., Vitacco et al. 2008) coded only the presence or absence of angry affect, in this coding scheme different kinds of affect were 
coded (e.g., frustration, excitement, anxiety etc.) and an open field was included to code for anything not listed, so as not to lose information. Each variable was defined carefully to optimise inter-rater reliability.

While these previous coding schemes (e.g., Cornell et al., 1996; Chase et al., 2001; Woodworth \& Porter, 2002; Falkenbach, Poythress, \& Creevy, 2008; Vitacco et al., 2008; Douglas, 2010; Tapscott, Hancock, \& Hoaken, 2012; Camp et al.,2013) provided a good starting point for the variables in the new coding scheme (scheme derived variables), past literature was reviewed for other variables related to the dichotomy (literature derived variables), and offence chains themselves were mined for any unique exploratory variables to add (data derived variables). These data derived variables were included to explore the distinction between instrumental and reactive violence in a more complete way than has occurred in previous literature. There is a set format to the information outlined in an offence chain: background factors leading to the offence; mood and thoughts before during and after offending; role of drugs and alcohol; role of others; offence descriptions; and post event feelings. This format enabled certain exploratory variables to be identified consistently over the sample (e.g., mood proximal to offending). Table 2 outlines the variables, and where they were derived from. These variables were grouped into thematic categories based on phases of offence - pre, during and post offence — to get a sense of the temporal nature of violence.

While the majority of variables selected related to characteristics of the violent offence itself, variables proximal to the offence occurring (e.g., provocation, frustration, incentives, stress, and alcohol use) have been included. Including the proximal factors provides greater detail into the nature of an offence as it codes both cause and effect of a violent act, this approach also gives a sense of the changing nature of offence overtime.

The variables in the new coding scheme have been separated out, where necessary, into type, function, and level. For example, level of emotional arousal during the offence was 
been separated from type of emotion, which has not been done in previous coding schemes.

This is necessary as it seems important to differentiate between violence done, for example, in excitement rather than anger, even if emotional arousal is high on both counts, as the aggression could be fundamentally different in motivation.

Table 2.

Outline of the variables used in the coding scheme of the current study

\begin{tabular}{ll}
\hline Source & Variables \\
\hline Coding Scheme Derived Variables & Provocation \\
& Planning \\
& Intoxication level \\
& Goal \\
& Offence Arousal and Affect \\
& Relationship to victim \\
& Severity of violence \\
Control
\end{tabular}

Data Derived Variables

Proximal stressors

Proximal affect

Provocation response (intensity and affective)

Intoxication relevance

Role of offender

Literature Derived Variables

Weapon use (Michie \& Cooke, 2006)

Post offence remorse (Barratt, Stanford, Dowdy, Liebman, \& Kent, 1999)

Another important point of difference between this new coding scheme and the previous schemes, is that instead of coding simply for the presence (or absence) of an 
external goal (e.g., Cornell et al., 1996), coding was done based on the view posited by Anderson and Bushman (2002) and Felson (2009) that reactive violence is not goalless and that all behaviour has an ultimate goal beyond that of simple harm. Coding for different goals enhances classification by indicating the motivation for the violent behaviour. For this reason a range of possible goals were included the new scheme: defence, compliance, material gain, self-presentation, payback, sensation seeking, catharsis, other, or no goal. Intention to harm was separated out from the other goals, as an independent variable so it could still be identified, where necessary, as an important driving factor in an offence, and because the coding by Douglas (2010) and Tapscott et al. (2012) use this goal to define reactive violence. Because the coding scheme was designed to be exploratory, unlike the previous topdown coding schemes, specific variables were not assumed to be particularly associated with either instrumental or reactive violence. The coding scheme did not assign groups or scores to the offences it was applied to. Instead the purpose of coding was to identify particular offence characteristics in an offence chain, rather than to identify instrumental or reactive violence per se.

Revisions to the coding scheme. The draft coding scheme consisted of 19 offence characteristics to be coded. These items contained a selection of either categorical or interval variables. Multiple selections could be made for categorical items, and an open field item was available if the response did not match the items listed.

An initial coding of ten offence chains was undertaken to test the suitability of the variables for the information: if all the variables could be discerned in the offence chain information, and whether the variables could be coded consistently with the levels and categories that had been put in place. Revisions were made based on findings, and then another selection of offences was coded and the process repeated before the coding scheme 
was finalised (Appendix E). Once finalised, all of the offence chains in the sample were coded.

Inter-rater reliability. A second rater trained on the use of the coding scheme independently scored a sub-set of the coded offence chains $(n=20)$. Cohen's kappa coefficient was used as the statistical measure of inter-rater agreement as it is generally thought to be a more robust measure than simple percent agreement calculation since it takes into account the agreement occurring by chance (Gwet, 2010). It is recommended on the Fliess's Kappa Benchmark Scale that $\kappa$ should be above 0.75 before claiming an excellent level of inter-rater reliability. A $\kappa$ of 1 is considered to be perfect agreement (Landis \& Koch, 1977). For this study the inter-rater reliability on each of the variables ranged between $\kappa=$ 0.74 to $\kappa=1.00$.

\section{Procedure}

Initial data collection. The data were coded simply by reading through the individual offence chain and marking the type or level of offence characteristics identified on a paper copy of the coding scheme. There was also space on the sheet to note evidence for the choices made. The aim was to code every variable for every offence chain; however the offence chains differed in detail so this was not always possible, so for some variables unclear was coded. Any offence chain that did not have enough information to code 17 of the 19 offence characteristics in the coding scheme, or were illegible, were removed from the initial pool of 167 offence chains. During the coding process, occasional checks were made of offence chains coded earlier to prevent inconsistencies caused by "drifting into an idiosyncratic sense of what the codes mean" (Schilling, 2006). Once an offence chain had been coded, the information was transferred to a Microsoft Excel spread sheet.

Data preparation for analysis. In order to undertake an exploratory multidimensional scaling analysis, a number of changes needed to be made to the coded data. 
For the 19 variables coded, a total of 89 items choices were available. The variables were variously categorical, ordinal and open field where information was recorded verbatim from the offence chain. Once a decision was made about the method of preliminary data analysis, these items needed to be fewer in number and to be recoded as dichotomous choices.

To make these changes a frequency analysis was conducted on all the items under each variable, across all the phases coded for in this study. The purpose was to remove lowfrequency items; the cut off was set at $<10 \%$ (for one item per variable). If there were many items that came under the $10 \%$ response frequency, the least frequently responded to item was removed from each variable. Items below the cut-off were unlikely to provide useful detail for differentiating between individual cases since most responses were the same. Exceptions were made to keep the more theoretically important variables even if they failed to meet the $10 \%$ cut off.

Where the number of items for each variable was still large (> 5), and it was possible to do so, two or more items were grouped together into larger categories. Watson and Tellegen's (1985) arousal/valence groupings two-factor structure of affect (Appendix F) was used as a parsimonious method of grouping affect items into larger emotion categories (e.g., fearful, anxious, frustrated were grouped as high negative affect). However, if it was theoretically important to leave an item as stand-alone this was done: anger was always kept separated from other forms of negative affect due to its apparent importance in defining reactive violence according to previous coding schemes and conceptualisations of the dichotomy (e.g., Cornell et al., 1996; Douglas, 2012; Vitacco et al., 2008). For ordinal variables the scales were collapsed and separated, while making sure that all information was still kept (e.g., not intoxicated, intoxication and severe intoxication became the dichotomous variables: intoxicated and not intoxicated). 
For the open field items, the responses were either reallocated to the closest fitting listed item, or the predominant themes were drawn out and used to group the responses. For example, for the variable proximal stress the open field items were grouped as correctional stress (stress that stems from having been arrested, charged with a crime or being imprisoned/awaiting imprisonment) and health stress (stress from mental or physical illness or injury) as these new variables encompassed all the responses. If the verbatim open field responses could not easily be categorised, these individual responses were removed.

Where there was insufficient detail in the offence chain to circle a response other than unclear during the initial coding, the offence chains were looked at again to see if these variables could be categorised more appropriately. This procedure was necessary to minimise any missing data (i.e., 'unknown' or 'insufficient detail') from the data set. Only the remorse/regret variables lacked sufficient information to recode these items, and subsequently these variables had to be dropped from most of the analysis.

Variables were also excluded because they had responses that were dependant on another variable (e.g., having the two variables intoxicated and intoxication contributes [to the offending] led to intoxication being dropped as the latter variable assumes intoxication).

At the end of the process 42 dichotomous variables remained, relating either to the offender's immediate pre-offence lifestyle or their offending behaviour. These variables were coded as 1 (indicating their presence) or 0 (indicating their absence) for each offence chain. The 42 dichotomous variables coded across the 112 offences provided the data matrix upon which the subsequent analysis was conducted. Appendix G provides a full list of the new variables, their descriptions, the abbreviations used in the analysis.

Data analytic strategy. The Statistical Package for the Social Sciences (SPSS 19; IBM Corp, 2010) was used for all analyses in the current research. By convention, an alpha level of 0.05 was considered statistically significant. Analysis for study one was undertaken 
using two complementary procedures: multidimensional scaling (MDS) and hierarchical cluster analysis of the variables (HCA). The large numbers of variables posed a challenge for analysis, however, a way to test the co-occurrence and differentiation of the many variables considered to be related to instrumental and reactive violence was via a visual representation. MDS is useful for this purpose as the output of this procedure is a map of co-occurrence of variables in geometric space. Variables that often co-occur are located close together in the output, and those that co-occur rarely, or not at all, are located far away from each other. This approach is a strength of the current study as it allows us to see associations of variables as they actually are rather than how they are assumed to be, as MDS allows variables to fit together where they will. Through the analysis of the co-occurrence of the variables, it can be easily seen if violence characteristics are dichotomously distributed, or how violence characteristics may otherwise co-vary.

MDS is a non-metric exploratory data analysis technique (Kruskal \& Wish, 1978) that spatially represents associations among variables, and presents the relationships between variables in the form of points on a map (scalogram). As Borg and Groenen observe: "The graphical display of the correlations provided by MDS enables the data analyst to literally 'look' at the data and to explore their structure visually' (1997, p.3). For this reason MDS can be used to explore and discover the defining characteristics of unknown social and psychological structures, but also to confirm a priori hypotheses about these structures (Giguere, 2006) and can be used to uncover the latent structure of implicit typologies (Walker \& Hennig, 2004). As such it is commonly used in psychology for criminal profiling research (e.g., Canter \& Fritzon, 1998; Salfati \& Canter, 1999).

The indication of goodness of fit of the map is termed the 'Kruskal stress index', and also described as s-stress (Takane, Young, \& de Leeuw, 1977) or stress formula 1 (Kruskal, 
1964). For a reasonable fit the stress indices should be low $(<0.15)^{2}$. Ideally results should demonstrate theoretical sense (Bishopp \& Hare, 2008), therefore the instrumental and reactive dichotomy was used primarily to aid interpretation of the findings.

To interpret the MDS map, variables are usually first considered from a dimensional perspective (i.e., how the points fall along a continuum). Other means of interpretation involves identifying clusters or distinctive groupings; if present these can also be interpreted according to both theory and how far apart they are (Hout, Papesh \& Goldinger, 2012). One of the strengths of MDS profile analysis is its representation of what typical configurations or profiles of variables actually exist in the sample of interest, from which profiles and typologies can be derived (Ding, 2003).

To achieve a MDS output for this study, a data matrix was prepared in which the presence or absence of each of the 42 offence variables (Tables 3 and 4) was noted for all 112 offence chains This matrix was then subjected to two dimensional MDS using the Alternating Least-Square Scaling Algorithm (ALSCAL) which uses the Euclidian model as a basis to compute optimal distances between variables. This procedure was repeated twice, once for all the coded variables, then for during offence variables only. Offence only variables are the ones that most closely align to the variables in previous coding schemes, and have the most relevance to the traditional conceptualisation of the instrumental/reactive dichotomy (see Table 1 for variables traditionally thought to define instrumentals and reactive violence). Previous research on instrumental and reactive violence has left out much of the temporal chain of violent offending by focusing only on the violent act, meaning that violence has been taken out of context. The inclusion of exploratory proximal factors in this study was aimed at

\footnotetext{
${ }^{2}$ Kruskal \& Wish (1978) have proposed meanings using the following levels: STRESS > .20: Poor; . $10 \leq$ STRESS $\leq .20$ : Fair; $.05 \leq$ STRESS $\leq .10$ : Good; $.025 \leq$ STRESS $\leq .05$ : Excellent; .00: Perfect.
} 
redressing these problems, however to enable more direct comparison with previous studies the proximal factors were removed for the during offence variables analysis.

Next, hierarchical cluster analysis (HCA) was used to explore how the offence variables grouped together by arranging the co-occurring variables into clusters. These two techniques provide different but converging lenses on the division and arrangement of these variables (Kruskal \& Wish, 1978).

HCA is an exploratory tool designed to reveal natural groupings (or clusters) within a data set so that the degree of association is strong between members of the same cluster and weak between members of different clusters. The objects in hierarchical cluster analysis can be cases or variables.

Once the MDS outputs had been analysed, the variables were subjected to HCA using Ward's method and Euclidian Distances Squared. Ward's method is a hierarchical agglomerative method: clusters are formed by progressively linking cases, starting with the two cases most similar to each other. Euclidian Distances Squared is the similarity measure.

In order to determine the best number of clusters, it is necessary to identify the point at which dissimilar clusters combine. One way is to look for a jump or a sudden notable increase in the agglomeration coefficient, which suggests that dissimilar clusters are being combined. Another way is to determine the number of clusters is through the dendrogram output. A dendrogram is a tree diagram; a graphical device for displaying clustering results, with vertical lines representing clusters that are joined together. Once all variables in the dataset had been allocated into clusters, differences between the clusters could be explored and a descriptive analysis undertaken. 


\section{Results and Discussion Study 1}

\section{Multidimensional scaling results for all variables}

The Multidimensional scaling (MDS) two-dimensional solution for all 42 variables (described in Appendix G) is presented in Figure 1. The stress index was 0.20, indicating a fair fit of the data (Kruskal \& Wish, 1978); the $\mathrm{R}^{2}$ was .79 indicating that $79 \%$ of the variance was explained by the model ${ }^{3}$.

To investigate whether instrumental and reactive violence is best conceptualised as a dichotomy, the dominant themes and patterns that can be used to classify violence were identified on the MDS output "map" (Figure 1). On the MDS map it can be seen that a number of coded violence characteristics co-occurred in a way that broadly corresponds to the usual conceptualisations of the instrumental and reactive dichotomy (see Table 1). Looking at the main patterns of variables (violence characteristics) on the map, it seems that the map can be divided into reactive (right of centre line) and instrumental (left of centre line) groupings. However, the array of variables does not suggest a dichotomy as the instrumental and reactive variables merge in the centre of the map. There are also variables on both instrumental and reactive sides that do not correspond with the way these forms of violence are usually defined; for example sources of provocation (e.g., Provthreat) that fall onto the instrumental side, even though provocation is only associated theoretically with reactive violence.

\footnotetext{
${ }^{3}$ A three-dimensional scaling was considered, as this improved the fit with a stress value of .15 and $\mathrm{R}^{2}$ of. 85 . However, increasing dimensionality decreases the interpretability of the data output, and it was decided in this instance that the improvement in fit did not compensate for the reduction in interpretability.
} 


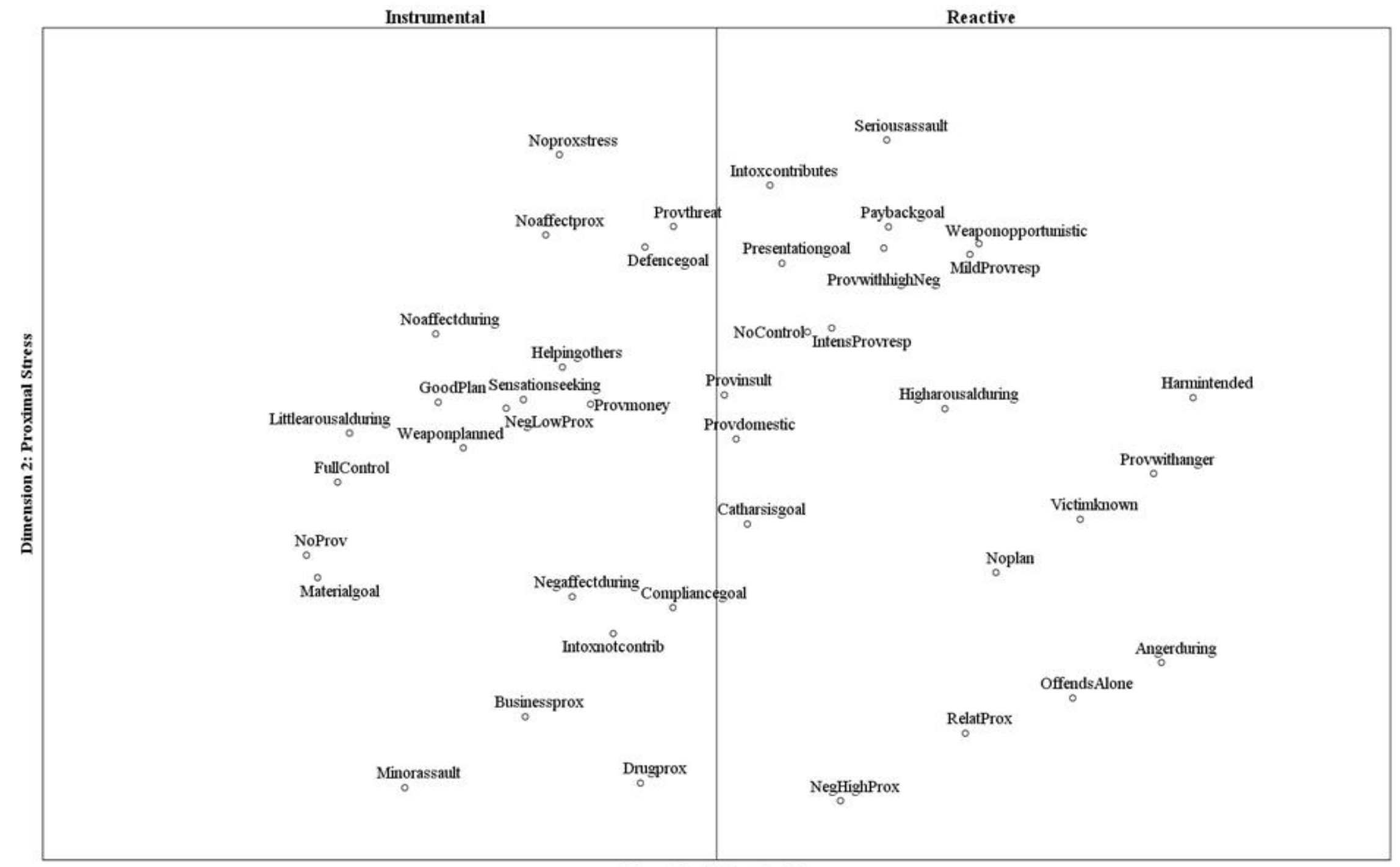

Dimension 1: Emotionality

Figure 1. The MDS scalogram "map". The map shows the distribution of all 42 variables related to instrumental and reactive violence. Labels have been added to show instrumental and reactive sides of the map, and the underlying dimensions. 


\section{Discussion of multidimensional scaling results}

The variables that have grouped together (i.e., co-occurred) on the reactive and instrumental sides of the MDS map will be looked at in turn. The variables characterising the reactive and instrumental groups on the MDS map will be described in the order they would have occurred and then commented on. The variables that overlap between the instrumental and reactive sides will then be discussed.

Reactive violence variables. Proximal to the violence occurring is the presence of background stress, this stress stems from problems with close relationships (RelatProx), and background feelings of anger, frustration or hurt (NegHighProx). The violence itself may begin with the offender responding with anger (Provwithanger) or other highly negative emotions (ProvwithhighNeg) to a perceived provocation: either an insult (Provinsult) or a domestic dispute (Proxdomestic). The offender either responds immediately (InstenseProvresp), or may wait (MildProvresp). The offence is conducted with no plan (NoPlan), targeting a known person (Victimknown) and the offender acts alone (OffendsAlone). During the offence there is anger (AngerDuring), or high emotional arousal (Higharousalduring) and no offender self-control (Nocontrol). Not surprisingly this behaviour leads to serious injury or fatal outcomes (Seriousassault). The offence may have the goal of physical harm (Harmintended).

With the exception of a mild provocation response, most of these variables fit with the previous conceptualisations of reactive violence. The goal of physical harm (Harmintended) is often considered one of the most important defining characteristics of reactive violence (e.g., Tapscot et al., 2012). On the MDS map the goal of harm is placed to the extreme right, which is the area containing the most typically reactive variables (e.g., anger, high arousal, provocations). The placement of Harmintended is a key point of similarity between the cooccurrence of variables in this study and the traditional definition of reactive violence. 
Physical harm, however, is not the only goal present on the reactive side; this finding is counter to what traditional definitions of reactive violence would suggest, and will be discussed further on.

Instrumental violence variables. The 'instrumental' group of variables on the left of the map shows that background proximal stressors and negative moods may or may not (Noproxstress) underlie these violent acts. Those background factors that may be present are related to business concerns (Businessprox) or problems surrounding drug abuse or addiction (Drugprox). Any background emotion, if present, is typically linked with low arousal levels: an inwardly focused, depressed or hopeless feeling (NegLowProx) rather than feelings of anger or frustration. There may, however, be no negative background emotion described at all (Noaffectprox). The violence that occurs is unlikely to have been provoked except by money or goods being stolen from or owed to them (Provmoney); this provocation will be discussed more fully, as provocation is considered to be characteristic of reactive rather than instrumental violence. The violence is conducted with: (a) little emotion (Noaffectduring) or non-angry negative emotions (Negaffectduring); (b) low arousal (Littlearousalduring); (c) with some consideration to planning (GoodPlan/Weaponplanned); and (d) little injury (Minorassault) inflicted on the victim. Again, this is similar to how instrumental violence has been conceptualised in the past.

The variables that sit the furthest to the left (the more instrumental side) of the mapfull control (FullControl), little arousal during violence (Littlearousalduring), no provocation (NoProv) and a goal of material reward (Materialgoal)-are all variables central to previous definitions of instrumental violence in the aggression literature and the cold, self-rewarding form it is thought to take.

Central variables. The central variables appear to fuse the instrumental and reactive sides of the map together, preventing a dichotomous split. The most centrally located 
variables are: catharsis as a goal (Catharsisgoal), defence as a goal (Defencegoal), and provocation in the forms of threat, insult and domestic dispute (Provthreat, Provinsult, and Provdomestic).

Dimensions. Examination of the violence characteristics along each dimension suggests that Dimension 1 (x-axis) could be labelled Emotionality as there appears to be an increasing level of emotionality (i.e., increasingly angry or hostile mood/ high arousal at all stages of offending) horizontally left to right. Dimension 2 (y-axis) could be labelled Proximal Stress as there seems to be decreasing importance of background stressors (e.g., Drugprox, Businessprox, Noproxstress) moving vertically toward the top of the map. While both the instrumental and reactive sides of the MDS map have variables of background stress and negative affect associated, the underlying dimensions suggest that the presence versus absence of proximal factors and the increasing or decreasing negativity of affect may be important factors in differentiating violence types.

Implications. The results suggest that there are instrumental and reactive variants of violent offending, and many of the violence characteristics co-occur with others of the same type; but that the two types do not split into a dichotomy. Rather than a dichotomy there is overlap between instrumental and reactive variables. Some variables which match traditional conceptualisations of reactive violence (e.g., no control, anger, no plan) sit in proximity to variables which are usually considered to be a feature of instrumental violence (e.g., clearly identifiable goals); similarly many of the instrumental variables (e.g., material goal, no provocation, good plan and little arousal) sit near variables considered to be typical of reactive violence (e.g., negative affect). While the left and right extremes of the map contain the most typically reactive or instrumental variables, the map is not clearly dimensional.

There are two findings particularly worth discussing in detail. As shown by the central area of the map the presence of goals does not differentiate reactive and instrumental 
violence, nor does the presence of provocation. This lack of differentiation connects back to criticisms suggesting that many real world acts of violence cannot be dichotomised (Bushman \& Anderson, 2001).

Goals do not differentiate subtypes of violence. Having a goal or clear purpose driving the violence, is generally considered to be a feature of instrumental violence (Felson, 2009). Some authors however, consider goals such as defence or retaliation to be reactive goals (e.g., Cornell et al., 1996). It can be seen on the MDS map that most goals sit centrally, being associated with the instrumental type variables as well as with the reactive. This placement suggests that the concept of goal or motivation is not clear cut in separating instrumental and reactive violence types, no matter which conceptualisation of reactive and instrumental violence is considered.

The present study went beyond typical distinctions of instrumental and reactive violence to examine all the specific goals (or lack of), that may be associated with different forms of violence and motivate its occurrence. For this reason the lack of differentiation could in part be an artefact of the coding system. Goals were multiply coded for analysis in this study: any goal present at any stage during the offence was coded, and goals could be singular or multiple. Both the goals that the offenders set out with, and goals that formed as the offence progressed, were coded; and it is these secondary goals that might be the reason for the overlap seen here. Violent goals can shift from instrumental to reactive and vice versa during an offence, for example a threat to the offender can occur during a robbery and the goal of material reward can turn to a goal of defence or, conversely, someone may opportunistically decide to take money from a victim while assaulting them. However, these shifts in purpose during an offence may not be the only reason goals are associated with both instrumental and reactive violence; it also maybe that the offenders go into an offence with more than one goal, for example a man may seek revenge via a robbery, hoping to pay back 
and get material reward all at once. One offence chain coded provided an example of a man who robbed his boss to "get back at him" (OCN: 1003).

Importantly this lack of differentiation means that reactive violence variables are associated on the MDS map with goals other than that of harm. Reactive violence is often conceptualised as only having harm as a goal or having no identifiable goals at all (e.g., Douglas, 2010). The issue of reactive violence being associated with goals other than harm doing, as is seen in these results, is explained successfully by the social-interactionist perspective of violence. This perspective is a theory of coercive actions emphasising the role of social interaction — rather than the inner state of the offender - in violence. The perspective concludes that all violence is instrumental as it has goals other than harm doing, even when it involves anger. In its current form the social-interactionist perspective includes predatory and dispute related violence based on whether or not physical harm is a key aim. These in turn are broken into three or four motives for using violence: compliance, grievance/justice, asserting or defending social identity, and (possibly) fun (Clarke \& Felson, 1993; see Table 3).

Table 3.

Motives in predatory and dispute related violence

Actor's concern Types of Violence

Predatory Dispute related

Compliance "Compellence" Deterrence

Justice $\quad$ Redistribution $\quad$ Retribution

Social identities Assertive self-presentation Defensive self-presentation

Note. From Clarke and Felson (1993, p 105). 
Although the motives outlined in Table 3 are conceptually distinct, they often occur jointly (Clarke \& Felson, 1993). The MDS map provides evidence that the socialinteractionist perspective may be correct. In contrast to the more common assumption that harm is the only goal of reactive violence (e.g., Tapscott et al., 2012), it appears that there are other identifiable goals. To use the previously noted suggestion of Bushman and Anderson (2001), the goal of harm may be only the proximal goal of reactive violence.

Provocations do not differentiate subtypes of violence. Provocation is, of course, what traditionally defines reactive violence (Ross \& Babcock, 2009). However, on the MDS map, a number of forms of provocation sit quite centrally (Provthreat, Provinsult, and Provdomestic) and provocation stemming from theft of, or being owed, material goods, (ProvMoney) in particular occurs with the instrumental type variables. ProvMoney denotes provocation from having money or material goods stolen or owed, or from a belief of entitlement to material goods, whether this belief is legitimate or not. In this form, provocation probably encourages instrumental above other crimes since material gain is what is at stake. However, the placement in the MDS of these variables does suggest that provocation and the reaction to it does not only characterise reactive violence, rather it can drive instrumental offences as well.

Again it may be because the coding scheme broke provocations into particular types, and some forms of provocation coded in this study may not have been considered provocations in other studies, which could explain the prevalence and spread of provocations on the MDS map. However a provocation was only coded in this study if it appeared to contribute directly to an offence occurring and if the offender also claimed to have been provoked, so this artefact of coding should not be the only reason that provocation does not differentiate between instrumental and reactive violence. 
Summary. The single most important point to emphasise is that the map clearly shows that it is not possible to apply a simple binary classification to the MDS results. Two distinct subgroups do not clearly emerge, as they would if the instrumental/reactive dichotomy held true. The groups merge and cut offs are not clear. This suggests a more sophisticated classification needs to be devised in which different types of violence are clearly separate, if this is possible.

\section{Hierarchical cluster analysis results}

The dendrogram resulting from the HCA of the 42 (Appendix H) variables showed that after four clusters emerged; there was a large increase in within-group distance before they combined to form three clusters, and another large increase before three clusters combined to form two clusters, and again before combining to form one. On the basis of these observations, a four cluster solution was selected. As indicated in Figure 2, the MDS map was divided into the four HCA clusters, which are based on the relative association (cooccurrence) of variables. These four clusters reflect a typology of violent crime for this sample. 


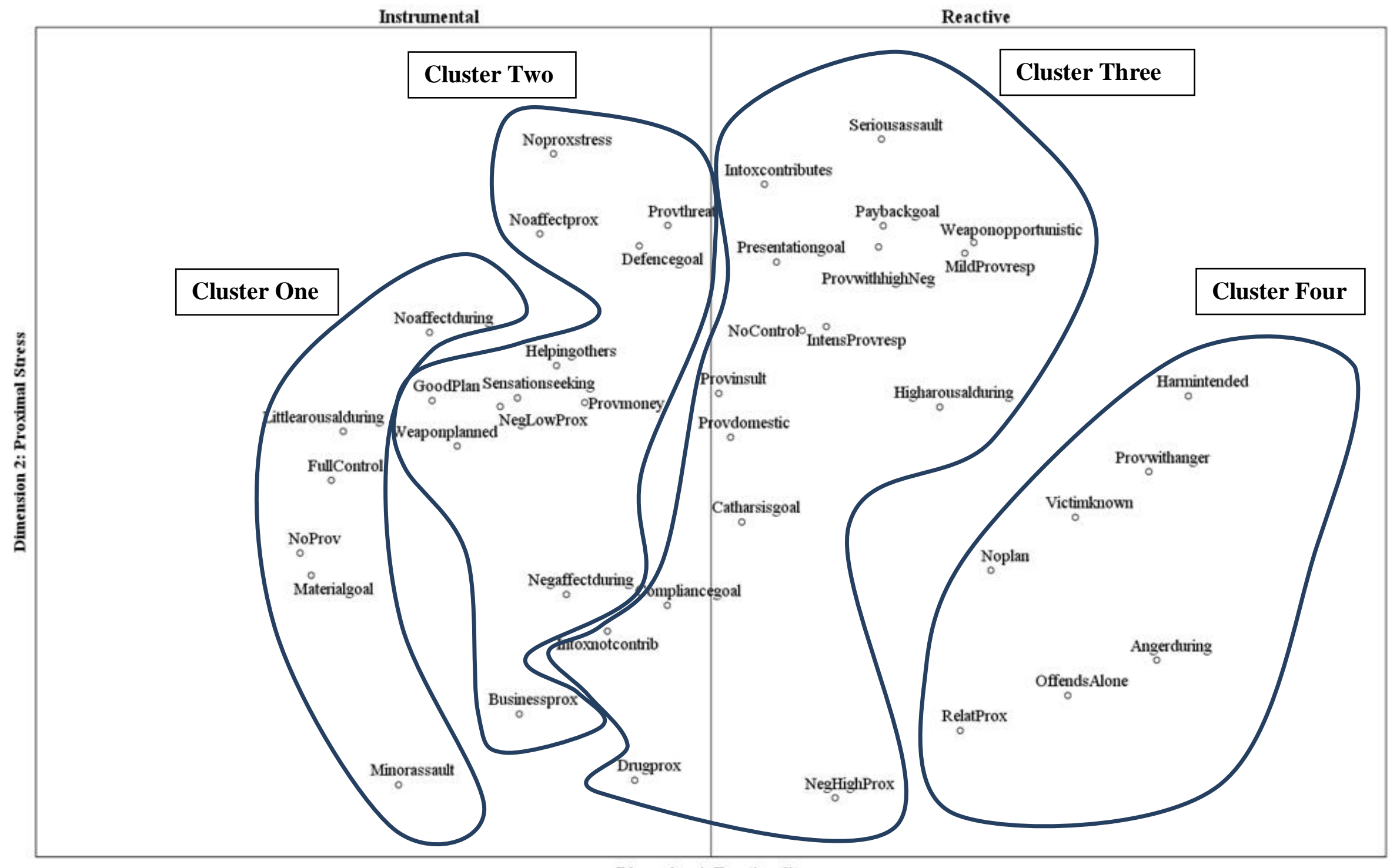

Dimension 1: Emotionality

Figure 2. Hierarchical cluster analysis solution for all variables. The HCA clusters have been superimposed on to the MDS map and cluster titles added. 


\section{Description and discussion of clusters}

Descriptions and interpretations of the clusters are outlined below. A summary label for each cluster is provided as well. Referral back to the offence chains (OCN) was occasionally necessary to understanding what type of violence these clusters may represent.

Cluster one: instrumental violence. The goal of this violence is exclusively material gain (Materialgoal) and it occurs without provocation (NoProv). When conducting the offence the offender is calm or neutral (Noaffectduring), and describes being fully in control of the violence (FullControl). Harm may be inflicted on victims, but only minor injury is caused (Minorassault).

These offences can be interpreted as the most typically instrumental of the clusters, (e.g., driven less by anger than a rewarding goal). In fact this combination of violence characteristics is very similar to how Tapscott et al. (2012) describe instrumental violence, where planning is no longer a defining criterion. Planning is the only variable typically considered to be important in describing instrumental violence that is not included in this cluster. However, it should be noted that the variable good plan does sit very close to this cluster on the MDS map, meaning that the variable has a relationship with the other variables of this cluster and often co-occurs with them. It is also interesting to note that there is no background affect or stress driving these offences.

These offences appear to be driven by wants: specifically the desire for extrinsic rewards (material goods) above all. Reward seeking and positive outcome expectations for violence tie instrumental acts to social learning theory: if people are rewarded from violence they are increasingly likely to repeat the violent behaviours (Bandura, 1977).

The violence described by the cluster is perhaps similar to what Canter, Bennell, Alison, and Reddy (2003) describe as a form of criminal sophistication, in which violence is part of the repertoire for achieving goals or gaining reward. Violence is not so much 
personally meaningful as it is simply an option used however the circumstances dictate. This finding is also in line with the routine activity theory of violence developed by Cohen and Felson (1979) which sees crime as normal behaviour, the occurrence of which is dependent on the available opportunities to offend.

Cluster two: premeditated violence. Violence stems from an individual who is in a neutral (Noaffectprox), low, or depressed (NegLowProx) proximal mood prior to committing the offence. The violence itself, although not carried out in anger, is undertaken in a highly negative emotional state such as tension, fear, anxiety, frustration, or hurt (Negaffectduring). If the offender is stressed prior to offending it is from money or business dealings (Businessprox). Similarly, violence is provoked by financial/material stressors (e.g., money stolen or owed; Provmoney) or by threat to self or others (Provthreat). Goals of violence include: defence (Defencegoal), sensation seeking (Sensationseeking), or helping family and friends (Helpingothers). Violence is well planned in advance (Goodplan), and the planning includes the use of weapons (Weaponplanned).

Interpreting this cluster, it seems evident that this violence is a mixed type, with both instrumental and reactive features. There are clearly identifiable goals, and good planning, which suggests instrumentality, but some of these offences are clearly committed as reactions to provocation. The offences also have a negative affective component driving the offending (pre and during offence), which is usually considered to be a characteristic of reactive offences only (e.g., Ohlsson \& Ireland, 2011). Although not angry, the offenders may be in a state of fear, frustration, or anxiety while committing the offence which suggests an affective component may exist for some instrumental, as well as reactive, violence (Raine et al., 2006).

Referring to the offence chains to aid interpretation, it is possible to interpret cluster two as offences planned to remedy a stressful situation. For cluster two, premeditation appears to be the feature that ties together the various goals and provocations which motivate 
offending. There is both a good plan and the weapon is chosen deliberately for the offence. The offence characteristics of planning suggests that this cluster may be a premeditated violence cluster (see Appendix A for features of this subtype) rather than instrumental, if instrumental violence is simply considered to be an act to get a desired reward.

This cluster appears to incorporate two or three violence motivations, which do not have to be mutually exclusive. The first possible motivation seems to be driven by needs, especially the perceived need to rectify a difficult business or financial situation. The offences stem from the background factor of financial or business problems; relatedly the offenders are provoked into violence by situations relating to money (e.g., stolen or owed). It should be noted that the goal of material reward, while in cluster one, does sit in fairly close proximity to this cluster on the MDS map, suggesting that material gain is important to these offences as well, but less often; so offences are instrumental in this sense.

Another motivation appears to stem from a low or depressed mood. The strong relationship between sensation seeking and low mood, indicated by the close proximity on the MDS map, may be important if those who feel depressed, hopeless or unhappy aim to relieve their mood via violent offences. A low or depressed mood may also lead to the belief that there is nothing to lose by committing an offence, making it more probable that an offence will occur.

Lastly there is a motivation to help another, seen here as the goal of helping others. The most commonly cited types of help given to others noted in the offence chain were helping others (family in particular) with their business, financial or gang troubles by offending with or for them. For example the robber committed to "help[ing] my bro get money" (OCN: 1005). It is possible that these "helpful" acts may in truth be self-serving rather than charitable (Polaschek, Calvert, \& Gannon, 2009) but in the offence chains the 
helping others offences were almost always described as being desired, and even directly requested, by other parties.

One possible interpretation of this cluster is that it shows offences that have started out as primarily instrumental but have become increasingly reactive. It is possible that the provocation of threat, the goal of defence, and the increasingly negative affect, have developed during the offence rather than being a cause of the offence. By returning to the offence chains for clarification, it is seen that instrumental offences often become increasingly reactive if the offender feels threatened.

Cluster three: goal driven reactive violence. The only form of background stress in this cluster is drug problems (Drugprox): addiction, abuse, or problems obtaining drugs. The offender is in a negative mood and highly aroused prior to offending (NegHighProx): angry, frustrated or hurt. The offender is also intoxicated when the offending takes place, although he may or may not consider intoxication to be a contributing factor (Intoxcontributes or Intoxnotcontrib). The offending is a response to provocation which stems from a domestic dispute (Provdomestic) or from the offender feeling insulted (Provinsult). In response to this provocation the offender feels frustrated, fearful, hurt or tense (ProvwithhighNeg). The time it takes for the offender to respond to provocation is irrelevant to these acts, the offender may respond immediately and intensely (IntensProvresp) or come back to deal with it later (MildProvresp). It is worth noting that when the provocation response is delayed, the response when it occurs may still seem "out of control" and severely violent. The offences have the self-referencing goals of self-presentation (Presentationgoal), payback (Paybackgoal), and catharsis (Catharsisgoal) which are all to do with how offenders want to feel, or how they want be seen by others. The practical goal of compliance (Compliancegoal) is also a factor. The offenders are highly aroused when they commit the offence (Higharousalduring) with no control over their actions (NoControl); relatedly weapon use 
tends to be opportunistic (Weaponopportunistic). Their violent behaviour leads to the serious or fatal injury of the victim (Seriousassault).

Again this cluster is mixed reactive and instrumental; however it appears much more reactive in quality due to the offence characteristics of provocation, high arousal and loss of control. There is usually a discernible provocation or trigger, suggesting reactivity. Offences seem to occur as a result of some sort of dispute, insult or argument — plus intoxicationbetween the offender and another. This dispute is an event to which the offender appears to feel compelled to respond, possibly to seek redress. The background factors of negative affect and relationship stress may contribute to the outcome of violence, as the offender is already "wound up". For these offences emotional arousal before and during the offence is extremely high, and injury inflicted is severe, suggesting these offences are often situations in which the offender just "lost it". The opportunistic weapon also suggests a lack of extensive planning. There are two key features which prevent this cluster from having only reactive characteristics: delayed provocation and the presence of identifiable goals other than harm.

The delayed provocation seen in this cluster response would not be traditionally associated with reactive violence; however it may indicate a number of things, for example it may indicate that these offenders have ruminated for long periods, or put the grievance aside until triggered or intoxicated and only then respond. The delay may not necessarily mean that the violence is not reactive, however, as there are conceptualisations of reactive violence, which do not consider immediacy of action to be a feature of reactive violence. Cornell et al. (1996) state: "bear in mind that reactive/hostile aggression can involve extended time-frames. For example, an abused family member may plan an ambush to rid the family of the abuser. The most recent episode of abuse could be long before the aggressive reaction. ..." (Cornell, 1996, p. 4). However this point emphasises again that the extent to which we see the clusters as instrumental or reactive depends on whose conceptualisation is used, and echoes the 
concerns of Busman and Anderson (2001) about whether violence in the real world can be meaningfully dichotomised (p. 276).

That there are clearly identifiable goals present other than the goal of harm is a finding that does not fit with many conceptualisation of reactive violence (e.g., Tapscott et al., 2012). The offences appear to serve a specific purpose (revenge for example) so in this sense can also be seen as instrumental (e.g., Felson, 2004) a finding which supports the social interactionist perspective of violence (Clarke \& Felson, 1993). The majority of associated goals in this cluster are self-referencing goals, which involve looking tough, getting revenge, expressing anger, or hurting someone to feel better. The exception to this is compliance; however this may be secondary to the other goals. In many ways this cluster is very typically reactive (e.g., high arousal, lack of planning, provocation); however, the violence is not simply to do harm. An example of this violence comes from an offender who assaulted his partner because he "wanted to show her how much she hurt me" (OCN: 2105).

A final interest point about this cluster is that it is associated with intoxication, both as a contributing factor to violence, and as a factor that does not contribute to the offence according to the offender. From the information in the offence chains it seems likely that it is the highly routine nature of drug and alcohol use which has meant intoxication is discounted as a reason for violence by some of the men.

The intoxication that offenders consider to contribute to violence sits near reactive variables of lack of control and serious assault: offence characteristics that seem in line with the disinhibiting effects of intoxication. Though whether the intoxication actually contributes to the lack of control, or is simply seen as a good excuse for it by the offender, is impossible to know. However, there is no previous rationale which suggests intoxication should not be linked to either instrumental or reactive violence. For example, as Douglas (2010) notes, it might be expected that substance use disorders, and substance intoxication, would be 
associated with reactive violence. However, Kingsbury et al. (1997) suggest that intoxication might be associated with instrumental violence, as it reduces the ability to anticipate aversive outcomes of violent behaviour. Another possibility, in line with the Routine Activity theory, is that it is not intoxication itself that is the contributing factor, rather it is that drug and alcohol use brings motivated offenders and suitable targets in to contact (Felson ,1997) creating likely environments for violence to occur.

Cluster four: expressive violence. The only proximal factors noted as being important to the offence occurring are based around problems with personal relationships (RelatProx). Any provocation that is apparent to the offender is responded to with anger (Provwithanger), which continues into the offence (Angerduring). The offending is undertaken alone (Offendsalone), without a plan (Noplan), and has the sole goal of physical harm (Harmintended). The victim is known to the offender (Victimknown), and referring back to the offence chains it appears that this person is usually an intimate partner, but may be a friend or child.

The violence seems to be driven from an expression of anger above all, where the desire is to cause harm. This offending may be an attempt to restore emotional equilibrium or alleviate distress caused by 'personal' relationship based background problems (Canter \& Fritzon, 1998). Referring back to the offence chains, it is likely that domestic violence falls primarily into this cluster. The violence is probably driven by a build-up of background stress, and in this sense the cluster may represent the over controlled offender conceptualised by Megargee $(1966,1979)$. In the coding scheme for this study a distinction was made between a provocation (a specific situation that drives the desire to offend and is directly linked to the offence occurring) and a trigger: a minor annoyance that seems trivial and unrelated but becomes "the straw that broke the camel's back" (Bushman, Bonacci, Pedersen, Vasquez, \& Miller, 2005). In this cluster the violence from built up stress seems to then be 
triggered rather than provoked, as no specific forms of provocation are directly related to this cluster. In this sense the violence could be concluded to be expressive rather than reactive. The conceptualisation of expressive violence is seen to differ from reactive violence in that expressive is seen to be an expression of anger rather than a response to provocation (reactive).

\section{Discussion of hierarchical cluster analysis results}

The most important comment to make about the HCA results is that again the offence characteristics do not fall into a dichotomy; the four non-overlapping clusters make it clear that a dichotomy is too simplistic to describe the types of violence. It is, however, possible to conceive of the clusters broadly as comprising an instrumental cluster, an expressive cluster, plus two mixed instrumental and reactive clusters: a typology similar to that suggested by Woodworth and Porter (2002). Much like the single dimension suggested by Woodworth and Porter, there is a movement from more instrumental to more reactive/expressive, violence characteristics across the four clusters.

The clusters in this study do show some parallels to the instrumental and reactive distinction as it is traditionally conceptualised. The offending cited in cluster three was similar to a description of reactive violence as an uncontrolled, unplanned, behaviour in response to external provocation and uncontrolled highly aroused emotions (Ireland \& Ireland, 2008); although there were goals other than harm present. Similarly, the description of cluster one is similar to the definition of instrumental violence (Cornell et al., 1996) where emphasis is given to deliberate, non-provoked actions done in the pursuit of material reward. However this cluster lacks the necessary emphasis on premeditation that is sometimes required for a definition of reactive violence (e.g., Woodworth and Porter, 2002), this again emphasises the lack of conceptual clarity regarding how the dichotomy should look and what variables should define each type. 
It is possible also that the clusters represent different forms of instrumental and reactive violence, breaking the traditional dichotomy into more meaningful units. In the case of reactive violence it appears that there might be something different about those who respond to a build-up of stress (relationship stress in particular) by lashing out at those they know (cluster four: expressive), and those offenders who start out angry and "lose it" at the point they are drunk and/or provoked (cluster three: goal driven reactive). It is interesting that reactive and expressive violence seem to differentiate in this study as, while they are usually used as interchangeable labels for a type of violence, they have never been considered separate groups within a single typology previously. Instrumentally there is a "cold, calm, and collected" instrumental cluster (cluster one) versus the more emotionally labile cluster that nevertheless plans their offence well (cluster two: premeditated).

There are some features of these clusters that are worth paying closer attention to. These features are: the underlying dimensional structure of the clusters; how the exploratory proximal variables differentiate; how the clusters may support criticisms of the instrumental and reactive dichotomy, specifically its confound with automatic and controlled processing; and whether the clusters found in this study have previously been seen in the scientific literature.

Underlying affective dimension. The clusters appear to fall along the underlying dimension of emotionality, giving the variables a distinct structure. The dimension again suggests that associated forms of affect - increasing arousal and anger — might be the underlying difference between how different acts of violence look: cluster one (more instrumental) is without affect; cluster two (more instrumental) has low level negative emotions (e.g., tired and depressed) before the offence and negative emotions (frustrated, tense, anxious) during the offence; cluster three (more reactive) is angry or frustrated before the offence and highly aroused and out of control during violence; and cluster four (more 
expressive) is angry at all offence stages. The placement of negative affect variables in the more reactive clusters is consistent with definitions of reactive violence (e.g., Woodworth \& Porter, 2002). However, the finding that instrumental violence variables co-occur with depressed, or low, mood (NegLowProx) just prior to offending, is not a finding seen elsewhere in studies of instrumental and reactive violence. Counterintuitive as this finding may seem, however, it is not without precedent, as Dutton and Karakanta (2013), reviewed studies linking depression and aggression, and concluded that comorbidity "was likely" (p.317).

It should be noted, that despite negative affect discriminating between clusters, it would be hard to use affect at this level of detail to differentiate types of violence in a practical sense. When only the presence or absence of anger is considered, it has not been found to differentiate violence clusters; for example, the clusters found by Ohlsson and Ireland (2011) all had anger as an important factor with regards to violence motivations. The study by Ohlsson and Ireland also could not determine whether anger acted as a precursor, biproduct or both with regards to violence motivation.

As this present study has considered affect at a much finer level of detail, rather than using the more general label of "anger", it gives a better understanding of how negative affect may impact on violent offending both as proximal and an immediate factor. An example of this is cluster two and three which both contain negative affect as a background (proximal) characteristic. It may be that negative affect prior to violence occurring may contribute to offending if offenders use violence for affect regulation. Bushman, Baumeister and Phillips (2001) found that positive expectations about violence as an affect regulation tool would encourage those that held them to aggress. While affect regulation through violence is commonly thought of as people dealing with anger or "letting off steam", it is apparent that it might also be true of those who are low and depressed (cluster two) rather than angry. This 
should probably not be surprising; these offenders, who are versatile in their use of violence, are no doubt the most likely to consider using violence to make them feel better.

Exploratory proximal variables. Proximal factors were included in this study as exploratory variables to deal with the previously noted criticism that violence acts as viewed through the instrumental /reactive dichotomy are taken out of context. The importance of these proximal factors is documented by Zamble and Quinsey (1997) who described impulsivity, anger, social alienation, and financial pressures as proximal cues that offenders report lead to their commission of crimes. For example, for those who had committed a robbery, financial gain was cited $88 \%$ of the time while peer pressure and boredom were less frequently cited, reflecting 10\% of respondents' reasons. Zamble and Quinsey (1997) stated that although these factors are unlikely to apply uniformly across all offenders, the results show that proximal factors influence violence outcomes and may serve to inform intervention and supervision strategies. Including proximal factors also gives a better sense of the temporal pathway of violent offending, which is not a discrete event, but evolves over time from the initial stimulus to the termination of the violence. The clusters found in this study are seen to have different background stressors contributing to violence enactment; personal relationship factors occur with reactive type variables, and problems such as the need for drugs or business and financial woes occur with instrumental type variables.

The fact that many offenders cited background stressors may also support Agnew's strain theory $(1992,2002)$. The theory suggests that strain, from not having access through legal channels to important things such as money or position, may lead to violence commission. Strain from the outside environment can cause many negative feelings in an individual including defeat, despair, and fear (seen here as NegLowProx). These feelings arouse frustration and hostility (seen here as Negaffectduring) lowering inhibitions, and create a desire for revenge (Agnew, 1992, p. 60). Agnew considered that there were specific 
forms of strain that could lead to criminal activity; the offence chains show examples of many of these. The first strain results from an individual's failure to achieve positively valued goals. According to Agnew these goals are money, status and autonomy. In the offence chains that desire for money, unobtainable lifestyles and status all contributed, either separately or in combination, to background stress for some offenders. This stress, often led to anger and a sense of being treated "unfairly" according to the offenders, and was seen to play a part in the violent acts occurring. The removal of positive stimuli and the presence of negative stimuli were also considered to cause strain by Agnew (1992). These strains are often seen in the offences chains as the loss of a relationship or close friendship, loss of job, or loss of goods through theft (loss of positive stimuli), and presence of aversive acquaintances (presence of negative stimuli).

Evidence for the automatic and controlled processing confound. A previously noted criticism put forward by Bushman and Anderson (2001) regarding the dichotomy is that planning and impulsivity (i.e., spontaneous, immediate action) cannot separate instrumental and reactive violence, as the dichotomy is confounded with automatic and controlled processing. There is evidence of this confound seen clearly in cluster three, which suggests that violence containing a number of reactive characteristics occurred either immediately post provocation, or after a delay (MildProvresponse), and so was not necessarily an immediate or impulsive action. Therefore a number of reactive variables are co-occurring with a controlled variable, suggesting that immediacy or planning does not differentiate reactive and instrumental violence easily.

The converse situation is also seen in cluster three; there is co-occurrence of immediacy of a violent response (IntensProvresponse) - a reactive feature — with goals (e.g., compliance, catharsis, presentation) which are an instrumental feature. This concurrence of variables was also discussed with reference to the MDS output. A review of studies by 
Todorov and Bargh (2000), may explain this placement of variables. The review suggests that goal directed violence can be automatically triggered, and that "if a person has repeatedly witnessed that a "normal" way of dealing with social problems is by using violence ...then this person can develop chronic motivations to harm people who are perceived as threatening or who are seen to stand in the way of the person's desired outcomes" (p64). According to Todorov and Bargh (2000) instrumental offences can involve the automatic - and therefore immediate - use of violence strategies, for example the offender who on the spur of the moment, "decided to do a robbery" (OCN: 3410). If this automisation of instrumental violence is correct, it can certainly explain how goal directed activity and an immediate provocation response can occur in the same cluster.

Evidence for the typology in previous literature. The clusters found here could be conceived as the beginnings of a typology of violence, for that reason it is interest to see if similar clusters have previously been found in the literature.

While no literature has found clusters which paralleled all four clusters found here, there have been other typologies of violence that have found clusters of similar violence characteristics. Cluster three and four, for example, are similar, despite quite different samples, to clusters found by Lopez and Emmer (2000). Lopez and Emmer (2000) found two types of violent offences in a sample of 24 male adolescent offenders: emotion-driven violent assault where the motivation was emotional-coping and belief-driven violent assault where the motivation was self-preservation. Adolescents who had negative emotional states (i.e., anger, grief, confusion) committed emotion-driven assaults due to a build-up of problems sometimes unrelated to the offence. This type of offending looks similar to cluster four in this study, where background relationship stress and anger appear to be drivers in the violence occurring. The other main assaultive offence type found by Lopez and Emmer (2000) was the belief-driven, self-preservation offence. Belief-driven crimes were fuelled by the offender's 
underlying demonstration of his masculinity through aggressive behaviour (Lopez \& Emmer, 2002). The offender believed he was threatened, either physically or psychologically, and most commonly acts in a non-predatory reactive manner with a high degree of violence. This type may be similar to cluster three who have self-referencing goals such as self-presentation and payback, and may be provoked by a sense being insulted, betrayed or undermined (ProvInsult), this offence cluster also shows a high degree of violence.

The two more reactive clusters (clusters three and four) are also similar to Toch's (1969) subtypes. Toch's typology relates to offenders rather than offences, but it has relevance as it considers the motivation for an offence. Toch (1969) produced a typology of the motives of violence through content analysis of interviews with 71 inmates and parolees. Two major categories of offender motive were identified: (a) self-preserving offenders, who use violence to bolster their ego (status seekers), and (b) manipulators, who regard themselves as the only factor of social relevance. Self-preserving offenders include the reputation-defender, who engages in violence in order to preserve his reputation as a social obligation; the self-image defender, who uses violence as a form of retribution when someone casts aspersions on his self-image; and the self-image promoter, who uses violence as a demonstration of worth and to convey to others his toughness and status. There is also a pressure-removing group (exploding in situations beyond social skills), where pressure has simply gotten too much. Cluster three and four offences could be seen as having been committed by Toch's self-preserving offenders. Cluster three relates to: reputation-defending and self-image defending and self-image promoting (use of violence to prove toughness); whereas cluster four may be an example of Toch's pressure-removing group.

Summary. Although clusters similar to instrumental and reactive groupings were found in the data and a dimensional structure was seen, a clear reactive-proactive dichotomy was not found due to the presence of mixed instrumental/reactive clusters. This finding leads 
to the conclusion that violence in forensic populations may be explained better by allowing for mixed motives rather than forcing a dichotomy (Gendreau \& Archer, 2005; Raine et al., 2006). Although the current results can only be described as preliminary, they nonetheless suggest a more comprehensive framework is required for forensic samples, one that moves away from a simple dichotomy.

\section{Multidimensional scaling and hierarchical cluster analysis results for offence variables}

The MDS two-dimensional solution for the offence variables is presented in Figure 3. The stress index was 0.18 , indicating a fair fit of the data (Kruskal \& Wish, 1978); the $\mathrm{R}^{2}$ was .88 indicating that $88 \%$ of the variance was explained by the map. The HCA analysis again suggested four clusters.

The results here reflect the same patterns as seen previously. The MDS map again shows that a traditional instrumental-reactive divide is present (reactive variables on right hand side) however there is a cluster of mixed instrumental and reactive variables (cluster two), the goals of sensation seeking, helping others, defence, self-presentation and catharsis in particular, merge the two sides of the map, emphasising again that the goals or functions of offending may be a poor way to differentiate between instrumental and reactive violence. 


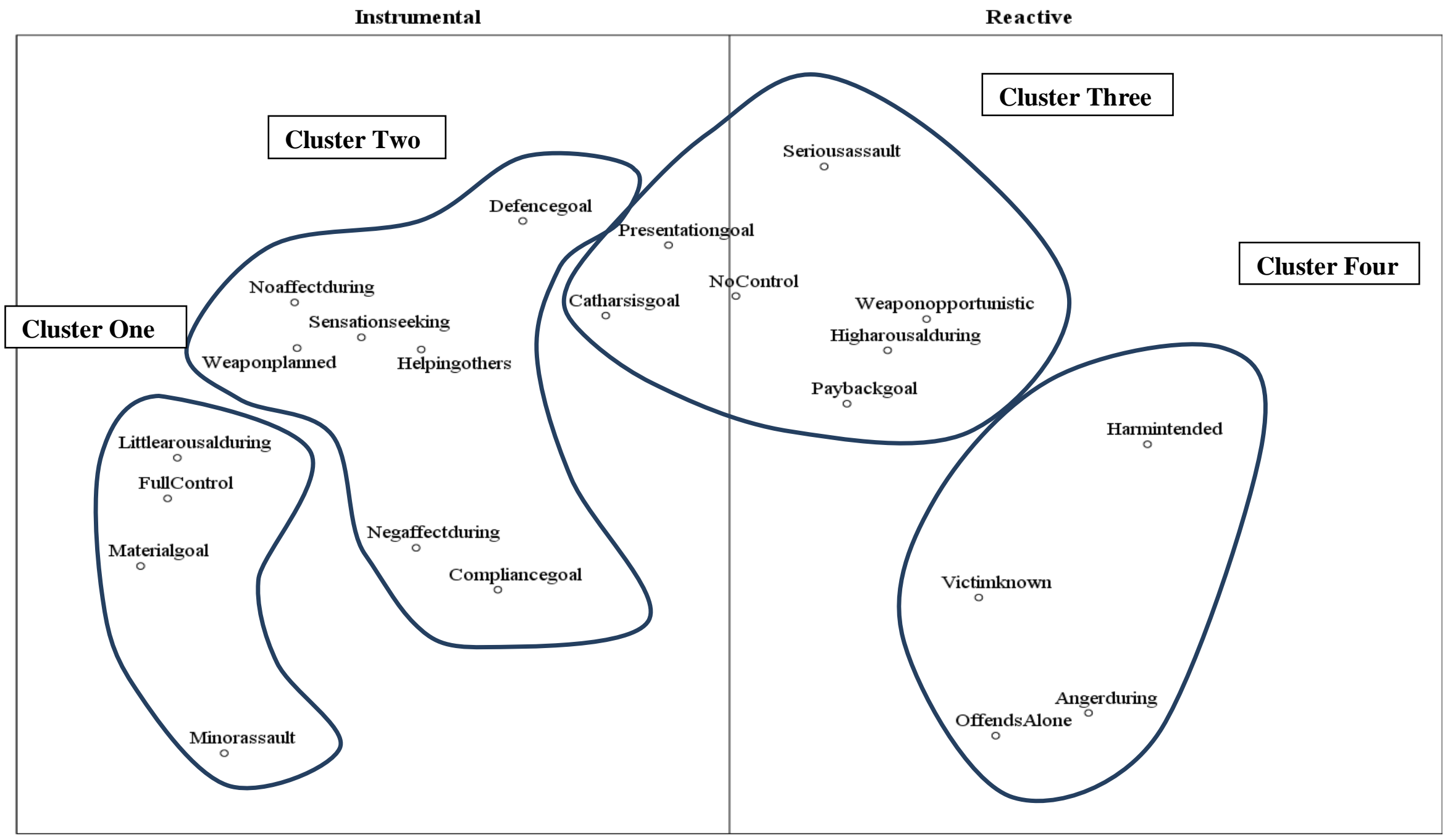

Figure 3. MDS output and HCA cluster solution for offence variables. The HCA clusters been superimposed on to the MDS map. 


\section{Discussion of offence only factors}

Looking at the clusters, the results are similar those in the prior analysis. One cluster is typically instrumental (cluster one), one is mixed (cluster two), and two clusters represent forms of reactive type violence, linked by the desire to do physical harm. Physical harm is a variable which (although it is in cluster four) sits approximately equidistant between the largest mass of variables in clusters three and four. However the reactive clusters differ in that the upper cluster (cluster three) has goals such as self- presentation, payback and catharsis, while the lower cluster (cluster four) appears to have no goals except that of harm. This suggests that the term "reactive" encompasses more than a single type of violence. And while the dichotomy can be loosely applied to the violent acts seen here, any useful detail is lost if the dichotomy is applied in a simplistic way to violence generally (Ohlsson \& Ireland, 2011).

\section{Method Study 2}

The second aim of this thesis is to further validate the notion of primary and secondary variants of psychopathy, via their theoretical association with different forms of violence. Due to the differing traits thought to underlie primary and secondary psychopathy, there is reason to suppose that these two variants may show different forms of violence. Therefore the next step in the analysis was to see what, if any, relationship the two subtypes of psychopathy would have with the different clusters of offence characteristics representing different types of violence, and created by the hierarchical cluster analysis (HCA) solution in study one (all variables solution).

\section{Procedure}

Study 2 compared pre-established clusters of primary and secondary psychopaths with the different types of violence uncovered in Study 1 to see if there are qualitative differences in the type of violence committed between psychopathy variants, and if the predicted 
relationship between instrumental and reactive violence characteristics and primary and secondary psychopathy is seen.

Primary and secondary psychopathy variants. This research drew its psychopathy subtype clusters from a prior study using the same sample (Daly, 2011). The classification of primary and secondary psychopaths used the K-means cluster analysis of offenders' responses on the MCMI-III. The rationale for this clustering approach was based on previous research using self-report and clinician-rated psychopathology scales to differentiate and validate primary and secondary psychopathy variants (Skeem et al., 2011).

The MCMI-III is the third revision of a self-report scale designed to measure personality and clinical psychopathology. Scales measure both axis I syndromes and axis II disorders, and Millon (1997) believed the axis I syndromes reflect the nature and degree of distress associated with dysfunctional personality styles. The scale consists of 175 true-false items that map onto 14 clinical personality sub-scales (schizoid, avoidant, depressive, dependent, histrionic, narcissistic, antisocial, sadistic, compulsive, negativistic, masochistic, schizotypal, borderline, and paranoid), and 10 clinical syndrome sub-scales (anxiety, somatoform, bipolar, manic, dysthymia, alcohol dependence, drug dependence, posttraumatic stress disorder, thought disorder, major depression, and delusional disorder). Of the sample, $62 \%$ of the men were classed as secondary psychopaths and $38 \%$ as primary psychopaths. Scores are transformed into base rate (BR) scores, by making adjustments for the prevalence of different disorders. BR scores of 85 or higher indicate that a clinical diagnosis is likely, and scores between 75 and 84 indicate the presence of traits consistent with the disorder (Millon, 1997). The secondary psychopaths were found to have generally high levels of psychopathology, which is consistent with the conceptualisation of secondary psychopathy (Karpman, 1941). The psychopaths included in the secondary cluster had clinical (BR > 75) scores on antisocial traits and alcohol use, with scores almost reaching the 
clinical cut-off (74.6) for both drug use and disclosure; this high score on disclosure suggests that these men may over report psychopathology, or "fake bad" (Millon, 1996). The secondary cluster also has moderate to high scores in the sub-clinical range (BR 65-75) on scales in the scales for anxiety, depression, narcissism, aggression, passive-aggression, paranoia, self-defeat, desirability and bipolar disorder. For those in the primary cluster it was found that the only clinical score was on the desirability scale, which indicated a possible "fake good" responding style (Millon, 1996) in which the offenders present themselves as better than they are, when they feel it will serve their interests. A follow up analysis of variance (ANOVA) showed that the clusters had significantly different scores on all subscales, except Narcissistic $(F(1.164) 2.605, p=.12)$.

Data analytic strategy. Using the clusters derived from HCA as outlined in Study 1 (all variables solution), a cluster score for each offence chain was calculated. For each offence chain coded, a cluster score for each cluster was assigned. Cluster scores were obtained by assigning each variable in each cluster a score of 1 (indicating presence) or 0 (indicating absence) depending on whether they were present or not for the offence in question. This was done for each offence, and then the numbers totalled for each cluster. Each offence ended up with four cluster scores (See Table 4). A cluster score represents how many of the violence characteristics contained in one cluster had had been present in an offence chain. Offences were grouped by whether the offender fell into the primary or secondary psychopathy groups for comparative analysis. Using a one way ANOVA it was then seen if groups (primary or secondary psychopathy) could be differentiated by cluster score. 
Table 4.

Cluster scores for primary and secondary psychopathy variants

\begin{tabular}{lllll}
\hline $\begin{array}{l}\text { Psychopathy } \\
\text { Variant }\end{array}$ & Cluster 1 Score & Cluster 2 Score & Cluster 3 Score & Cluster 4 Score \\
\hline Primary & 61 & 100 & 233 & 172 \\
Secondary & 140 & 152 & 364 & 261 \\
\hline
\end{tabular}

\section{Results and Discussion Study 2}

A one way analysis of variance (ANOVA) comparing cluster scores to psychopathy subtype showed that subtypes were not significantly different for any violence cluster $(F(1,446)=0.016, p=.90)$. This finding suggests that overall the likelihood for instrumental and reactive violence is approximately equal for each subtype. To get further detail on the relationship between the subtypes and the instrumental and reactive variables, the variable response frequencies for the two subtypes were calculated for each offender. To see if there were differences in response frequencies between the subtypes, chi square analysis was run for each variable (Table 5). Post offence (e.g., remorse, regret) factors were re-included in this analysis. 
Table 5.

Differences in variable frequency between primary and secondary psychopathy variants.

\begin{tabular}{llllll}
\hline Variables & \multicolumn{2}{l}{ Primary } & \multicolumn{2}{l}{ Secondary } & Chi \\
\hline \multicolumn{1}{l}{ Proximal stress } & n & \% & n & $\%$ & $\boldsymbol{\chi}^{\mathbf{2}}(1, \Lambda$ \\
Business & & & & & \\
Relationship & 14 & 33 & 21 & 30 & 0.06 \\
Drug & 22 & 51 & 30 & 44 & 0.63 \\
No stressors & 18 & 42 & 25 & 36 & 0.36 \\
& 9 & 21 & 17 & 25 &
\end{tabular}

\section{Proximal mood}

No affect proximal

$\begin{array}{lllll}9 & 21 & 17 & 25 & 0.20 \\ 9 & 21 & 15 & 22 & 0.58 \\ 17 & 40 & 27 & 39 & 0.01\end{array}$

Negative low

Negative high

9

Insult

Money

Domestic

4

21

12

17

0.22

Threat

7

9

6

0.01

No provocation

$9 \quad 21$

12

0.02

Provocation Response

$11 \quad 26$

12

0.22

Intense/immediate

$10 \quad 23$

$19 \quad 28$

0.25

Mild/delayed

22

51

$25 \quad 36$

Provocation affect

Anger

$24 \quad 56$

$39 \quad 57$

0.01

High Negative

4

11

0.91

\section{Planning}

No plan

$\begin{array}{lllll}19 & 44 & 29 & 42 & 0.05 \\ 6 & 14 & 14 & 20 & 0.73\end{array}$

Good plan

0.73

Intoxication

$13 \quad 30$

22

32

0.03

Intoxication doesn't contribute

$12 \quad 27$

22

32

0.20

Goals

Compliance

$\begin{array}{lllll}11 & 26 & 17 & 25 & 0.01 \\ 10 & 23 & 14 & 20 & 0.14 \\ 13 & 30 & 11 & 16 & 3.21 \\ 12 & 28 & 27 & 39 & 1.47\end{array}$

Catharsis

Defence

Payback

(2)




\begin{tabular}{llllll}
\hline Variables & \multicolumn{2}{l}{ Primary } & \multicolumn{2}{l}{ Secondary } & Chi Square \\
\hline Material & 14 & 32 & 24 & 35 & 0.06 \\
Self-Presentation & 8 & 19 & 22 & 32 & 2.38 \\
Sensation Seeking & 1 & 2 & 7 & 10 & 2.44 \\
Helping Others & 0 & 1 & 4 & 6 & 0.24
\end{tabular}

\section{Affect During}

Anger

$29 \quad 67$

43

62

0.30

Negative Affect

22

51

36

52

0.01

No Affect

5

12

15

22

1.85

\section{Arousal During}

High Arousal

$\begin{array}{lllll}15 & 35 & 22 & 32 & 0.12 \\ 10 & 23 & 21 & 30 & 0.68\end{array}$

Little arousal

(10)

$24 \quad 56$

37

54

0.05

Severity of Assault

Minor Assault

$\begin{array}{llll}14 & 33 & 32 & 46\end{array}$

2.09

Severe/Fatal Assault

20

47

25

1.17

\section{Intention of Harm}

Harm intended

29

67

42

61

0,49

\section{Control}

Full Control

No Control

$\begin{array}{lllll}7 & 16 & 24 & 35 & 4.53^{*} \\ 10 & 23 & 16 & 23 & 0.00\end{array}$

Weapon use

Uses Weapon

$35 \quad 81$

44

64

3.96*

Weapon planned

$10 \quad 23$

12

17

0.58

Weapon opportunistic

$24 \quad 56$

$27 \quad 39$

2.97

\section{Role}

Offends Alone

$25 \quad 58$

41

59

0.02

Feelings immediate

$\begin{array}{llllll}\text { Regret } & 9 & 21 & 11 & 16 & 0.45 \\ \text { Remorse } & 1 & 2.3 & 3 & 4.3 & 0.32 \\ \text { None } & 17 & 40 & 42 & 61 & 4.84 *\end{array}$

\section{Feelings delayed}

\begin{tabular}{llllll} 
Regret & 20 & 47 & 29 & 42 & 0.22 \\
Remorse & 7 & 16 & 13 & 19 & 0.12 \\
None & 9 & 21 & 18 & 26 & 0.39 \\
\hline
\end{tabular}

Note. ${ }^{*}$ Chi-square analysis significant $p<0.05$. 
Overall very little difference was seen between primary and secondary psychopaths.

Of the 48 variables (the 42 variables outlined in Appendix G, plus the variables: post violence remorse, immediate and delayed; post violence regret, immediate and delayed; and no regret or remorse immediate and delayed) compared, the variants of psychopathy were found to significantly differ on only three. The first significantly different variable was that of full control; $\left(\chi^{2}(1, N=112)=4.53, p=.45\right)$. The difference was in the opposite direction to what would be predicted, with more secondary psychopaths showing good control, an instrumental type variable, during offending. Weapons use was the second variable that was significantly different between subtypes $\left(\chi^{2}(1, N=112)=3.96, p=.47\right)$ with more primary psychopaths opting to use a weapon (often opportunistically). This opportunism suggests a lack of forethought and planning so may be considered to be a reactive violence variable and therefore was expected to be associated with secondary psychopaths. The final significant variable is a lack of remorse or regret immediately after the offence occurs $\left(\chi^{2}(1, N=112)=\right.$ $4.48, p=.28$ ) with secondary psychopaths having less remorse or regret immediately after the offence commission. Again this is surprising as Barratt, Stanford, Dowdy, Liebman, and Kent (1999) found high post violence remorse to be a feature of reactive violence, and therefore it was expected that it would link to secondary rather than primary psychopaths. All the findings here are in a direction opposite to what has been hypothesised, with primary psychopaths showing the more reactive violence features.

While there were no other significant differences in violence characteristics between primary and secondary psychopaths, there were some results of theoretical interest, many of which approached significance. Primary and secondary variants reported similar levels of anger and arousal before and during offending. However, during the offence, the secondary groups were more likely to express hurt (e.g., betrayal) or state that they felt "fine" or "calm", while the primary psychopaths were more likely to express fear and/or anxiety. This is also 
counter to expectation, and draws into question the use of MCMI-III data as a classification tool to identify variants of psychopathy.

Both variants of psychopathy however are driven by a similar amount of desire to do physical harm, and tied to this are similar levels of injury, though with the primary psychopaths showing a slight tendency to do more harm overall. Again, the primary on the whole show more reactive features than the secondary psychopaths do, when the opposite was hypothesised.

\section{Discussion}

The findings ran counter to the hypothesis that primary psychopaths would have violence with more instrumental characteristic and secondary psychopaths would have violence with more reactive features. Instead it seems that primary and secondary psychopaths were not found to differ on most violence-related characteristics coded here. Primary and secondary psychopaths in this instance were similar groups with similar offending behaviours in which there was some variation in levels of instrumentality and reactivity. However, as no significant difference was seen between the primary and secondary variants in violent offending characteristics, differences in offending do not validate the primary and secondary variants. This is surprising, given what is hypothesised about the different affective deficits of each group.

The results also suggest that psychopaths in general are as likely to use reactive as instrumental types of violence rather than being particularly associated with instrumental violence (e.g. Cornell et al., 1996; Woodworth \& Porter, 2002; Hare, Williamson \& Wong, 1987), although it is impossible to know from these results if they are more or less instrumental than a non-psychopathic group would be. If there are primary and secondary variants of psychopaths, evidence suggests that the violence clusters or characteristics in this study cannot be used to predict subtypes, or vice versa. 
These offenders, however, are violently versatile men, used to using violence for different purposes. The fact that primary psychopaths can act "out of control" and secondary psychopaths can plan their offending may not be so surprising in the light of offender versatility.

\section{General Discussion}

The primary aim of the first study was to describe violent offending characteristics; specifically the goal was to see how offence variables considered important to the instrumental and reactive violence dichotomy (e.g., affect, planning, and goal) co-occur within an offence, and whether they co-occur in a way that supports the instrumental and reactive dichotomy hypothesis. The study used an exploratory approach to resolve the conceptual inconsistencies seen in violence literature by seeing what violence characteristics do co-occur to make up different subtypes.

This goal in turn relates to the question of whether or not two underlying theories, with separate aetiological pathways, are necessary or suitable to explain instrumental and reactive types of violent offending. To this end, the results of Study 1 provided a profile of the consistency and differentiation of offence characteristics for a sample of high risk violent psychopaths, a group over represented in New Zealand prisons. The most significant finding from study one is that instrumental and reactive violence characteristics do not present as a dichotomy.

In order to validate the dichotomy of instrumental and reactive violence, it would be expected that two mutually exclusive groups of offence types would emerge from the data. The instrumental group would have identifiable goals, show advance planning, and the offenders would not be provoked and would demonstrate little or no affect. The reactive group would have offenders who were high in arousal and negative affect, have claimed to 
have been subject to provocation, and the offence would have occurred quickly and without planning.

Although the MDS output indicated variables associations that looked somewhat like instrumental and reactive types, clearly a dichotomy was not seen in the present study. The MDS gave a clear sense of the instrumental and reactive violence division, but the patterns of offence characteristics in the results of the present study showed that instrumental and reactive type violence, far from being independent, appeared to overlap and merge into one another. Characteristics commonly used to distinguish instrumental and reactive violence (e.g., provocation and goal directedness), did not separate types of violence in a simple way in the current study. It is perhaps not surprising that Barratt and Slaughter (1998) estimated that only 50 per cent of aggressive acts could be categorised as either hostile or instrumental, leaving approximately 50 per cent of acts to be categorised as 'mixed', 'can't determine' or 'medically related'(Barratt \& Slaughter, 1998).

From HCA four clusters emerged, two of which looked like some prior conceptualisations of instrumental and reactive/expressive violence, and two much larger clusters which were a mixture of both instrumental and reactive violence characteristics. The overlap suggested that in the real world, some violence is mixed in type. It seems some offences can be adequately categorised by the dichotomy, however, rigidly adhering to the dichotomy leaves a portion of the current sample of offences impossible to classify adequately. Overall these findings suggest a dichotomy is too "crude" (Ohlsson \& Ireland, 2011, p.284); and that criticisms that the dichotomy over simplifies violence (e.g., Bushman \& Anderson, 2001; Woodworth \& Porter, 2002), are correct. This in turn suggests that act specific theories are not necessary or adequate to explain instrumental and reactive violence.

The results of the present study present a more sophisticated understanding of offence types and a more complete and complex model of violence than the traditional dichotomy 
does. This model may present a starting point in the development of a more useful classification system of violence which is underpinned by a single dimensional structure of increasing negative affect and arousal.

In addition to assessing the fit of the current data to the theoretical underpinnings of instrumental and reactive violence, it was further the aim of the current study to contribute to the literature base surrounding the subtyping of psychopaths. In this regard Study 2 aimed to address a conspicuous gap in the current psychopathy violence literature. Study 2 used the results provided by Study 1 to further explore the relationship between variants of psychopathy and violence characteristics. To this end, the second study considered if psychopaths are heterogeneous in regard to offending style and type, specifically with regard to the instrumentality/reactivity of the violent offence. The hypothesis for study two was that primary psychopaths would show more instrumental violence characteristics, and secondary psychopaths would show more reactive characteristics.

The hypothesis for study two was not supported. Like the overlap between instrumental and reactive variables, there was also overlap in the types of violence used by these different offender groups. The two subtypes of psychopaths were more versatile than predicted and could not be discriminated by the offence characteristics which had been clustered into four types of violent offending.

No validation for the primary and secondary variants of psychopathy was provided by the results of this study. Results from the current investigation indicated that different violent offence characteristics do not relate differentially to different psychopathic variants. Instead both the psychopathic subtypes seemed to show the same general tendency toward aggression and criminality, only differing on weapons use, remorse and control variables; in each case in an unexpected direction. 
A possible explanation for this overlap is the criminal versatility that is seen in seriously violent offenders. Criminal versatility is an item measured by the PCL-R (Hare, 2003), so mixed crime is in fact a symptom and identifier of PCL-R psychopathy. There is every reason to expect that the men sampled in this study should be expert at using both instrumental and reactive violence styles depending on the needs of the situation.

\section{Theoretical Implications}

Different theories of aggression are currently seen to be better suited to explain one form of violence or the other, rather than both. Social learning theory is considered to explain instrumental violence, and frustration aggression is used to explain reactive violence. If, as this study suggests, the two forms of violence cannot be reliably distinguished, having different theories for each makes little sense (e.g., Polman, de Castro, Koops, van Boxtel \& Merk, 2007). The dichotomy of instrumental and reactive aggression does not appear to account well for the patterns of offending characteristics evident in this sample. While it does seem that some violence is more driven by reward and other violence more driven by anger or the desire to harm, this division isn't clear cut, and violence offence characteristics appear to be more "mix and match" than is traditionally conceived. Because the division between instrumental and reactive violence was not clear in this study, it provides little support for having separate underlying theories. Having separate theories for instrumental and reactive violence suggests that there is something fundamentally different about these forms of violence and, by extension, the people that commit them; but it appears that instrumental and reactive violence may be grounded in similar developmental, psychological, and sociological processes and as such could be explained more simply (Walters, 2008). It would seem that the theory tied to violence classification has been unnecessarily complicated to date.

General theoretical models of violence rest on the pivotal assumption that a single causal process may be invoked to apply to all types of violence (Benda, 2003). Tapscott et al. 
(2012) challenge the use of a general theory of crime to explain instrumental and reactive violence, specifically Tapscott and colleagues challenge the use of Gottfredson and Hirschi's (1990) general theory of crime to explain different types of violence based on the findings of their study. The theory states that variation in unlawful or deviant behaviours between and within individuals can be fully accounted for by low self-control (Gottfredson \& Hirschi, 1990). However, unlike Tapscott et al. the current study does not discount a general theory to explain all violent acts based on the findings, in fact the reverse is true. Act specific theories may have a place in explaining violence, but the findings in this study of mixed instrumental and reactive violence characteristics suggest that a general theory will suffice.

According to Andrews and Bonta (1994) another general theory, social learning theory, by itself poses no difficulties in explaining the distinction between reactive and instrumental violence. Any behavioural outcome, including violence, could be explained as the enactment of learned responses. Reactive violence could be driven from negative reinforcement, either from the release of anger (catharsis), or removal of an aversive stimulus (negative reinforcement), or increased status and respect (positive reinforcement); and as such be a learned behaviour. This notion is echoed by Felson (2009), who notes that explaining violence does not need specific theories, or even need a general theory of aggression; rather, "we can use the most widely accepted theory of human behaviour, one that emphasises rewards and costs...such an approach is preferable on grounds of parsimony" (p.28).

In regards to the theories thought to underpin violence, Felson (2009), "the study of violence has become Balkanized" (p.25), and, "if independent variables are only associated with particular types of violence, we may need more specialised theories. However, one should not assume that a particular type of violence has a special aetiology without convincing evidence that this is the case" (p.25). As it stands, there is no evidence for this 
case, even Cornell et al., (1996) noted that variables are never only associated with a particular type of violence and that offence histories tend to be mixed. Instead it would seem that there is no compelling rationale why any form of violence cannot be explained on general learning principles, such as those suggested by social learning theory.

Regarding psychopathy it would seem that there is little support of the concept of primary and secondary variants based on the findings here, at least there is no support for the hypothesis that these different groups will differ on violence enactment. It is possible that the way these variants have been conceptualised needs further refinement. What is important to note is that this study does not overturn the notion of subtyping psychopaths, but raises questions about how they should be grouped and what predications can be made about their use of violence.

\section{Applications}

The data in the current study have been drawn from offence chains—offenders' own descriptions of their violent offending - to get a real-world answer to the issue of violence subtyping. These offenders are all male high risk repeat offenders who meet the Psychopathy Checklist (Hart, Cox, \& Hare, 1995; Hare, 2003) criteria for psychopathy, and who have spent time in Te Whare Manaakitanga, a New Zealand in-prison violence treatment facility. These are the individuals for whom it is most important to better understand violence heterogeneity. However, it must be emphasised that the purpose of the study is to better understand the violent acts of these men, rather than the men themselves.

The better we truly understand what violence looks like rather than relying on assumptions, the better chance there is of preventing its future occurrence. It may be important to understand violence characteristics, as various parts of the offence process may be useful targets for relapse prevention purposes. In particular, precipitating factors and reinforcement contingencies may suggest crucial targets for intervention (Nightingale, 2002); 
also the function of cognitive distortions, poor behavioural controls, and emotional regulation may be areas that can be targeted to prevent further offending (Howells and Day 2002, in Chambers). The identification of recurring common characteristics shared within offence types may help clinicians to develop specific offence relapse interventions in line with the principles of risk, need and responsivity (Andrews \& Bonta, 2010). The findings of the current study may be the starting point of a more accurate typology than the instrumental and reactive dichotomy, which can be used to target treatment more effectively. The findings suggest that the underlying affect and contextual factors of the offending are good starting points for intervention as it is these that most clearly differentiate the clusters.

There is a caveat to using a violence typology to target treatment however. For example studies often apply the instrumental and reactive subtypes to offenders as if people are clearly instrumental or reactive (e.g., Cornell et al., 1996) and can be classified in a way that will have clinical utility: for example, it has been hypothesised that instrumental offences will have perpetrators that will respond to behavioural therapies, as it is thought to be driven by reward and underpinned by social learning theory, while those who commit reactive behaviours are thought to respond better with emotional regulation programmes. Tapscott et al. (2012) for example state: the " apparent divergence between subtypes of violence and aggression raises the possibility that the characteristics of offenders' violent offences can be reviewed to identify priorities for more individualized rehabilitation initiatives...individuals with different proportions of instrumental versus reactive violent offences may benefit from alternative courses of treatment that target the predominating motivation behind their violent behaviour" (p. 214).

These allocations rely on the basic assumption that offenders who commit the same types of offences will have the same treatment needs (Cassar, Ward, \& Thakker, 2003). There is no reason why this should be considered to be the case. While a future study needs to 
include more than one offence per offender to be certain, the mixing of violence characteristics found in the current study suggests that it may be unsound to label the offenders instrumental or reactive, or to assume they should differ significantly in developmental factors or on personality traits. This is especially true considering that when the offenders were divided on personality traits (Study 2), they did not differ on the type of violence committed.

There are also practical difficulties with using a dichotomy that does not clearly separate, such as that of instrumental and reactive violence, to group treatment receivers. It would be difficult to know how to classify mixed offences and where the cut-offs should lie. In the case of the treatment groups suggested by Tapscott et al. (2012), just how much instrumental versus reactive violence equates to a "predominating motivation" (p. 214) is unclear. Due to these concerns, Ohlsson and Ireland (2011) emphasise that treatment suitability should not be based around the application of the instrumental and reactive dichotomy.

Knowing which offence characteristics are present in a violent act may still be useful however, as it is possible that classifying or describing offences may identify some specific offence behaviours that can be targeted; for example the functions of the acts in question, or the underlying drivers of violence. The present study suggests that there are different underlying drivers of violence at work, different wants, needs, background stressor and underlying moods all may contribute to what the end product of violence looks like. For the process of desistence and change to be successful, more attention needs to be paid to the offender's motivation and to the impact of his or her social context on the outcomes of the intervention (Farrall, 2002 cited in McNeill, Farrall, Lightowler, \& Maruna, 2012). It is possible that the findings of this study could be used to identify these offence drivers in a systematic way. 
What is very important for applied settings, however, is an understanding that the instrumental and reactive dichotomy does not exist in a clear cut way. If these subtypes are considered to exist in a real-world way but in fact do not, it may have significant implications. For example the distinction between instrumental and reactive violence is one that has legal bearing, given that variations in the motivations for violent behaviour often influence a sentencing judgment. As Melton, Petrila, Poythress, and Slobogin (1997) wrote. "All would agree; for example, that the unjustified killing of another is reprehensible. But we would all probably agree that...the husband who in a rage kills the man he finds sleeping with his wife, and the 'cold-blooded' murderer should not be punished equally" (p. 203). However, it may not be as simple to divide violent acts into angry reactive or cold-blooded instrumental as it would appear on the surface. Nothing here should suggest that that violence cannot be classified, but simply that that the use of the instrumental and reactive dichotomy makes little sense in its current form.

Study 2 suggests that assumptions should not be made regarding the relationship between psychopathy and violence characteristics at this stage. Although Study 2 did not find any differences between psychopathy variants, it is important for future studies to continue to consider this question; as if it is known how psychopaths differ we can address the different rehabilitation needs of the primary and secondary groups. It may be that different types of psychopathy directly impact amenability to treatment (Salekin, Rogers, \& Sewell, 1996). As it stands, psychopathy is currently a global label that provides little "point of reference for clinical intervention' (Blackburn, as cited by Skeem et al., 2003, p.515). If variants of psychopathy can be identified reliably and supported empirically, they may improve our ability to understand, treat, and manage a class of individuals who have largely been regarded as dangerous and incurable (Skeem et al., 2003). 


\section{Limitations and Future Research}

There are a number of limitations associated with the current study, these are: 1) self-report, 2) use of archival data, 3) sampling and generalisability, and 4) statistical analyses.

1) Self-report. The current research was a retrospective study based solely upon offence chains written from the offender perspective. The reliability and validity of research in criminal justice is commonly threatened by reliance on retrospective, self-report data from incarcerated offenders.

The limitations of self-report data are well known (Wright \& Decker, 1997), including issues of social desirability, acquiescence, distortion, poor recall, non-disclosure, fabrication, and lack of awareness of cognitive processes. Offenders may minimise behaviours to look less culpable or enhance their capabilities to impress others, either leaving out important details of a crime, (Ekman, 2002) or embellishing detail. Social desirability and selfpresentational concerns produce inaccuracy. When dealing with a socially unacceptable behaviour such as violence, respondents may be hesitant to admit the extent of such behaviour (Ramirez, Rodríguez, \& Manuel, 2006). There is also the problem of selfawareness; that is, it is likely that respondents may not be honest with themselves about their own aggressive behaviour; they may deny the extent of their own aggressiveness (Österman, Björkqvist, Lagerspetz, Kaukiainen, Huesmann, \& Fraçzek, 1994). Despite these limitations, the offender's perspective is probably the best resource for creating offence descriptions as accurately as possible. Nevertheless, due to the biases inherent in the use of self-report, the results from this study should be viewed with an appropriate level of caution (Canter, 2004).

2) Use of archival data. The use of archival data created two limitations, firstly only a single self-selected offence was coded for each offender, and secondly the available offence chains varied considerably in the level of descriptive detail. 
Only one offence per offender was available for inclusion into the study, and the offence described was selected by the offender. There are several issues that may arise from using single offence descriptions, but in the main it comes down to the concern that the offences may not be very representative of the offender's offending overall. The offence selection process may have offenders choosing, for example, offences where they demonstrated less control and planning than usual. It is possible that given a broader range of offences the results here may look different. Using a single offence description for each offender meant that only a "snap-shot" of an offender was available. Therefore, using current criminal offence as a method to classify and compare offence types (Study 1) and offenders (Study 2), while valuable in its own right, may not be the most appropriate method of assessing instrumental and reactive violence characteristics.

The available offence chains also varied considerably in the level of descriptive detail, ranging from a comprehensive description of the entire offence process to the briefest of details. Particularly problematic was the inconsistency of post-offence information recorded; these post-offence variables were eventually excluded from Study 1 entirely. Future studies, using alternative or multiple data sources, may prove more successful in accurately capturing such information. A longitudinal approach examining different offences committed by the same offenders across time may be worthwhile.

3) Sampling and generalisability. An obvious limitation is sample size. After removing the offence chains that did not have enough information or were illegible a sample of 112 remained. While a small sample is often a feature of research using archival data or forensic samples, it of course does limit what conclusions can be drawn. Greater numbers of participants in this study would have permitted further analyses of patterns of co-occurrence of variables, and would have generated more robust conclusions.

There are also the problems of generalisability which come from using such as 
specific sample. The sample used in this study was high risk, generally violent, male PCL-R psychopaths incarcerated in New Zealand who had chosen to enrol in a treatment programme. That such a sample is representative of neither prison nor overall offender populations is clear. There are almost certainly qualities peculiar to the sample that may prevent these results from generalising to other non-psychopathic or non-treatment group violent offenders. For example, it is possible that psychopaths would be more likely than other offenders to reframe the level of instrumentality that had been involved, in terms of minimising the degree of premeditation and exaggerating the victim's role in, and the spontaneity of, the offence. They may also be more likely than non-psychopaths to omit or alter the facts of their offence, (Ekman, 2002). On the other hand, it is also possible that psychopaths would be more likely than non-psychopaths to boast about their involvement in the offence, even to the point of exaggerating its instrumentality. The sample is also highly prolific and experienced violent offenders. This may impact the findings of both studies, since it suggests that the offenders will have an extremely versatile, rather than specific use of violence, and use violence for many situations. As such it is unlikely that these men will fall into clear cut instrumental or reactive "camps".

Furthermore, all offence chains in this sample were obtained from offenders who completed them as part of their rehabilitation programme. In order for offenders to attend rehabilitation they must be identified as eligible and also willing to attend. Therefore the sample does not reflect those violent offenders who were still at large, were imprisoned but ineligible, or those that were eligible but refused to take part in the programme. Since the focus of the current study was on a sample of high-risk violent offenders, the selection criteria of the current sample did not take into consideration other relevant aspects relating to generalisability of results. For instance, age range, offence type and cultural differences were not considered in the selection procedure. Future studies should consider including much 
larger, more varied samples to gain a comprehensive understanding of the nature of the dichotomy.

4) Statistical analyses. The main statistical method used in this study also presents its own strengths and weaknesses. An advantage of using multidimensional scaling method is that it is simple to immediately assess how commonly different variables co-occur. A disadvantage, though, is that this technique does not deal in real numbers. Using this technique it was impossible to know exactly how many times a pair of variables is associated in the offence chains, or how much more closely one pair or variables is associated compared to another pair; also no claims to statistical significance could be made.

Another disadvantage of this method is that it adds another layer of subjectivity to psychological data, as modelling tabled data into a multidimensional scale requires some decision-making, such as: which data will go into the scale? What number of dimensions should be considered? Also the output map is open to interpretation. This has an effect on the multidimensional scale's validity, and the method has been accused of being "unscientific" (Kaid, 2004, p. 49). The number of clusters derived via hierarchical cluster analysis is likewise chosen with a level of subjectivity.

While the cluster analysis — to classify offenders as primary or secondary—was undertaken in a prior study, it is still worth noting that there may be issues surrounding the use of the MCMI-III to cluster variants of psychopathy. This is suggested by the anxiety found in the primary psychopaths in study 2 ; anxiety is an important differentiating trait which would be expected to only be seen in secondary psychopaths. Indeed, primary psychopaths are in part defined by low anxiety. Other methods of classifying primary and secondary variants of psychopathy may provide a more accurate basis for future study.

Other comments on future research. Future studies should focus on examining the specific elements of the subtypes of violence in more detail (Douglas, 2010). The typology 
found by this study was a four cluster typology rather than a dichotomy, and although there are parallels to instrumental and reactive classes of violence, this new typology is more sophisticated. Three of the four clusters had goal driven violence, and two showed various provocations in play, negative affect discriminated between groups but only when the type of affect was considered. Three of the four groups displayed some form of negative mood before or during the offence. The clusters and the patterns of variables in the clusters remained the same when contextual factors, such as background stressors (i.e., drugs or money) were added or removed. Therefore, it may be that we need to look to a finer detail of violence characteristics to find clear subtypes. If, by doing so, the clusters found in the current study are replicated, it may suggest the beginning of more comprehensive and accurate model of violence than what is provided by the instrumental/reactive dichotomy.

It would be worthwhile also to consider examining a dimensional structure of violence more closely in the future. Woodworth and Porter's (2002) dimensional approach with instrumental and reactive violence sitting at either end of a single dimension seems to fit the findings, at least approximately. The dimensions of affect (including proximal) and background stress seem to underlie the distribution of violence variables, which suggests that any new typology should look at violence within context, rather than looking only at violence offences.

\section{Conclusion}

This study has both novel approaches and findings as compared to other instrumental and reactive violence literature. Firstly, offence characteristics have been coded without prior assumption. Instead the variables linked to the division between instrumental and reactive have been allowed to fall naturally into clusters. Secondly the study also looked to tie the findings back to the suitability of the theories underpinning violence, rather than accepting unquestioningly the theoretical basis of instrumental and reactive violence as being social 
learning theory and frustration-aggression respectively. Thirdly the study brought the context of offending into the typology of instrumental and reactive violence; being able to contextualise some offender behaviours may enhance the understanding of typologies (Nightingale, 2002). Lastly the study looked to tie the instrumental and reactive violence research to primary and secondary variants of psychopathy, thereby beginning to fill in the large evidence gap on this topic.

The study has provided a fresh way of looking at an old topic. While classification is a useful scientific tool the findings suggest that the instrumental reactive dichotomy, as it has been traditionally conceptualised, seems to have reached the limits of its usefulness. The results undermine the need for type specific theories, and also the use of offence typologies to classify offenders. A more sophisticated typology, which is operationalised with consistency and divides violent offences unambiguously, needs to be developed if violence classification is to have any practical application. Future studies on what violent offending looks like are worthwhile, however, as a more thorough understanding of offending characteristics can only assist with the task of developing personalised and relevant treatment approaches that will improve lives as well as reducing offending. 


\section{References}

Agnew, R. (1992). Foundation for a general strain theory of crime and delinquency. Criminology, 30(1), 4788.

Agnew, R. (2001). Building on the foundation of general strain theory: Specifying the types of strain most likely to lead to crime and delinquency. Journal of research in crime and delinquency, 38(4), 319361.

Anderson, C. A., \& Bushman, B. J. (2002). Human aggression. Annual Review of Psychology, 53(1), 27-51.

Andrews, D. A., \& Bonta, J. (2010). The Psychology of Criminal Conduct (5th ed.). New Providence, NJ: Anderson.

Bandura, A. (1965). Influence of models' reinforcement contingencies on the acquisition of imitative responses. Journal of personality and social psychology,1(6), 589-595.

Bandura, A. (1973). Aggression: A Social Learning Analysis. New Jersey: Prentice Hall.

Bandura, A. (1977). Self-efficacy: Toward a unifying theory of behavioural change. Psychological Review, 84, 191-215.

Bandura, A. (1978). Social learning theory of aggression. Journal of communication, 28(3), 12-29.

Bandura, A., Ross, D., \& Ross, S. A. (1963). Imitation of film-mediated aggressive models. Journal of abnormal and social psychology, 66(1), 3-11.

Barratt, E. S. (1991): Measuring and predicting aggression within the context of a personality theory. Journal of Neuropsychiatry and Clinical Neuroscience, 3(2), 35-39.

Barratt, E. S., \& Felthous, A. R. (2003). Impulsive versus premeditated aggression: implications for mens rea decisions. Behavioral Sciences and the Law, 21(5), 619-630.

Barratt, E. S., \& Slaughter, L. (1998). Defining, measuring, and predicting impulsive aggression: a heuristic model. Behavioral Sciences \& the Law, 16(3), 285-302. 
Benda, B. B. (2003). Survival analysis of criminal recidivism of boot camp graduates using elements from general and developmental explanatory models.International Journal of Offender Therapy and Comparative Criminology, 47(1), 89-110.

Barratt, E. S., Stanford, M. S., Dowdy, L., Liebman, M. J., \& Kent, T. A. (1999). Impulsive and premeditated aggression: a factor analysis of self-reported acts. Psychiatry research.86(2), 163-173.

Berkowitz, L. (1962). Aggression: A social psychological analysis. New York: McGraw-Hill.

Berkowitz, L. (1969). Resistance to improper dependency relationships. Journal of Experimental Social Psychology, 5(3), 283-294.

Berkowitz, L. (1989). Frustration-aggression hypothesis: Examination and reformulation. Psychological bulletin, 106(1), 59-73.

Berkowitz, L. (1993). Aggression: Its causes, consequences, and control. New York, NY, England: McgrawHill Book Company.

Bishopp, D., \& Hare, R. D. (2008). A multidimensional scaling analysis of the Hare PCL-R: Unfolding the structure of psychopathy. Psychology, Crime \& Law, 14(2), 117-132.

Blackburn, R. (1975). An empirical classification of psychopathic personality. The British Journal of Psychiatry, 127(5), 456-460.

Blackburn, R. (1988). On moral judgements and personality disorders: The myth of psychopathic personality revisited. British Journal of Psychiatry, 153, 505-512.

Blackburn, R. (1998). Psychopathy and the contribution of personality to violence. In T. Millon, E. Simonsen, M. Birket-Smith, R. D. Davis, T. Millon, E. Simonsen, ... (Eds.), Psychopathy: Antisocial, criminal, and violent behavior. (pp. 50-68). New York, NY, US: Guilford Press.

Blackburn, R., \& Coid, J. W. (1998). Psychopathy and the dimensions of personality disorders in violent offenders. Personality and Individual Differences, 25(1), 129-145. 
Blackburn, R., Logan, C., Donnelly, J. P., \& Renwick, S. J. D. (2008). Identifying psychopathic subtypes: Combining an empirical personality classification of offenders with the psychopathy checklistrevised. Journal of Personality Disorders, 22(6), 604-622.

Block, R., \& Block, C. R. (1992). Homicide syndromes and vulnerability: Violence in Chicago community areas over 25 years. Studies on Crime \& Crime Prevention. 1(1), 61-87.

Borg, I., \& Groenen, P. J. F. (1997). Modern multidimensional scaling: Theory and applications. New York: Springer.

Bushman, B. J. (2002). Does venting anger feed or extinguish the flame? Catharsis, rumination, distraction, anger, and aggressive responding. Personality and social psychology bulletin, 28(6), 724-731.

Bushman, B. J., \& Anderson, C. A. (2001). Is it time to pull the plug on hostile versus instrumental aggression dichotomy? Psychological Review, 108(1), 273-279.

Bushman, B. J., Baumeister, R. F., \& Phillips, C. M. (2001). Do people aggress to improve their mood? Catharsis beliefs, affect regulation opportunity, and aggressive responding. Journal of personality and social psychology, 81(1), 17-32.

Bushman, B. J., Bonacci, A. M., Pedersen, W. C., Vasquez, E. A., \& Miller, N. (2005). Chewing on it can chew you up: Effects of rumination on triggered displaced aggression. Journal of personality and social psychology, 88(6), 969.

Buss, A. H. (1961). The Psychology of Aggression. New York: Wiley.

Buss, A. H. (1982). This week’s citation classic. Current Content, 2, 20.

Camp, J. P., Skeem, J. L., Barchard, K., Lilienfeld, S. O., \& Poythress, N. G. (2013). Psychopathic predators? Getting specific about the relation between psychopathy and violence. Journal of Consulting and Clinical Psychology. Advance online publication.

Canter, D. (2000). Offender profiling and criminal differentiation. Legal and Criminological Psychology, 5, 23-46. 
Canter, D. (2004). Offender profiling and investigative psychology. Journal of Investigative Psychology and Offender Profiling, 1(1), 1-15.

Canter, D. V., Bennell, C., Alison, L. J., \& Reddy, S. (2003). Differentiating sex offences: A behaviorally based thematic classification of stranger rapes. Behavioral sciences \& the law, 21(2), 157-174.

Canter, D., \& Fritzon, K. (1998). Differentiating arsonists: A model of firesetting actions and characteristics. Legal and Criminological Psychology, 3(1), 73-96.

Card, N. A., \& Little, T. D. (2006). Proactive and reactive aggression in childhood and adolescence: A metaanalysis of differential relations with psychosocial adjustment. International Journal of Behavioral Development, 30(5), 466-480.

Cassar, E., Ward, T., \& Thakker, J. (2003). A descriptive model of the homicide process. Behaviour Change, 20(2), 76-93.

Chambers, J. (2006). The violence situation: A descriptive model of the offence process of assault for male and female offenders (Doctoral Thesis, University of Melbourne). Retrieved from http://repository.unimelb.edu.au/10187/2085.

Chase, K. A., O'Leary, K. D., \& Heyman, R. E. (2001). Categorizing partner-violent men within the reactiveproactive typology model. Journal of Consulting and Clinical Psychology, 69(3), 567 -572.

Cima, M., \& Raine, A. (2009). Distinct characteristics of psychopathy relate to different subtypes of aggression. Personality and Individual Differences, 47(8), 835-840.

Cima, M., Tonnaer, F., \& Lobbestael, J. (2007). Moral emotions in predatory and impulsive offenders using implicit measures. Netherlands journal of psychology, 63(4), 133-142.

Clarke, R. V. G., \& Felson, M. (1993). Routine activity and rational choice Vol 5. New Brunswick, NJ: Transaction Publishers. 
Cleckley, H. M. (1941). The mask of sanity; an attempt to reinterpret the so-called psychopathic personality. St. Louis: C.V. Mosby.

Cohen, L. E., \& Felson, M. (1979). Social change and crime rate trends: A routine activity approach. American sociological review, 44, 588-608.

Cornell, D. G. (1996). Coding guide for violent incidents: Instrumental versus hostile/reactive aggression. Unpublished manuscript.

Cornell, D. G., Warren, J., Hawk, G., Stafford, E., Oram, G., \& Pine, D. (1996). Psychopathy in instrumental and reactive violent offenders. Journal of Consulting and Clinical Psychology, 64(4), 783-790.

Cornish, D. B., \& Clarke, R. V. (1986). The Reasoning Criminal: Rational Choice Perspectives on Offending. New York: Springer-Verlag.

Crick, N. R., \& Dodge, K. A. (1996). Social information-processing mechanisms in reactive and proactive aggression. Child development, 67(3), 993-1002.

Daly, T. (2011). Investigating the relationship between in-treatment behaviour and reoffending in high-risk violent psychopaths. Unpublished doctoral thesis, Victoria University, Wellington, New Zealand.

Decker, S. H. (1996). Deviant homicide: A new look at the role of motives and victim-offender relationships. Journal of Research in Crime and Delinquency, 33(4), 427-449.

Dempster, R. J., Lyon, D. R., Sullivan, L. E., Hart, S. D., Smiley, W. C., \& Mulloy, R. (1996). Psychopathy and instrumental aggression in violent offenders. In 104th Annual Convention of the American Psychological Association, Toronto, Ontario, Canada.

Ding, C. (2003). Exploratory longitudinal profile analysis via multidimensional scaling. Practical Assessment, Research \& Evaluation, 8(12). Retrieved from http://PAREonline.net/getvn.asp?v=8\&n=12.

Dodge, K. A., \& Coie, J. D. (1987). Social-information-processing factors in reactive and proactive aggression in children's peer groups. Journal of personality and social psychology, 53(6), 1146 -1158. 
Dodge, K. A., Lochman, J. E., Harnish, J. D., Bates, J. E., \& Pettit, G. S. (1997). Reactive and proactive aggression in school children and psychiatrically impaired chronically assaultive youth. Journal of Abnormal Psychology, 106(1), 37.

Dollard, J., Doob, L., Miller, N., Mowrer, O., \& Sears, R. (1939). Frustration and aggression. New Haven, CT: Yale University Press.

Douglas, R. L. (2010). Instrumental and reactive violence: the role of mental health factors and maltreatment history in the manifestation of violent offending (Doctoral dissertation, Dalhousie University, Halifax). Retrieved from http://dalspace.library.dal.ca/handle/10222/12822?show=full.

Dutton, D. G., \& Karakanta, C. (2012). Depression as a Risk Marker for Aggression: A Critical Review. Aggression and Violent Behavior.18(2), 310-319.

Ekman, P. (2002). Telling lies: clues to deceit in the marketplace, politics, and marriage (2nd ed.). New York, NY: Norton.

Falkenbach, D.M. (2004). The Subtypes of Psychopathy and their relationship to hostile and instrumental aggression. (Doctoral dissertation, University of South Florida, Florida). Retrieved from http://digital.lib.usf.edu:8080/fedora/get/usfldc:E14-SFE0000569/DOCUMENT.

Falkenbach, D., Poythress, N., \& Creevy, C. (2008). The exploration of subclinical psychopathic subtypes and the relationship with types of aggression. Personality and Individual Differences, 44(4), 821-832.

Feldman, P. (1993). The psychology of crime. Cambridge: Cambridge University Press.

Felson, R. B. (2004). A Rational Choice Approach to Violence. In M.A. Zahn, H.H. Brownstein, \& S.L Jackson (Eds.), Violence: from theory to research (pp .71-90). Newark, NJ: LexisNexis/Anderson.

Felson, R. B. (2009). Violence, crime, and violent crime. International Journal of Conflict and Violence, 3(1), 23-39.

Feshbach, S. (1964). The function of aggression and the regulation of aggressive drive. Psychological Review. $71,257-272$. 
Fontaine, G. R. (2007). Disentangling the psychology and law of instrumental and reactive subtypes of aggression. Psychology, Public Policy, and Law, 13, 143-165.

Fulero, S. M. (1995). Review of the Hare psychopathy checklist-revised. In J.C. Conoly \& J.C. Imara (Eds.), Twelfth mental measurements yearbook (pp. 453-454).Lincoln, NE: Buros Institute.

Geen, R. G. (1990). Human aggression. Belmont, CA, US: Thomson Brooks/Cole Publishing Co.

Geen, R. G. (2001). Human aggression (2nd ed.). Philadelphia: Open University Press.

Gendreau, P.L., Archer, J., (2005). Subtypes of aggression in humans and animals. In R.E.Tremblay,W.W. Hartrup, \& J. Archer (Eds.), Developmental origins of aggression (pp. 25-46). New York: Guilford Press.

Giguère, G. (2006). Collecting and analyzing data in multidimensional scaling experiments: A guide for psychologists using SPSS. Tutorials in Quantitative Methods for Psychology, 2(1), 27-38.

Gilbert, F., \& Daffern, M. (2010). Integrating contemporary aggression theory with violent offender treatment: How thoroughly do interventions target violent behavior?. Aggression and Violent Behavior, 15(3), 167-180.

Gottfredson, M. R., \& Hirschi, T. (1990). A general theory of crime. Stanford, CA:Stanford University Press.

Gray, J. A. (1985). The neuropsychology of anxiety. Issues in Mental Health Nursing, 7(1-4), 201-228.

Gwet, K. L. (2010). Handbook of Inter-Rater Reliability: The Definitive Guide to Measuring the Extent of Agreement Among Multiple Raters (2nd ed.). Gaithersburg: Advanced Analytics Press.

Hair, Jr., J. R. \& Black, W. C. (2010). Cluster Analysis. In J.F. Hair, W.C. Black, B.J. Babin, R.E. Anderson, \& R.L. Tatham (Eds.), Multivariate data analysis (pp. 487-495). Upper Saddle River, NJ: Prentice Hall.

Hare, R. D. (1991). The Hare psychopathy checklist-revised (PCL-R). Toronto, Ontario: Multi-Health Systems. 
Hare, R. D. (2003). The Hare psychopathy checklist-revised (2 ${ }^{\text {nd }}$ ed.). Toronto: Multi-Health Systems.

Hare, R. D., Harpur, T. J., Hakstian, A. R., Forth, A. E., Hart, S. D., \& Newman, J. P. (1990). The revised psychopathy checklist: Reliability and factor structure. Psychological Assessment: A Journal of Consulting and Clinical Psychology, 2(3), 338-341.

Harpur, T. J., Hare, R. D., \& Hakstian, A. R. (1989). Two-factor conceptualization of psychopathy: Construct validity and assessment implications. Psychological Assessment: A Journal of Consulting and Clinical Psychology, 1(1), 6-17.

Hart, S. D., \& Dempster, R. J. (1997). Impulsivity and psychopathy. In C. D. Webster, M. A. Jackson, C. D. Webster \& M. A. Jackson (Eds.), Impulsivity: Theory, assessment, and treatment. (pp. 212-232). New York, NY, US: Guilford Press.

Hartup, W. W., \& deWitt, J. (1974). The development of aggression: Problems and perspectives.In J deWitt \& W.W. Hartup (Eds.), Determinants and origins of aggressive behavior (pp. 595-620).The Hague: Mouton.

Henderson, M. (1982). An Empirical Classification of Convicted Violent Offenders. British Journal of Criminology, 22, 1-20.

Hicks, B., Markon, K., Patrick, C., Krueger, R., \& Newman, J. (2004). Identifying psychopathy subtypes on the basis of personality structure. Psychological Assessment, 16(3), 276-288.

Hollin, C. (1989). Psychology and crime: An introduction to criminological psychology. New York: Routledge.

Hout, M., Papesh, M., \& Goldinger, S. (2012). RSVPupillometry: Incidental memory and psychophysiology in rapid-serial multiple-target search. Journal of Vision, 12(9), 1151-1151.

Hubbard, J. A., Smithmyer, C. M., Ramsden, S. R., Parker, E. H., Flanagan, K. D., Dearing, K. F., ... \& Simons, R. F. (2002). Observational, physiological, and self-report measures of children's anger: Relations to reactive versus proactive aggression. Child Development, 73(4), 1101-1118. 
IBM Corp. Released 2010. IBM SPSS Statistics for Windows, Version 19.0. Armonk, NY: IBM Corp.

Ireland, J. L., \& Ireland, C. A. (2008). Intra-group aggression among prisoners: bullying intensity and exploration of victim-perpetrator mutuality. Aggressive behavior, 34(1), 76-87.

Kaid, L.L. (Ed.). (2004). Handbook of political communication research. Mahwah NJ: Erlbaum.

Karpman, B. (1941). On the need of separating psychopathy into two distinct clinical types: the symptomatic and the idiopathic. Journal of Criminal Psychopathology, 3, 112-137.

Karpman, B. (1948a). The myth of psychopathic personality. American Journal of Psychiatry, 104, 523-535.

Karpman, B. (1948b). Conscience in the psychopath: another version. American Journal of Orthopsychiatry, $18,455-491$.

Kempes, M., Matthys, W., de Vries, H., \& Van Engeland, H. (2005). Reactive and proactive aggression in children: A review of theory, findings and the relevance for child and adolescent psychiatry. European child \& adolescent psychiatry, 14(1), 11-19.

Kingsbury, S. J., Lambert, M. T., \& Hendrickse, W. (1997). A two-factor model of aggression. Psychiatry: Interpersonal and Biological Processes, 60(3), 224-232.

Kockler, T. R., Stanford, M. S., Meloy, J. R., Nelson, C. E., \& Sanford, K. (2006). Characterizing aggressive behavior in a forensic population. American journal of orthopsychiatry, 76(1), 80-85.

Kruskal, J. B. (1964). Multidimensional scaling by optimizing goodness of fit to a nonmetric hypothesis. Psychometrika, 29(1), 1-27.

Kruskal, J. B., \& Wish, M. (1978). Multidimensional scaling.Newbury Park, CA: Sage.

Landis, J. R., \& Koch, G. G. (1977). The measurement of observer agreement for categorical data. Biometrics, $33,159-174$.

Levenson, M. R., Kiehl, K. A., \& Fitzpatrick, C. M. (1995). Assessing psychopathic attributes in a noninstitutionalized population. Journal of personality and social psychology, 68, 151-151. 
Lilienfeld, S. O., \& Arkowitz, H. (2007). What "psychopath" means. Scientific American Mind, 18(6), 80-81.

Little, T. D., Jones, S. M., Henrich, C. C., \& Hawley, P. H. (2003). Disentangling the "whys" from the "whats" of aggressive behaviour. International Journal of Behavioral Development, 27(2), 122-133.

Lopez, V. A., \& Emmer, E. T. (2000). Adolescent Male Offenders A Grounded Theory Study of Cognition, Emotion, and Delinquent Crime Contexts. Criminal justice and behavior, 27(3), 292-311.

Lykken, D. T. (1995). The antisocial personalities. Hillsdale, NJ, England: Lawrence Erlbaum Associates, Inc.

Megargee, E. I. (1966). Undercontrolled and overcontrolled personality types in extreme antisocial aggression. Psychological Monographs: General and Applied, 80(3), 1-29.

Megargee, E. I. (1979). Classifying Criminal Offenders. Beverly Hills: Sage.

Meloy, J. R. (2006). Empirical basis and forensic application of affective and predatory violence. Australian and New Zealand Journal of Psychiatry, 40(6-7), 539-547.

Melton, G. B., Petrila, J., Poythress, N. G., \& Slobogin, C. (1997). Psychological evaluations for the court: A handbook for mental health professionals and lawyers. New York: Guilford.

Merk, W., de Castro, B. O., Koops, W., \& Matthys, W. (2005). The distinction between reactive and proactive aggression: Utility for theory, diagnosis and treatment? European Journal of Developmental Psychology, 2(2), 197-220.

Miller, J. D., \& Lynam, D. R. (2006). Reactive and proactive aggression: Similarities and differences. Personality and Individual Differences, 41(8), 1469-1480.

Millon, T. (1997). The Millon Clinical Multiaxial Inventory-III manual (2nd ed.). Minneapolis, MN: National Computer Systems.

Nightingale, J. (2002). Feeling a million dollars: A grounded theory investigation of preliminary offence chains in aggravated robbery (Doctoral thesis), Victoria University, Wellington. 
Ohlsson, I. M., \& Ireland, J. L. (2011). Aggression and offence motivation in prisoners: exploring the components of motivation in an adult male sample.Aggressive behavior, 37(3), 278-288.

Österman, K., Björkqvist, K., Lagerspetz, K. M., Kaukiainen, A., Huesmann, L. R., \& Fraczek, A. (1994). Peer and self-estimated aggression and victimization in 8-year-old children from five ethnic groups. Aggressive Behavior, 20(6), 411-428.

Ostrov, J. M., \& Houston, R. J. (2008). The utility of forms and functions of aggression in emerging adulthood: Association with personality disorder symptomatology. Journal of Youth and Adolescence, 37(9), 1147-1158.

Parrott, D. J., \& Giancola, P. R. (2007). Addressing "The criterion problem" in the assessment of aggressive behavior: Development of a new taxonomic system. Aggression and Violent Behavior, 12(3), 280299.

Patrick, C. J., \& Zempolich, K. A. (1998). Emotion and aggression in the psychopathic personality. Aggression and Violent Behaviour, 3, 303-338.

Polaschek, D. L., Calvert, S. W., \& Gannon, T. A. (2009). Linking Violent Thinking Implicit Theory-Based Research with Violent Offenders. Journal of interpersonal violence, 24(1), 75-96.

Polman, H., de Castro, B. O., Koops, W., van Boxtel, H. W., \& Merk, W. W. (2007). A meta-analysis of the distinction between reactive and proactive aggression in children and adolescents. Journal of Abnormal Child Psychology: An Official Publication of the International Society for Research in Child and Adolescent Psychopathology, 35(4), 522-535.

Porter, S., \& Woodworth, M. (2007). "I'm sorry I did it... but he started it": A comparison of the official and self-reported homicide descriptions of psychopaths and non-psychopaths. Law and human behavior, 31(1), 91-107.

Poythress, N. G., \& Skeem, J. L. (2006). In Patrick C. J. (Ed.), Disaggregating psychopathy: Where and how to look for subtypes. New York, NY, US: Guilford Press. 
Poythress, N., Skeem, J., Douglas, K., Patrick, C., Edens, J., Lilienfeld, S., Frick, P., Epstein, M., \& Wang, T. (2010). Identifying subtypes among offenders with antisocial personality disorder: a cluster analytic study. Journal of Abnormal Psychology, 119(2), 389-400.

Raine, A., Dodge, K., Loeber, R., Gatzke-Kopp, L., Lynam, D., Reynolds, C., ... \& Liu, J. (2006). The Reactive-Proactive Aggression Questionnaire: Differential correlates of reactive and proactive aggression in adolescent boys. Aggressive behavior, 32(2), 159-171.

Ramirez, J. M., Rodríguez, A., \& Manuel, J. (2003). Aggression's typologies. International Review of Social Psychology, 16(3), 125-141.

Ramirez, J. M., Rodríguez, A., \& Manuel, J. (2006). Aggression, and some related psychological constructs (Anger, Hostility, and Impulsivity): comments from a research project. Neuroscience and Biobehavioural Reviews, 30(3), 276-291.

Ramirez, J. M. (2010). The usefulness of categorizing aggression according its function. International Social Science Journal, 61(200), 263-272.

Robarchek, C. A. (1977). Frustration, aggression, and the nonviolent Semai.American Ethnologist, 4(4), 762779.

Salekin, R. T., Rogers, R., \& Sewell, K. W. (1996). A review and meta-analysis of the psychopathy checklist and psychopathy Checklist—Revised: Predictive validity of dangerousness. Clinical Psychology: Science and Practice, 3(3), 203-215.

Salfati, C. G., \& Canter, D. V. (1999). Differentiating stranger murders: Profiling offender characteristics from behavioral styles. Behavioral sciences \& the law,17(3), 391-406.

Sampson, R. J., \& Laub, J., H. (2005). A life-course view of the development of crime. Annals of the American Academy of Political and Social Science, 62, 12-45.

Schilling, J. (2006). On the pragmatics of qualitative assessment. European Journal of Psychological Assessment, 22(1), 28-37. 
Simon, L. M. (1997). Do criminal offenders specialize in crime types? Applied and Preventive Psychology, $6(1), 35-53$.

Skeem, J., Johansson, P., Andershed, H., Kerr, M., \& Louden, J. E. (2007). Two subtypes of psychopathic violent offenders that parallel primary and secondary variants. Journal of Abnormal Psychology, 116(2), 395-409.

Skeem, J. L., Polaschek, D. L., Patrick, C. J., \& Lilienfeld, S. O. (2011). Psychopathic personality bridging the gap between scientific evidence and public policy. Psychological Science in the Public Interest, 12(3), 95-162.

Skeem, J. L., Poythress, N., Edens, J. F., Lilienfeld, S. O., \& Cale, E. M. (2003). Psychopathic personality or personalities? exploring potential variants of psychopathy and their implications for risk assessment. Aggression and Violent Behavior, 8(5), 513-546.

Spielberger, C. D., Gorsuch, R.L., and Lushene. R.E. (1970). Manual for the State-Trait Anxiety Inventory. Palo Alto, CA: Consulting Psychologists Press.

Stanford, M. S., Houston, R. J., Mathias, C. W., Villemarette-Pittman, N. R., Helfritz, L. E., \& Conklin, S. M. (2003). Characterizing aggressive behavior. Assessment, 10(2), 183-190.

Stanford, M. S., Houston, R. J., Villemarette-Pittman, N. R., \& Greve, K. W. (2003). Premeditated aggression: Clinical assessment and cognitive psychophysiology. Personality and Individual Differences, 34, 773781.

Swogger, M. T., \& Kosson, D. S. (2007). Identifying subtypes of criminal psychopaths: A replication and extension. Criminal Justice and Behavior, 34(8), 953-970.

Swogger, M. T., Walsh, Z., \& Kosson, D. S. (2008). Psychopathy subtypes among African American county jail inmates. Criminal justice and behavior, 35(12), 1484-1499.

Takane, Y., Young, F. W., \& De Leeuw, J. (1977). Nonmetric individual differences multidimensional scaling: an alternating least squares method with optimal scaling features. Psychometrika, 42(1), 7-67. 
Tapscott, J. L., Hancock, M., \& Hoaken, P. N. (2012). Severity and frequency of reactive and instrumental violent offending. Criminal Justice and Behavior, 39(2), 202-219.

Tedeschi, J. T., \& Felson, R. B. (1994). Violence, aggression \& coercive actions (p. 179). Washington, DC: American Psychological Association.

Tkatchouk, M. (2006). Background Characteristics of Stranger Homicide Offenders:

Empirical Profiling (Doctoral dissertation, Simon Fraser University, Vancouver). Retrieved from http://www.psyc.sfu.ca/ugrad/files/HonoursProjects/2006may/TkatchoukMasha.pdf.

Todorov, A., \& Bargh, J. A. (2002). Automatic sources of aggression. Aggression and Violent Behavior, 7(1), 53-68.

Toch, H. (1969). Violent men. Chicago: Aldine.

Van’t Klooster, J. (2011). Development of Violence Across a Lifespan: A Preliminary Model (Master's Thesis, Victoria University, Wellington). Retrieved from http://hdl.handle.net/10063/1996.

Vassileva, J., Kosson, D. S., Abramowitz, C., \& Conrod, P. (2005). Psychopathy versus psychopathies in classifying criminal offenders. Legal and Criminological Psychology, 10(1), 27-43.

Vitacco, M. J., Neumann, C. S., Caldwell, M. F., Leistico, A., \& Van Rybroek, G. J. (2006). Testing factor models of the psychopathy checklist: Youth version and their association with instrumental aggression. Journal of Personality Assessment, 87(1), 74-83.

Vitacco, M. J., Neumann, C. S., \& Wodushek, T. (2008). Differential Relationships Between the Dimensions of Psychopathy and Intelligence Replication With Adult Jail Inmates. Criminal Justice and Behavior, 35(1), 48-55.

Vitaro, F., Barker, E.D., Boivin, M., Brendgen, M. \& Tremblay, R.E. (2006). Do early difficul temperament and harsh parenting differentially predict reactive and proactive aggression? Journal of Abnormal Child Psychology, 34(5), 685-695. 
Vitaro, F., \& Brendgen, M. (2005). Proactive and reactive aggression. Developmental origins of aggression, 25(5), 178-201.

Wales, D. (1995). Personality disorder in an outpatient offender population. Criminal Behaviour and Mental Health, 5(2), 85-94.

Walker, L. J., \& Hennig, K. H. (2004). Differing conceptions of moral exemplarity: just, brave, and caring. Journal of personality and social psychology, 86(4), 629.

Walters, G. D. (2008). Self-Report Measures of Psychopathy, Antisocial Personality, and Criminal Lifestyle Testing and Validating a Two-Dimensional Model. Criminal Justice and Behavior, 35(12), 14591483.

Watson, D., \& Tellegen, A. (1985). Toward a consensual structure of mood. Psychological Bulletin, 98(2), 219-235

Weinshenker, N. J., \& Siegel, A. (2002). Bimodal classification of aggression: Affective defense and predatory attack. Aggression and Violent Behaviour, 7, 237-250.

Williamson, S., Hare, R. D., \& Wong, S. (1987). Violence: Criminal psychopaths and their victims. Canadian Journal of Behavioral Science, 19(4), 454-462.

Woodworth, M., \& Porter, S. (2002). In cold blood: Characteristics of criminal homicides as a function of psychopathy. Journal of Abnormal Psychology, 111(3), 436-445.

Wright, R., \& Bennett, T. (1990). Exploring the Offender's Perspective: Observing and Interviewing Criminals. In K. L. Kempf (Ed.), Measurement Issues in Criminology (pp. 138-151). New York: Springer-Verlag.

Wright, R. T., \& Decker, S. H. (1997). Armed Robbers in Action: Stickups and Street Culture. Boston: Northeastern University Press.

Zamble, E., \& Quinsey, V. L. (1997). The Criminal Recidivism Process. Cambridge, UK: Cambridge University Press. 
Zillmann, D. (1979). Hostility and aggression. Hillsdale, NJ: Lawrence Erlbaum Associates. 


\section{Appendices}

\section{Appendix A}

Overview of the main dichotomous distinctions in the violence literature and the violence characteristic thought to be associated with each.

\begin{tabular}{|c|c|c|c|c|c|c|c|c|}
\hline & \multicolumn{4}{|l|}{ Reactive types } & \multicolumn{4}{|c|}{ Instrumental types } \\
\hline & Impulsive & Reactive & $\begin{array}{l}\text { Expressive } \\
\text { (Hostile/Angry) }\end{array}$ & $\begin{array}{l}\text { Dispute } \\
\text { related }\end{array}$ & Instrumental & Premeditated & Proactive & Predatory $^{4}$ \\
\hline $\begin{array}{l}\text { Brief } \\
\text { description }\end{array}$ & $\begin{array}{l}\text { Spontaneous violence } \\
\text { without forethought. }\end{array}$ & $\begin{array}{l}\text { A response to } \\
\text { provocation to } \\
\text { make the victim } \\
\text { suffer. }\end{array}$ & $\begin{array}{l}\text { Violence which is } \\
\text { used as a way to } \\
\text { express anger and } \\
\text { reduce stress }\end{array}$ & $\begin{array}{l}\text { Angry } \\
\text { violence with } \\
\text { proximate goal } \\
\text { of victims } \\
\text { suffering }\end{array}$ & $\begin{array}{l}\text { Violence for } \\
\text { reward other } \\
\text { than victim } \\
\text { suffering }\end{array}$ & $\begin{array}{l}\text { Planned } \\
\text { violence }\end{array}$ & $\begin{array}{l}\text { Purposeful } \\
\text { violence, } \\
\text { without } \\
\text { provocation }\end{array}$ & $\begin{array}{l}\text { Harm is } \\
\text { incidental to } \\
\text { this form of } \\
\text { violence but } \\
\text { may be } \\
\text { necessary to } \\
\text { achieve other } \\
\text { goals }\end{array}$ \\
\hline Affect & $\begin{array}{l}\text { Anger/hostility } \\
\text { emotionally charged. }\end{array}$ & $\begin{array}{l}\text { Negative (anger } \\
\text { or frustration) }\end{array}$ & $\begin{array}{l}\text { Anger-always } \\
\text { present }\end{array}$ & Angry & $\begin{array}{l}\text { No anger } \\
\text { associated or } \\
\text { required }\end{array}$ & $\begin{array}{l}\text { Without } \\
\text { emotion }\end{array}$ & $\begin{array}{l}\text { "Cold-blooded" } \\
\text { (Dodge, 1991), } \\
\text { No anger }\end{array}$ & $\begin{array}{l}\text { Not usually } \\
\text { angry }\end{array}$ \\
\hline
\end{tabular}

\footnotetext{
${ }^{4}$ Note: While Felson (1993) distinguished between dispute-related and predatory violence Although very similar to the other typologies outlined here this typology is conceptually different to the others, as Felson believed that all acts of violence are at heart instrumental in the sense that they are always underscored by goals beyond that of harm doing (e.g. revenge or status). Felson also allows for mixed types and motives in violent offences.
} 
Appendix A continued

\begin{tabular}{|c|c|c|c|c|c|c|c|c|}
\hline & \multicolumn{4}{|l|}{ Reactive types } & \multicolumn{4}{|c|}{ Instrumental types } \\
\hline & Impulsive & Reactive & $\begin{array}{l}\text { Expressive } \\
\text { (Hostile/Angry) }\end{array}$ & $\begin{array}{l}\text { Dispute } \\
\text { related }\end{array}$ & Instrumental & Premeditated & Proactive & Predatory \\
\hline Planning & $\begin{array}{l}\text { Automatic/unplanned } \\
\text { (Barratt et al, 1999) }\end{array}$ & $\begin{array}{l}\text { Impulsive } \\
\text { (Miller and } \\
\text { Lynam, 2006) or } \\
\text { in response to } \\
\text { provocation } \\
\text { (Merk, de } \\
\text { Castro, Koops } \\
\text { and Mattys, } \\
\text { 2005). When } \\
\text { response to } \\
\text { provocation may } \\
\text { be immediate or } \\
\text { planned. }\end{array}$ & $\begin{array}{l}\text { Unplanned/spontaneous } \\
\text { (Rameriz) }\end{array}$ & $\begin{array}{l}\text { Less likely to } \\
\text { be planned as } \\
\text { offenders are } \\
\text { angry and } \\
\text { because the } \\
\text { motivation to } \\
\text { commit } \\
\text { violence is } \\
\text { more likely to } \\
\text { arise during } \\
\text { the situation, } \\
\text { after a } \\
\text { verbally } \\
\text { aggressive } \\
\text { exchange } \\
\text { (Felson, 1993) }\end{array}$ & Premeditated & $\begin{array}{l}\text { Planned and } \\
\text { purposeful }\end{array}$ & $\begin{array}{l}\text { Reasoned and } \\
\text { organised } \\
\text { (Dodge, 1991) } \\
\text { premeditated } \\
\text { (Merk, de } \\
\text { Castro, Koops } \\
\text { and Mattys, } \\
\text { 2005) }\end{array}$ & Planned \\
\hline
\end{tabular}




\section{Appendix A continued}

\begin{tabular}{|c|c|c|c|c|c|c|c|c|}
\hline & \multicolumn{4}{|l|}{ Reactive types } & \multicolumn{4}{|c|}{ Instrumental types } \\
\hline & Impulsive & Reactive & $\begin{array}{l}\text { Expressive } \\
\text { (Hostile/Angry) }\end{array}$ & $\begin{array}{l}\text { Dispute } \\
\text { related }\end{array}$ & Instrumental & Premeditated & Proactive & Predatory \\
\hline Goal & Harm & $\begin{array}{l}\text { Retaliation or } \\
\text { defence } \\
\text { Protective } \\
\text { function (Merk, } \\
\text { de Castro, } \\
\text { Koops and } \\
\text { Mattys, 2005) }\end{array}$ & $\begin{array}{l}\text { Aimed at causing } \\
\text { damage to the victim } \\
\text { (Vitello and Stoff } \\
\text { 1997) }\end{array}$ & $\begin{array}{l}\text { Harm is } \\
\text { proximate goal } \\
\text { - ultimate } \\
\text { goals of } \\
\text { retribution, } \\
\text { deterrence and } \\
\text { defence }\end{array}$ & $\begin{array}{l}\text { Various } \\
\text { (reward or } \\
\text { advantage) but } \\
\text { non -aggressive } \\
\text { (Berkowitz } \\
\text { 1993, Geen } \\
1990 \text { ) }\end{array}$ & $\begin{array}{l}\text { Goal-directed } \\
\text { e }\end{array}$ & $\begin{array}{l}\text { External reward } \\
\text { and social goals } \\
\text { (e.g. power and } \\
\text { domination) }\end{array}$ & $\begin{array}{l}\text { May represent } \\
\text { relatively } \\
\text { stable long- } \\
\text { term goals, the } \\
\text { precede the } \\
\text { criminal event } \\
\text { - in the short } \\
\text { term violence } \\
\text { is to control the } \\
\text { behaviour of } \\
\text { others to meet } \\
\text { these goals }\end{array}$ \\
\hline Antecedent & $\begin{array}{l}\text { Provoked (Barratt et al, } \\
\text { 1999) }\end{array}$ & $\begin{array}{l}\text { Reaction to } \\
\text { perceived threat, } \\
\text { harm, or } \\
\text { provocation } \\
\text { (Dodge, 1991) }\end{array}$ & $\begin{array}{l}\text { Can be a stimulus that } \\
\text { evokes rage, fear, or } \\
\text { anger }\end{array}$ & $\begin{array}{l}\text { Grievances } \\
\text { with victims } \\
\text { from } \\
\text { perceived } \\
\text { provocation }\end{array}$ & $\begin{array}{l}\text { Driven by } \\
\text { positive } \\
\text { outcome } \\
\text { expectation and } \\
\text { high efficacy } \\
\text { beliefs. }\end{array}$ & $\begin{array}{l}\text { Not specifically } \\
\text { noted, but like } \\
\text { proactive } \\
\text { assumed to be } \\
\text { positively } \\
\text { reinforced. }\end{array}$ & $\begin{array}{l}\text { Occurs in } \\
\text { absence of } \\
\text { provocation }\end{array}$ & $\begin{array}{l}\text { No } \\
\text { provocation, } \\
\text { but attempt to } \\
\text { use target for } \\
\text { own purposes. }\end{array}$ \\
\hline
\end{tabular}




\section{Appendix B}

Overview of the operationalisations of instrumental and reactive violence variables in previous literature

\begin{tabular}{|c|c|c|c|c|c|c|c|c|c|}
\hline Author & Affect & Affect & Goal & Goal & Planning & Planning & Provocation & Provocation & $\begin{array}{l}\text { Other items } \\
\text { coded }\end{array}$ \\
\hline Author & Instrumental & Reactive & Instrumental & Reactive & Instrumental & Reactive & Instrumental & Reactive & \\
\hline $\begin{array}{l}\text { Cornell } \\
\text { et al, } \\
1996\end{array}$ & $\begin{array}{l}\text { Calm or tense } \\
\text { at most }\end{array}$ & $\begin{array}{l}\text { Enraged, } \\
\text { furious, out } \\
\text { of control, } \\
\text { irrational - } \\
\text { short } \\
\text { duration }\end{array}$ & $\begin{array}{l}\text { Unequivocal } \\
\text { goal } \\
\text { directedness } \\
\text { (motivated by } \\
\text { external } \\
\text { incentive) }\end{array}$ & $\begin{array}{l}\text { No apparent } \\
\text { goal } \\
\text { directedness }\end{array}$ & $\begin{array}{l}\text { Extensive } \\
\text { planning }\end{array}$ & $\begin{array}{l}\text { Little or no } \\
\text { planning }\end{array}$ & $\begin{array}{l}\text { No apparent } \\
\text { provocation }\end{array}$ & $\begin{array}{l}\text { Exceptionally strong } \\
\text { provocation (e.g. } \\
\text { severe abuse) }\end{array}$ & $\begin{array}{l}\text { Intoxication } \\
\text { Relationship to } \\
\text { victim } \\
\text { Severity of } \\
\text { violence } \\
\text { Psychosis } \\
\text { Displacement } \\
\text { of target }\end{array}$ \\
\hline $\begin{array}{l}\text { Meloy, } \\
1998\end{array}$ & $\begin{array}{l}\text { Minimal or } \\
\text { absent } \\
\text { autonomic } \\
\text { arousal/no } \\
\text { conscious } \\
\text { emotion }\end{array}$ & $\begin{array}{l}\text { Intense } \\
\text { autonomic } \\
\text { arousal/ } \\
\text { subjective } \\
\text { experience } \\
\text { of emotion }\end{array}$ & $\begin{array}{l}\text { Variable } \\
\text { goals }\end{array}$ & $\begin{array}{l}\text { Goal is } \\
\text { threat } \\
\text { reduction }\end{array}$ & $\begin{array}{l}\text { Planned or } \\
\text { purposeful }\end{array}$ & $\begin{array}{l}\text { Reactive and } \\
\text { immediate }\end{array}$ & $\begin{array}{l}\text { No imminent } \\
\text { perceived } \\
\text { threat - } \\
\text { primarily } \\
\text { attack }\end{array}$ & $\begin{array}{l}\text { Internal or external } \\
\text { perceived threat - } \\
\text { primarily defensive }\end{array}$ & $\begin{array}{l}\text { Displacement } \\
\text { of target } \\
\text { time-limited } \\
\text { sequence } \\
\text { Preceding } \\
\text { behaviour, } \\
\text { awareness }\end{array}$ \\
\hline $\begin{array}{l}\text { Chase et } \\
\text { al., } 2001\end{array}$ & $\begin{array}{l}\text { Not negatively } \\
\text { affectively } \\
\text { charged (i.e., } \\
\text { not angry) or } \\
\text { physiologically } \\
\text { aroused } \\
\text { violence. }\end{array}$ & $\begin{array}{l}\text { Intense anger } \\
\text { or other } \\
\text { increased } \\
\text { negative } \\
\text { affectivity } \\
\text { and/or } \\
\text { physiological } \\
\text { arousal }\end{array}$ & $\begin{array}{l}\text { Evidence of } \\
\text { instrumental } \\
\text { gain }\end{array}$ & $\begin{array}{l}\text { No } \\
\text { evidence of } \\
\text { instrumental } \\
\text { gain }\end{array}$ & $\begin{array}{l}\text { Evidence of } \\
\text { effortful } \\
\text { cognitive } \\
\text { processing prior } \\
\text { to and/or during } \\
\text { the violence (e.g., } \\
\text { mentions that the } \\
\text { violence was } \\
\text { goal-directed, } \\
\text { planned, } \\
\text { calculated, or } \\
\text { otherwise } \\
\text { purposeful). }\end{array}$ & $\begin{array}{l}\text { An impulsive } \\
\text { retaliation or } \\
\text { defence to } \\
\text { perceived } \\
\text { threat, } \\
\text { provocation, } \\
\text { or frustration. } \\
\text { This may be a } \\
\text { misperception. }\end{array}$ & & $\begin{array}{l}\text { Inter-partner conflict } \\
\text { and/or perceived } \\
\text { aversive partner } \\
\text { behaviour }\end{array}$ & \\
\hline
\end{tabular}


Appendix B continued

\begin{tabular}{|c|c|c|c|c|c|c|c|c|c|}
\hline Author & Affect & Affect & Goal & Goal & Planning & Planning & Provocation & Provocation & $\begin{array}{l}\text { Other items } \\
\text { coded }\end{array}$ \\
\hline $\begin{array}{l}\text { Author } \\
\text { Woodworth } \\
\text { and Porter } \\
2002\end{array}$ & $\begin{array}{l}\text { Instrumental } \\
\text { Low affect } \\
\text { arousal }\end{array}$ & $\begin{array}{l}\text { Reactive } \\
\text { High affect } \\
\text { arousal }\end{array}$ & Instrumental & Reactive & $\begin{array}{l}\text { Instrumental } \\
\text { Not impulsive }\end{array}$ & $\begin{array}{l}\text { Reactive } \\
\text { Highly } \\
\text { impulsive }\end{array}$ & Instrumental & Reactive & \\
\hline $\begin{array}{l}\text { Falkenbach, } \\
\text { Poythress, } \\
\text { Creevy, } \\
2008\end{array}$ & $\begin{array}{l}\text { Calm or tense at } \\
\text { most }\end{array}$ & $\begin{array}{l}\text { Enraged, } \\
\text { furious, out } \\
\text { of control, } \\
\text { - short } \\
\text { duration. }\end{array}$ & $\begin{array}{l}\text { Unequivocal } \\
\text { goal } \\
\text { directedness }\end{array}$ & $\begin{array}{l}\text { No } \\
\text { apparent } \\
\text { goal }\end{array}$ & Extensive planning & $\begin{array}{l}\text { Little or no } \\
\text { planning }\end{array}$ & & & $\begin{array}{l}\text { Victim } \\
\text { relationship }\end{array}$ \\
\hline $\begin{array}{l}\text { Vitacco et } \\
\text { al., } 2008\end{array}$ & & $\begin{array}{l}\text { Presence } \\
\text { of intense } \\
\text { anger }\end{array}$ & $\begin{array}{l}\text { Goal- } \\
\text { directed act }\end{array}$ & & $\begin{array}{l}\text { Planning or } \\
\text { preparation before } \\
\text { the aggression }\end{array}$ & & $\begin{array}{l}\text { No apparent } \\
\text { provocation }\end{array}$ & $\begin{array}{l}\text { Exceptionally } \\
\text { strong provocation }\end{array}$ & \\
\hline $\begin{array}{l}\text { Douglas, } \\
2010\end{array}$ & $\begin{array}{l}\text { No evidence of } \\
\text { "hot-blooded" } \\
\text { spontaneous } \\
\text { anger or } \\
\text { frustration. }\end{array}$ & $\begin{array}{l}\text { Hostile, } \\
\text { and angry } \\
\text { behaviour } \\
\text { (e.g., rage) }\end{array}$ & $\begin{array}{l}\text { Evidence of } \\
\text { some type of } \\
\text { goal could } \\
\text { include } \\
\text { reasons such } \\
\text { as: revenge } \\
\text { or } \\
\text { retribution }\end{array}$ & $\begin{array}{l}\text { Motive } \\
\text { appears to } \\
\text { be anger or } \\
\text { displaying } \\
\text { aggression } \\
\text { - primarily } \\
\text { engaged in } \\
\text { to harm the } \\
\text { victim }\end{array}$ & $\begin{array}{l}\text { Evidence of } \\
\text { planning or } \\
\text { premeditated }\end{array}$ & $\begin{array}{l}\text { Appears to be a } \\
\text { spontaneous or } \\
\text { unplanned } \\
\text { (or violence } \\
\text { was not } \\
\text { initially used) }\end{array}$ & $\begin{array}{l}\text { Perception } \\
\text { that the act } \\
\text { was } \\
\text { unprovoked }\end{array}$ & & $\begin{array}{l}\text { Crime Scene - } \\
\text { evidence of } \\
\text { carelessness and } \\
\text { Severity of } \\
\text { Violence }\end{array}$ \\
\hline
\end{tabular}


Appendix B continued

\begin{tabular}{|c|c|c|c|c|c|c|c|c|c|}
\hline Author & Affect & Affect & Goal & Goal & Planning & Planning & Provocation & Provocation & $\begin{array}{l}\text { Other items } \\
\text { coded }\end{array}$ \\
\hline $\begin{array}{l}\text { Author } \\
\text { Tapscott, } \\
\text { Hancock, } \\
\text { Hoaken } \\
2012\end{array}$ & Instrumental & Reactive & $\begin{array}{l}\text { Instrumental } \\
\text { Violence } \\
\text { clearly goal } \\
\text { oriented }\end{array}$ & $\begin{array}{l}\text { Reactive } \\
\text { No apparent } \\
\text { goal other } \\
\text { than } \\
\text { harming } \\
\text { victim }\end{array}$ & $\begin{array}{l}\text { Instrumental } \\
\text { Does not } \\
\text { require } \\
\text { premeditation } \\
\text { - may be } \\
\text { opportunistic }\end{array}$ & $\begin{array}{l}\text { Reactive } \\
\text { No } \\
\text { planning }\end{array}$ & $\begin{array}{l}\text { Instrumental } \\
\text { May be } \\
\text { provocation, } \\
\text { but with a } \\
\text { "Cooling } \\
\text { off" period }\end{array}$ & $\begin{array}{l}\quad \text { Reactive } \\
\text { Evidence of provocation, } \\
\text { without a "cooling off" } \\
\text { period. }\end{array}$ & $\begin{array}{l}\text { Severity of } \\
\text { Violence }\end{array}$ \\
\hline $\begin{array}{l}\text { Camp, et } \\
\text { al., } 2013\end{array}$ & $\begin{array}{l}\text { Calm or tense at } \\
\text { most }\end{array}$ & $\begin{array}{l}\text { Enraged, } \\
\text { furious, out } \\
\text { of control, } \\
\text { irrational - } \\
\text { short } \\
\text { duration }\end{array}$ & $\begin{array}{l}\text { Unequivocal } \\
\text { goal } \\
\text { directedness } \\
\text { (beyond } \\
\text { responding } \\
\text { provocation) }\end{array}$ & $\begin{array}{l}\text { No apparent } \\
\text { goal } \\
\text { directedness }\end{array}$ & $\begin{array}{l}\text { Extensive } \\
\text { planning }\end{array}$ & $\begin{array}{l}\text { Little or } \\
\text { no } \\
\text { planning }\end{array}$ & $\begin{array}{l}\text { No evidence } \\
\text { of } \\
\text { provocation } \\
\text { or "cooling } \\
\text { off" period } \\
\text { since } \\
\text { provocation }\end{array}$ & $\begin{array}{l}\text { Violence immediately } \\
\text { post } \\
\text { provocation/interpersonal } \\
\text { conflict }\end{array}$ & $\begin{array}{l}\text { Intoxication } \\
\text { Relationship to } \\
\text { victim } \\
\text { Severity of } \\
\text { violence } \\
\text { Psychosis } \\
\text { Material gain } \\
\text { Power/domination } \\
\text { Substance abuse } \\
\text { Drug dealing } \\
\text { Gang involvement } \\
\text { Sensation seeking } \\
\text { Lack of } \\
\text { motivation } \\
\text { Respect }\end{array}$ \\
\hline
\end{tabular}




\section{Appendix C}

Overview of the correlates of instrumental and reactive violence found in previous literature

\begin{tabular}{|c|c|c|}
\hline $\begin{array}{l}\text { Correlates of } \\
\text { instrumental } \\
\text { violence }\end{array}$ & Reference & $\begin{array}{l}\text { Correlates of Reactive } \\
\text { violence }\end{array}$ \\
\hline
\end{tabular}

Popularity among

peers

Substance use

Planned and

purposeful

behaviour

Cold/lack of emotion

Goal directed

Violence

conducted for

anticipated reward

Dominance

Low anger

Aggressive sadistic

Low emotional response to threat or conflict

Goals of social gain and dominance

Impulsivity

Intoxication
Berkowitz, (1993);

Weinshenker \& Siegel, (2002).

Siegel, (2004); Stanford,

Houston, Villemarette-

Pittman, \& Greve, (2003);

Williamson, Hare, \& Wong, (1987).

Brendgen et al., (2006);

Berkowitz, (1993);

Weinshenker \& Siegel, (2002).

Dodge \& Coie,

(1987); Walters 2007

Chase, O'learly \& Heyman (2001).

Chase, O’learly \& Heyman (2001).

Chase, O'learly \& Heyman (2001).

Scarpa \& Raine, (1997).

Barratt, Stanford, Dowdy, Liebman, \& Kent, (1999).

Bailey \& Ostrov, (2007).

Connor et al., (2004); Vitiello et al., (1990); Stanford, Houston, Mathias et al, (2003).
Behavioural and autonomic

over arousal

Social isolation

Vitaro \& Brendgen, (2005)

Anger

Vitaro et al., (2002);

Chase, O'learly \&

Heyman, (2001);

Miller \& Lynam,

(2006).

Depressive feelings

Vitaro et al., (2002), Maser \& Clninger, (1990).

Poor impulse control/impulsivity

Anxiety

Miller \& Lynman, (2006), Barratt (1991); Bailey \& Ostrov (2007) Vitaro (2002); Vitaro \& Brendgen, (2005).

Low threshold for disturbing, frustrating or threating stimuli

Miller \& Lynman, (2006).

Irritability (defined as 'readiness to explode with negative affect at the slightest provocation')

Easily provoked

Coccaro et al., (1989).

High remorse and guilt post offence

Barratt, Stanford, Dowdy, Liebman, \& Kent, (1999)

Vitaro (2002); Vitaro \& Brendgen (2005).

High levels of

Vitaro (2002); Vitaro violence/severity
\& Brendgen (2005). 
Appendix C continued

\begin{tabular}{llll}
\hline $\begin{array}{l}\text { Correlates of } \\
\text { instrumental } \\
\text { violence }\end{array}$ & Reference & $\begin{array}{l}\text { Correlates of } \\
\text { Reactive } \\
\text { violence }\end{array}$ & Reference \\
\hline Substance abuse & Hubbard et al 2002, & $\begin{array}{l}\text { Negative } \\
\text { emotionality }\end{array}$ & Vitaro et al., (2006) \\
\end{tabular}

Substance use Paula J. Fite, Adrian

Raine, Magda Stouthamer-

Loeber, Rolf Loeber, \& Dustin

A. Pardini, (2009).

Low physiological Stanford, Houstern,

arousal

Villemarette-Pittman \& Greve, (2003).

Low moral emotion Cima et al., (2007).

Substance use

Paula J. Fite, Adrian

Raine, Magda Stouthamer-

Loeber, Rolf Loeber, \& Dustin

Family violence

Connor, Steingard,

A. Pardini (2009).

Cunningham, Anderson, \&

Cornell et al., (1996).

Melonni, (2004).

Weapon use

Michie \& Cooke, (2006).

Chase et al., (2001).

partner violence

Known victim

(Brendgen, Vitaro, Tremblay \& Lavoie, (2001). 
Appendix D

\title{
CODING GUIDE FOR VIOLENT INCIDENTS: \\ INSTRUMENTAL VERSUS HOSTILE/REACTIVE AGGRESSION
}

\author{
Dewey G. Cornell \\ Curry Programs in Clinical and School Psychology \\ University of Virginia
}

This is the coding guide we used to code violent crimes as instrumental or hostile/reactive forms of aggression. The coding guide is being made available to researchers. This is not an established clinical instrument and is intended only for research purposes. For additional information, see the published study.

Cornell, D. G., Warren, J., Hawk, G., Stafford, E., Oram, G., \& Pine, D. (1996). Psychopathy of instrumental and reactive violent offenders. doumal of Consulting and Clinical Psychology, 64, 783-790.

October 4, 1996. These coding guidelines were developed for research purposes with grant support of the Harry Frank Guggenheim Foundation. Project researchers include Drs. Dewey Cornell, Gary Hawk, and Janet Warren. We thank Ed Stafford, Guy Oram, and Denise Pine for their contributions to this project. These guidelines are subject to revision. Email dcornell@virginia.edu. 
Appendix D Continued

Coding Guide

\section{CODING GUIDE FOR VIOLENT INCIDENTS}

The primary distinction is between instrumental and reactive/hostile aggression. Originally we attempted to make this distinction through a global rating based on the rater's overall evaluation of the incident. However, some violent incidents had both instrumental and reactive/hostile qualities. For example, a person planned and carried out a robbery, but in the course of the robbery became angry when a storekeeper resisted him, and shot him in anger. Therefore, we decided to give priority to the presence of instrumental qualities, based on the theory that reactive hostility is the more common, pervasive form of aggression in criminal behavior and that instrumental aggression in criminal behavior represents a more pathological development and elaboration of the capacity for reactive aggression.

In addition to coding for the presence of instrumental and reactive aggression, the coders will make secondary ratings of these specific aspects of the aggressive act:

1) Planning - degree of premeditation or preparation for aggression

2) Goal-directedness - degree to which aggression is motivated by some external gain or incentive such as money

3) Provocation - degree of provocation, frustration or threat from victim

4) Arousal - degree of anger experienced by aggressor

5) Severity of violence - degree of injury to victim

6) Relationship to victim - closeness of relationship between victim and aggressor

7) Intoxication - intoxication on drugs or alcohol during incident

8) Psychosis - presence of psychotic symptoms during incident

These secondary ratings reflect aspects of the aggressive act which are not necessarily independent of one another. For example, planning and goal-directedness may be correlated. However, each of the components can be distinguished conceptually from the others and we are able to identify specific cases which support these distinctions.

In our discussion of various aggressive acts, the secondary ratings (especially the first four) seem to tap characteristics which contribute to the primary distinction between reactive and instrumental aggression, but these ratings are not equivalent to it. We used the secondary ratings to examine several questions:

1) Is there a stable combination or set of decision rules for the secondary ratings which is equivalent to the primary distinction?

2) Do the secondary ratings permit a sub-classification or refinement of the primary distinction which improves upon it? 
Appendix D Continued

Coding Guide

Page 3

Subjects may be dishonest, inaccurate, or incomplete in their account of the offense. Consider all available sources. Code what you believe to be true, what actually happened. If the subject claims self-defense, but all other available information indicates otherwise, and the subject is of doubtful credibility, code what you believe to be true.

\section{Instrumental Aggression}

The two cardinal characteristics of instrumental aggression are goal-directedness and planning. The instrumental aggressor acts to obtain a readily apparent goal such as power, money, sexual gratification, or some other objective beyond inflicting injury on the victim. Examples of instrumental aggression include shooting a police officer in the course of a bank robbery, stabbing a homeowner during a burglary, and strangling a rape victim. Rape is almost always instrumental. Sadistic aggression is a special form of instrumental aggression in which the objective is some form of pleasure (e.g., power or sexual gratification) that stems from the infliction of pain or attainment of dominance over the other person. Instrumental aggression is initiated as a means to an end rather than as an act of retaliation or self-defense.

Instrumental aggression often involves planning or preparation. However, in some cases instrumental aggression involves relatively little planning, such as in the case of a criminal who engages in an opportunistic offense (e.g., unexpected opportunity to rob someone that involves assaulting the victim). In some cases, a subject may plan a robbery or burglary, and when something goes wrong, engages in an act of aggression, such as shooting someone in order to get away. In these cases the coder should consider that the subject's plans included the possibility of violence, even if there was no specific plan to shoot someone.

Instrumental aggression usually involves little or no provocation by the victim. In some cases subjects may be "provoked" into violence in the course of another crime, e.g., a robbery victim who insults the subject or resists the robbery in some way. These acts are still considered instrumental acts of aggression.

Instrumental aggressors are motivated by goals, not emotions. It follows that their level of emotional arousal, especially anger, is relatively low or is secondary to the act. Some instrumental aggressors try to calm themselves prior to an offense through drug use or drinking. In extreme cases, instrumental aggressors are not angry toward their victims and may have a cold, "business-like" attitude about their behavior. Nevertheless, many less hardened instrumental aggressors are nervous and highly aroused while committing a crime, even though it is not their arousal which motivates their actions.

The term "instrumental" should not be defined so broadly that it encompasses all aggressive behavior simply because there is a definable goal or desired outcome to the aggression, such as warding off an attacker or taking revenge on someone. Aggressive 
Appendix D Continued

Coding Guide

Page 4

behavior whose purpose is to defend against a threat or in some way respond to provocation is defined as reactive/hostile aggression. If the subject is engaged in some form of criminal activity, such as a drug deal, associated violence is almost always instrumental.

\section{Reactive/Hostile Aggression}

The two cardinal characteristics of reactive/hostile aggression are reaction to provocation and arousal of hostility. Aggressive behavior represents reactive hostility to the extent that the aggressor reacts to perceived provocation or threat by the victim. The provocation may include insults, threats of aggression, or other acts that frustrate and anger the aggressor. The objective of the aggressive act is to harm or injure the victim, in response to feelings of hostility that may include a mixture of anger, resentment, fear, or other distress aroused by the victim's actions. Typically, there should be some form of interpersonal conflict (argument, dispute, prior aggression) between aggressor and victim. In many cases the aggressor and victim have a prior relationship as relatives or acquaintances, but in other cases there is no prior relationship and the parties are strangers to one another.

Bear in mind that reactive/hostile aggression can involve extended time-frames. For example, an abused family member may plan an ambush to rid the family of the abuser. The most recent episode of abuse could be long before the aggressive reaction. The critical issue is that the reactive/hostile subject is reacting to an interpersonal conflict that arouses hostility.

3 - Clearly instrumental aggression

2 - Both reactive and instrumental qualities are prominent

(subsequently these cases combined with instrumental group)

1 - Clearly reactive hostile aggression

Do not consider "displaced anger" or any form of displacement from one situation to the next. Many instrumental offenders may be angry at someone else, upset over a failed relationship, lost job, etc. This provides a context for understanding the person, but it should not enter into the determination that a person engaged in instrumental versus reactive/hostile violence. A person who sets out to rob a bank is committing an instrumental act, regardless of any prior life stress. A person who is embroiled in an intense interpersonal conflict with the victim will commit a reactive/hostile offense. 
Appendix D Continued

\section{SECONDARY SCALES FOR VIOLENT INCIDENTS}

\section{Planning}

How much did the subject plan or prepare for the aggressive action? Consider both the length of time involved in preparation and the amount of preparatory activity.

4 - extensive planning (detailed plan or preparation, rehearsal)

3 - moderate planning (contemplation of action for more than 24 hours)

2 - some planning (action within 24 hours, some plan or preparation)

1 - very little or no planning (acts during argument or fight, no preparation)

Assign a (1) to actions which are part of contiguous event, such as pausing during an argument to grab and load a gun. Assign a (2) if there is a break in the argument where the subject leaves the scene of an argument and returns with a gun later in the day.

\section{Goal-Directedness}

How much is the subject motivated by an external incentive, goal, or objective beyond just responding to provocation or threat? Readily apparent goals include money, power, sexual gratification, or some other external goal of benefit to the aggressor. Do not include such goals as self-defense, escaping harm, taking revenge for previous aggression, or acting out of frustration.

4 - Clear, unequivocal goal-directedness (include shooting during crimes)

3 - Primary goal-directedness, with presence of other motives

2 - Secondary goal-directedness, in presence of other primary motives

1 - No apparent goal-directedness (motive to injury victim, retaliate, defend)

\section{Provocation}

Did the victim's actions provoke the subject's aggression? Include provocation that occurred prior to the incident (e.g., prior abusive treatment).

6 - Exceptionally strong provocation (repeated assault, severe abuse)

5 - Very Strong provocation (assault)

4 - Strong (break-up of a romantic relationship, threat of major life change)

3 - Moderate provocation (serious argument or dispute, threat of assault)

2 - Mild provocation (insult, minor argument, confrontation with police)

1 - No apparent provocation

Consider the subject's personal point of view, even if the subject has a delusional perception of threat. 


\section{EXPLORING THE INSTRUMENTAL AND REACTIVE DICHOTOMY}

Appendix D Continued

Coding Guide

Page 6

Arousal

How much emotional arousal, especially anger, did the subject experience at the time of the aggressive act? Just code the subject's mental state, not attitude toward the victim.

4 - Enraged, furious, described as "out of control" or "irrational"

3 - Angry, mad, extremely frightened (can be protracted state)

2 - Excited, very nervous, anxious

1 - Calm or tense at most

Arousal at the (4) level is extraordinary, and should be of short duration.

\section{Severity of violence}

7 - Extreme homicide (multiple killing, mutilation)

6 - Homicide

5 - Severe injury (lasting impairment or life-threatening injury, some rapes)

4 - Serious injury, requiring substantial hospital treatment (broken limb, rape, gunshot)

3 - Minor injury (e.g., bruises, minor medical treatment, attempted rape)

2 - Assault without injury

1 - No assault (e.g., threatened with weapon)

\section{Relationship with victim}

Code the degree of contact or closeness between aggressor and victim. The scores listed here are typical scores. Some relationships may require higher or lower scores than indicated. Generally give maximum scores to immediate family members, unless there has been prolonged separation or lack of contact that substantially alters the relationship (e.g., father who never lived in the home, mother who turned over care of child to grandmother). A step-parent may receive the same score as a parent if there appears to have been similar bonding and contact since early childhood. Code based on duration and closeness of relationship.

5 - Very close relationship (immediate family member, romantic partner)

4 - Close relationship (friend, relative, dating partner, etc.)

3 - Specific relationship (teacher, babysitter, etc.)

2 - Acquaintance

1 - Stranger 


\section{Intoxication}

Code whether the subject was intoxicated at the time of the aggressive incident. Consider alcohol and other drugs. Primary concern is degree to which the person is impaired or has clouded consciousness. Consider how much intoxication played a role in the subject's actions.

4 - Severe intoxication (large quantities of alcohol or drugs, very impaired)

3 - Intoxicated

2 - Mild intoxication (e.g., 1 or 2 drinks)

1 - Not intoxicated

Generally code (4) for subjects who are "falling down drunk" or extremely impaired by multiple substances, etc.

Psychosis (reality testing, not mood)

4 - Substantial psychotic symptoms (e.g., bizarre or pervasive delusions)

3 - Moderate psychotic symptoms (intermittent voices or delusions)

2 - Non-psychotic disturbance (e.g., depersonalized)

1 - Not psychotic

Generally code (4) for subjects who are very impaired by psychosis and have active symptoms. What you might call "falling down psychotic." Code (3) for individuals with mild, residual symptoms or more circumscribed symptoms that do not seriously impair everyday functioning. A man with a paranoid delusion about the victim who is nevertheless able to hold a job and function in many social situations is a (3). An actively psychotic man living on the street is probably a (4). 
EXPLORING THE INSTRUMENTAL AND REACTIVE DICHOTOMY

Appendix E

Instrumental and Reactive Coding Scheme

This coding scheme is intended to identify variables relating to the instrumental and reactive subtypes of violence. 
EXPLORING THE INSTRUMENTAL AND REACTIVE DICHOTOMY

Appendix E Continued

Offence chain No:

In the case of multiple offences, specify here where the offence to be coded begins and ends:

General instructions on use of coding scheme:

1. Read through offence chain before coding.

2. Follow the definitions set out in the coding scheme carefully.

3. Code what is stated in the offence chain (even where it seems untrue).

4. Note evidence for the selections made.

5. If nothing is stated for a particular variable infer the most likely answer if possible.

6. If there is no perfect answer, chose the answer which is the "best fit" 


\section{Appendix E Continued}

\section{Pre-offence (Lead up to offence, days/weeks)}

1. Proximal stressors - these are general factors which in the lead up (days or weeks) to the offence may influence the offender's state of mind, well-being, point of view, mood or willingness to aggress. Note:

- Proximal stressors are not the same as the immediate triggers or provocations that directly instigate the offending (though they may be related).

- Only code these factors if they are actually causes stress (e.g. an offender might be in prison, but think they are doing OK there), but code all stressors regardless of whether or not they appear to contribute to offence.

- Can code multiple answers.

0. None apparent

1. Business, employment or financial problems (e.g. Financial struggles, bad business deals, job loss etc.)

2. Relationship problems (difficulties with or stress relating to partner/friends/family - include, for example, arguments, problems with family heath or wellbeing)

3. Gang related problems

4. Drug related problems (Apparent abuse or addiction, crime committed to obtain drugs for personal use etc. Do not code drug or alcohol intoxication.)

5. Other:

2. Proximal mood - this is general mood of the offender in the few hours preceding the offence (not during offending).

Note:

- Code the most predominate affective state/s prior to provocation; try not to be overly concerned with slight mood aberrations.

- If there is little information code any mood that is mentioned prior to the offence/provocation.

- Code (5) if there is no other information and emotional arousal cannot be inferred

- Can state generally negative, neutral or positive if there is too little information to choose a particular affective state.

- Can code multiple answers.

1. Angry

2. Frustrated

3. Tense (stressed, worried, upset or agitated)

4. Depressed (feels hopeless, sad, a failure or generally down)

5. Calm or not obviously emotionally aroused (neutral, just getting on with things)

6. Excited or positive mood

7. Other stated: 


\section{Appendix E Continued}

\section{Pre-Offence (immediate)}

3. Provocation - Did the victim/other's actions provoke the subject's aggression? Provocation, even if from someone other than the victim or in the past must appear to be directly linked to the offence occurring (e.g., prior abusive treatment), and arouse the desire to offend (not just the offending behaviour) e.g. don't code being talked into offending as provocation.

Note:

- Provocations do not include simple stressors. Provocations should be specific events or situations in which another person/s, directly or indirectly, arouses the desire to aggress in the offender. Provocation, however, does not need to be deliberate.

- $\quad$ There may be a difference between the truly provoking event and an event that appears to trigger offending when there is a delay between provocation and offending. The provocation is what causes the aggression, the trigger might relight it. When this is the case code what appears to be the more provoking event (the event that appears to directly lead to offence occurring) but make a note of the trigger. When there is a general build-up of stress from various, not specifically provoking events, the trigger ("The straw that broke the camel's back") may be coded as a provocation.

- $\quad$ Consider the subject's personal point of view, rather than personal notions of provocation when coding.

\section{A. Type/Level of provocation}

Note the instigating event (who and what provoked the offender), also note triggers if relevant:

\section{B. Intensity of provocation/response to provocation}

Note:

This relates to the response to provocation from the offenders perspective - e.g. the provocation may seems objectively highly provoking, but the offender may respond to it initially calmly and walk away and put aside, for this example a (1) would be coded, even if the offender responded to the provocation highly aggressively later.

0. No discernable provocation

1. Mildly provoking to offender: response is calm and offender able to inhibit aggression easily. Still thinks the other's actions may require a response from him but it does not need to be immediate and he can "let it go" and/or wait for a good opportunity to respond.

2. Moderately provoking, offender highly aroused by provocation but may be able to inhibit aggression as effect of provocation is not as initially overwhelming as for (3); may be able to put it aside for a time, wait until there is a good opportunity. However when he thinks about it at later times, or encounters the provocation again, he gets wound up again. He may also respond immediately, but will not be as overwhelmed or out of control as for (3)/ is able to think about his actions.

3. Intensely provoking, offender "ramped up" and unable to inhibit aggression, offence appears directly driven from the provocation "overwhelming" the offender; offender has abandoned any serious consideration of whether they should carry out the intended act, what the consequences might be etc. Unless prevented, they will respond immediately to provocation. 


\section{Appendix E Continued}

C. Immediate affective response to provocation (code the immediate response even when provocation happened some time prior to the offence).

Note: Can code multiple answers.

0. No discernable provocation

1. Angry

2. Frustrated

3. Tense (stressed, worried, upset or agitated)

4. Hurt (feelings hurt, injured pride, betrayed)

5. Calm or not obviously emotionally aroused

6. Excited

7. Other stated:

\section{Planning for offence}

0. No planning (completely impulsive, actions may even take the offender by surprise)

1. Very little (offender decides to offend or knows he wants to offend, but no real thought given to how the offence will be carried out e.g. "he had to pay", "if I see him I'll kill him", "I decided to rob a store")

2. Moderate planning (some contemplation of action for a few hours to day or has a few basic details laid out e.g. weapon has been obtained, roles decided, target chosen, some thought given to how the act will be carried out)

3. Extensive planning (detailed plan or preparation, rehearsal)

5. Intoxication - the primary concern is degree to which the person is impaired or has clouded consciousness

Note:

- For (A) generally code (2) for subjects who are "falling down drunk" or extremely impaired by multiple substances, etc. (Cornell et al, 1996).

- For (A) code (0) when there is insufficient detail about substances taken prior to offending.

- Intoxication or severe intoxication maybe inferred if the offender is a daily user even if pre-offence drug use is not stated specifically (e.g. if it is known that drugs were consumed every morning).

\section{A. Level of Intoxication}

0 . Not intoxicated

1. Intoxicated (has consumed alcohol or other drugs, but appears able to function well and has no memory or other impairment due to drug use)

2. Severe intoxication (has consumed very large quantities of any single drug or a variety of drugs and/or is mentally or physically impaired, "out of it".

\section{B. Relevance of intoxication}

0 . No drug use

1. Routine - the offender uses regularly or is intoxicated - but no relevance of intoxication to the offending is attributed by offender/the offender doesn't mention intoxication in relation to offending.

2. Contributes - being intoxicated is seen to contribute in some way to the offence occurring/the offender may often mention intoxication in reference to offending.

3. Causal - intoxication allows the offending to occur - e.g. gives courage to go through with it, amplifies the intensity of the offence: the offence would not have occurred without intoxication. 


\section{Appendix E Continued}

\section{Offence}

6. Goals of offence - Goals refer to the primary goals/motivations driving the offence. Note:

- $\quad$ Code all the goals that appear relevant to the offending, even if they seem to be very different to each other or change suddenly. Consider what the offender states is driving the offence or what they want to get from offending.

- Note what appears to be the predominant goal overall (there may be more than one if the goal changes), code these goals (M). Code any goals that may seem more secondary as well.

- If the goal of offending appears to change during the offence, code the predominant goal at outset of offence (M1) first, then the other goals (M2), (M3)...etc. in temporal order.

- It is not relevant to the coding whether the goals where achieved or not.

- $\quad$ For the purposes of coding (3) if the threat has passed, or if it is too minor to warrant defence, do not code the offence as defence.

- $\quad$ Can code multiple answers.

0. Primary goal unclear, no apparent goal or accidental harm

1. Material gain

2. Compliance ("compellence" or deterrence, a desire or attempt to control the behaviour of others, e.g. making target hand over money, controlling behaviour of partner or other (e.g. preventing them from leaving)

3. Defence (responding to physical or verbal threat against their physical wellbeing, position or lifestyle, (e.g. violence used to escape the crime scene), also defending others against threat)

4. Self-presentation (gangs, enhancing status, social dominance, promoting self-image, showing how "tough" they are, power and control, bolstering reputation, teaching the target "a lesson" setting an example to others or "putting out a message")

5. Payback (revenge, retribution, justice, retaliation for wrongs to self or others)

6. Sensation seeking (e.g. excitement, thrill, sadism, escaping boredom)

7. Catharsis (release of a build-up of anger or frustration, expressing anger and frustration)

8. Other:

7. Emotion - Emotions of offender at outset of, during or immediately post offence Note:

- $\quad$ Code the most predominant emotion/mood at the time of the offence occuring (M).

- $\quad$ Code any other stated emotions also.

- If the predominant emotion of the offender appears to change during the offence code the predominant emotion at outset of offence (M1) then the other emotions (M2), (M3)...etc. in temporal order.

- $\quad$ Can code multiple.

\section{A. Associated Emotions}

1. Fear (code this only if offender is extremely frightened or scared e.g. for their life, code simple nerves/anxiety under "other")

2. Anger

3. Frustration

4. Neutral, calm, "don't care"

5. Excitement, pleasure, adrenalin "rush"

6. Other Stated:

7. Unclear 


\section{Appendix E Continued}

B. Level of emotional arousal - level of emotion at outset of/during offence - how aroused or "worked up" the offender appears to be.

Note:

- Code the overall level of arousal.

0. No emotional arousal (e.g. seems "cold" or "unmoved" by offending, offender is calm and collected, not bothered by offence)

1. Low emotional arousal (e.g. states that he was tense, nervous, anxious, excited)

2. Moderate (e.g. angry, mad, extremely frightened)

3. High emotional arousal (e.g. extremely angry, enraged, furious, "out of control", "irrational", or "seeing red").

4. Insufficient information.

\section{Relationship to victim/s}

Note:

- If there is more than one victim, code for whom you consider to be the main victim only

0. Unknown

1. Known (e.g. acquaintance gang rival, partner's family, fellow inmate, 'mate' etc.)

2. Close relationship (e.g. close friend, partner, immediate family member)

9. Harm - refers to the physical violence that occurs within an offence - code harm that is either done by the offender or that he has actively contributed to (e.g. holding someone down while they are beaten).

A. Severity of Violence/ level of injury - this refers to the most severe act of violence during the offence - if injury level not explicitly stated code what is implied in offence description.

0. No assault e.g., threatened with weapon

1. Minor injuries e.g., bruises, minor medical treatment, cuts

2. Moderate e.g. major bruising, minor breaks (fingers etc.), and larger cuts.

3. Serious injuries requiring hospital treatment e.g., broken limb, rape, gunshot, serious stab wounds

4. Severe injury e.g. lasting impairment or life-threatening injury

5. Death

B. Intention of harm - this considers whether when the offending started, the offender had intent to physically harm the victim - does causing harm seem to be a significant goal? For example In violent offending that started out as a burglary there may be no intent to harm at the outset of the offence, even if this changes during the offence. The extent of the harm intended or done is not relevant, only the general intent to cause bodily injury when offending. Where there is little information make a "best guess".

1. Harm unintended at outset of offence

2. Harm intended at outset of offence (offends with intent to harm physically - regardless of other goals - does not need to be planned, may appear automatic) 


\section{EXPLORING THE INSTRUMENTAL AND REACTIVE DICHOTOMY}

\section{Appendix E Continued}

C. Loss of control - the extent to which the offender appeared to be able to control himself during violence enactment (harm doing).

1. Full control (violence infliction is measured and offender remains controlled - e.g. violence may be used to achieve a goal (such as getting money) only and stops when goal is achieved)

2. Some control (violence has some disinhibited elements but offender demonstrates some control and is able to stop)

3. No control/lost control (out of control, seeing red, can't or won't stop, violence far exceeds what is required to achieve goal)

D. Weapon use - weapon use includes threatening behaviour, not just physical assault. Note:

- Weapons can be any external physical object used for the purpose of aggression (e.g. carving knife, bottle, screwdriver, axe, brick, crowbar etc.)

- The functionality of weapon is irrelevant, code an unloaded gun or a replica the same as a loaded weapon.

- Weapon use only refers to the offender - not co-offenders.

0. No weapon use (includes not having a weapon, or having one about person but not using it, or no weapon mentioned)

1. Had weapon prior to offending and used it (e.g. may carry weapon as a matter of course, having the weapon may not be directly linked to the offending but the weapon is used during the offence)

2. Acquired weapon specifically to commit offence and used the weapon (even offending is already underway - deliberately seeks out weapon e.g. breaks off offending to find an axe he knows is around then returns to offending with weapon)

3. Acquired weapon during offence opportunistically (e.g. took weapon off victim or other, grabs nearby bottle) and uses weapon.

4. Uses weapon - no information about acquisition.

10. Role of offender

Note:

- If it is unclear whether offender is recruited or recruited, code offender as "recruiter" if they appear to have a primary/main role when offending with others.

1. Sole offender

2. Recruits and leads co-offenders for offence, and is the primary offender

3. Is a recruited co-offender - does not plan/instigate offence but has a role which may or may not be active. (Being recruited offender does not preclude the possibility of the offender having a primary role). Consider the offender recruited if pushed into offending by others.

4. Bystander who becomes involved in the offence (e.g. might get involved in a bar brawl that he did not instigate, takes the opportunity to offend). 


\section{Appendix E Continued}

\section{Post-Offence}

11. Feelings of regret/remorse - immediately after offence - how offender feels about the offense immediately after it occurs.

Note:

- $\quad$ Do not code post event anger with self or offence going wrong, or concern about being caught as regret. Both regret and remorse require an element of "being sorry".

0. None (e.g. glad, "not sorry" etc.) Offender states or implies that neither regret nor remorse is felt; either there is an absence of remorse /regret or the offender is pleased about the offence.

1. Regret - the offender is disappointed or sorry for how the situation has turned out or may turn out in regards to his own outcome (including how his family may be affected) - e.g. regrets being in prison or leaving his son without a dad

2. Remorse - the offender shows deep regret which involves a strong emotional reaction involving anguish or guilt and shame or repentance; applied to those his offending harmed, and their loved ones e.g. offender may be deeply remorseful about the death of a victim or the pain they have caused the victim's family). If there is recognition of how his victims may have felt without an actual demonstration of remorse, code as regret e.g. "she must have felt really scared".

3. Insufficient information.

12. Feelings of regret/remorse - delay (days, weeks, months or years) - how offender feels about the offense in retrospect.

Note:

- Do not code post event anger with self or offence going wrong, or concern about being caught as regret. Both regret and remorse require an element of "being sorry".

0. None (e.g. glad, "not sorry" etc.) Offender states or implies that neither regret nor remorse is felt; either there is an absence of remorse /regret or the offender is pleased about the offence.

1. Regret - the offender is disappointed or sorry for how the situation has turned out or may turn out in regards to his own outcome (including how his family may be affected) - e.g. regrets being in prison or leaving his son without a dad

2. Remorse - the offender shows deep regret which involves a strong emotional reaction involving anguish or guilt and shame or repentance; applied to those his offending harmed, and their loved ones e.g. offender may be deeply remorseful about the death of a victim or the pain they have caused the victim's family). If there is recognition of how his victims may have felt without an actual demonstration of remorse, code as regret e.g. "she must have felt really scared".

3. Insufficient information. 
EXPLORING THE INSTRUMENTAL AND REACTIVE DICHOTOMY

Appendix F

Watson and Tellegen's Two-Factor Structure of Affect (1985, p.221)

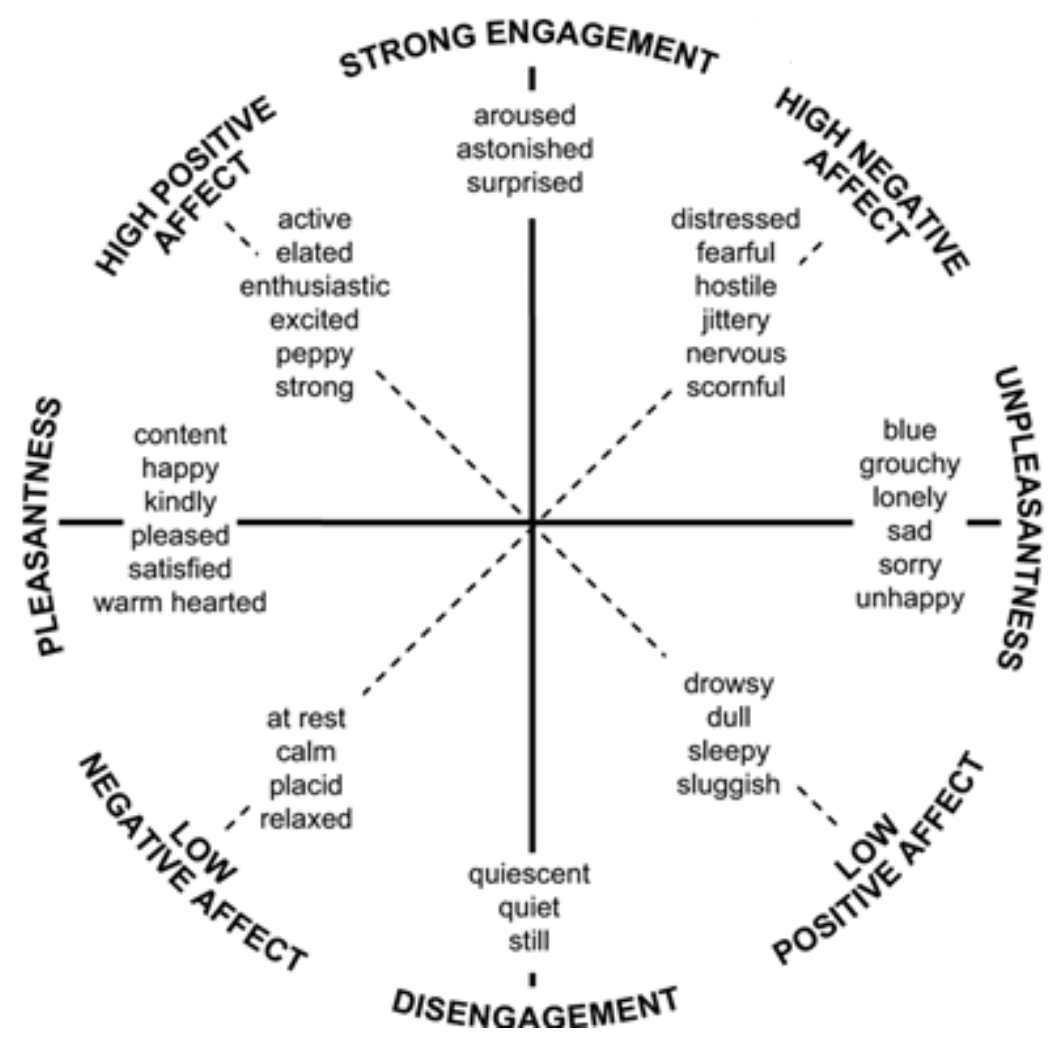


EXPLORING THE INSTRUMENTAL AND REACTIVE DICHOTOMY

Appendix G

Definitions and abbreviations of variables used in MDS analysis

Variables Abbreviation Definition

\section{Proximal Factors}

Business as proximal stressor

Relationship as proximal stressor

Drug as proximal stressor Drugprox

No proximal stress

Negative affect with high arousal proximal

No affect proximal

Negative affect with Low arousal proximal
Businessprox Business, employment or financial problems

RelatProx Problems with relationships, including intimate partners, family and close friends.

Drug/alcohol abuse or addiction is apparent. The abuse/addiction may have also led to other problem such as having committed crimes to obtain drugs, or the need of money for drugs.

Noproxstress No background stress was mentioned or offender stated life was going well.

NegHighProx Anger, tension and frustration are present prior to provocation or the offence occurring.

Noaffectprox Neutral mood: calm or just "getting on with things" prior to offending.

NegLowProx

Depressed or feeling hopeless. Prior to offending the offenders' mood is negative but low in energy. Negativity is directed at self rather than outwardly.

Offender is annoyed or offended by another person or feels betrayed by the actions of this person (excluding intimate partner actions).

Provmoney Money, possessions or drugs are stolen or owed to the offender.

Provdomestic Intimate partner argument, insult, or infidelity

Provthreat
Verbal or physical threat to self or others - can be threat of physical harm or threat to position or lifestyle. 


\section{Provocation/response}

No provocation

Intense response to provocation

Mild/ moderate considered response to provocation

Provocation with Anger Provwithanger

Provocation with non-angry Negative affect with high arousal

\section{Planning}

No planning

NoPlan

GoodPlan

Moderate to extensive planning (planned)

\section{Intoxication}

Intoxication contributes to offence

Intoxication does not contribute to offence
No provocation cited.

Provocation is immediately triggering. The offender is unable to inhibit aggression and has abandoned any serious consideration of what the consequences might be. Unless prevented, they will respond immediately to provocation.

MildProvresp Provocation appears mildly arousing to the offender: the offender is able to inhibit aggression easily and/or wait for a good opportunity to respond.

Offender response to provocation includes anger.

ProvwithhighNeg Offender responds to provocation with strongly negative affect (hurt, frustrated, tense etc.) and high arousal. No anger was reported to be present.

Offence appears completely impulsive or automatic; actions may even take the offender by surprise. There seems to be no prior knowledge of intent to offend.

There is a degree of consideration given to how the offence will be carried out beyond simply knowing he intended to offend.

Intoxcontributes

Being intoxicated is seen to either contribute to the offence in some way, or be causal to the offence occurring.

Intoxnotcontrib

No relevance of intoxication to the offending is attributed by offender. 


\begin{tabular}{lll}
\hline Variables & Abbreviation & Definition
\end{tabular}

\section{Goals}

Compliance goal

Compliancegoal

"Compellence" (Felson, 2009) or deterrence, a desire or attempt to control the behaviour of others, (e.g., making target hand over money, preventing them from leaving).

Catharsis goal Catharsisgoal

Defence goal

Payback goal

Material goal

Self-Presentation goal

Goal of helping others

Sensation seeking goal.

\section{Affect/arousal}

Non angry

Negative affect

during offence

No affect during offence

Anger
Defencegoal

Paybackgoal

Materialgoal

Presentationgoal

Offence occurs to release a build-up of anger or frustration, or to express anger and frustration.

Responding to physical or verbal threat against physical wellbeing, or to maintain status or position against threat. Also defending others against threat.

Revenge, retribution, justice or retaliation for wrongs to self or others.

Offender seeks material reward.

Enhancing status, social dominance, promoting control, bolstering reputation, teaching the target "a lesson" setting an example to others or "putting out a message".

Helpingothers

Offends to help another person to achieve goals; these goals maybe be external (e.g., money) or internal (e.g., retaliation). This variable does not include defending others, which is coded as a defence goal

Sensationseeking Offending for e.g., excitement, thrill, sadism, escaping boredom.

Negaffectduring

Hurt, frustrated, fearful or tense while committing offence.

Noaffectduring

Seems cold, calm or “doesn't care” during offending.

Offender feels anger during offending. self-image, showing how "tough" he is, power and 


\section{Variables \\ Affect/arousal \\ Highly aroused}

Abbreviation

Higharousalduring

Low arousal / no arousal

\section{Victim}

Victim known

Victimknown

\section{Injury}

No or minor

assault

Serious to fatal Seriousassault assault

Physical harm Harmintended intended outcome

\section{Control}

Full control

Fullcontrol

No control
Minorassault

Harmintended

Offender is highly emotionally charged while committing the offence e.g., extremely angry, enraged, furious, "out of control", "irrational", or "seeing red".

\section{Definition}

Offender has little emotionality during commission of offence. "Cold" or "unmoved" by offending, offender is calm and collected, or no more than tense or slightly anxious.

Victim is known to the offender in some way, ranging from acquaintances though to intimate relationships

No assault occurred (e.g., threatened with weapon) or minor injuries (e.g., bruises, minor medical treatment, cuts) were the most serious physical injuries caused by the offender in the course of the offence.

Serious injuries requiring hospital treatment (e.g., broken limb, rape, gunshot, or serious stab wounds), severe injury (e.g., lasting impairment or life-threatening injury) or death was caused by the offender during the course of the offence.

Offends with clear intent to cause physical harm to the victim - this intent does not need to be planned, and may appear automatic, but harm is the desired outcome of the offence.

Violence infliction is considered and offender remains controlled - e.g., violence may be used with the sole purpose of achieving a goal (such as getting money), and stops when goal is achieved.

Out of control, seeing red, cannot or will not stop, violence far exceeds what is required to achieve goal. 
EXPLORING THE INSTRUMENTAL AND REACTIVE DICHOTOMY

Appendix G Continued

Variables Abbreviation

Definition

\section{Proximal Factors}

\section{Weapons}

Weapon - acquired Weaponplanned

to offend/planned

Weapon - had prior/ Weaponopportunistic opportunistic

\section{Offender}

Offends alone
OffendsAlone
Weapon was deliberately sought out for the commission of offence.

Weapon was already "at hand" or otherwise acquired opportunistically e. g. took weapon off victim or other or grabbed nearby bottle

Offender carries out offence without the intervention or assistance of others. 
EXPLORING THE INSTRUMENTAL AND REACTIVE DICHOTOMY

Appendix $\mathrm{H}$

Dendrogram output for HCA of all variables

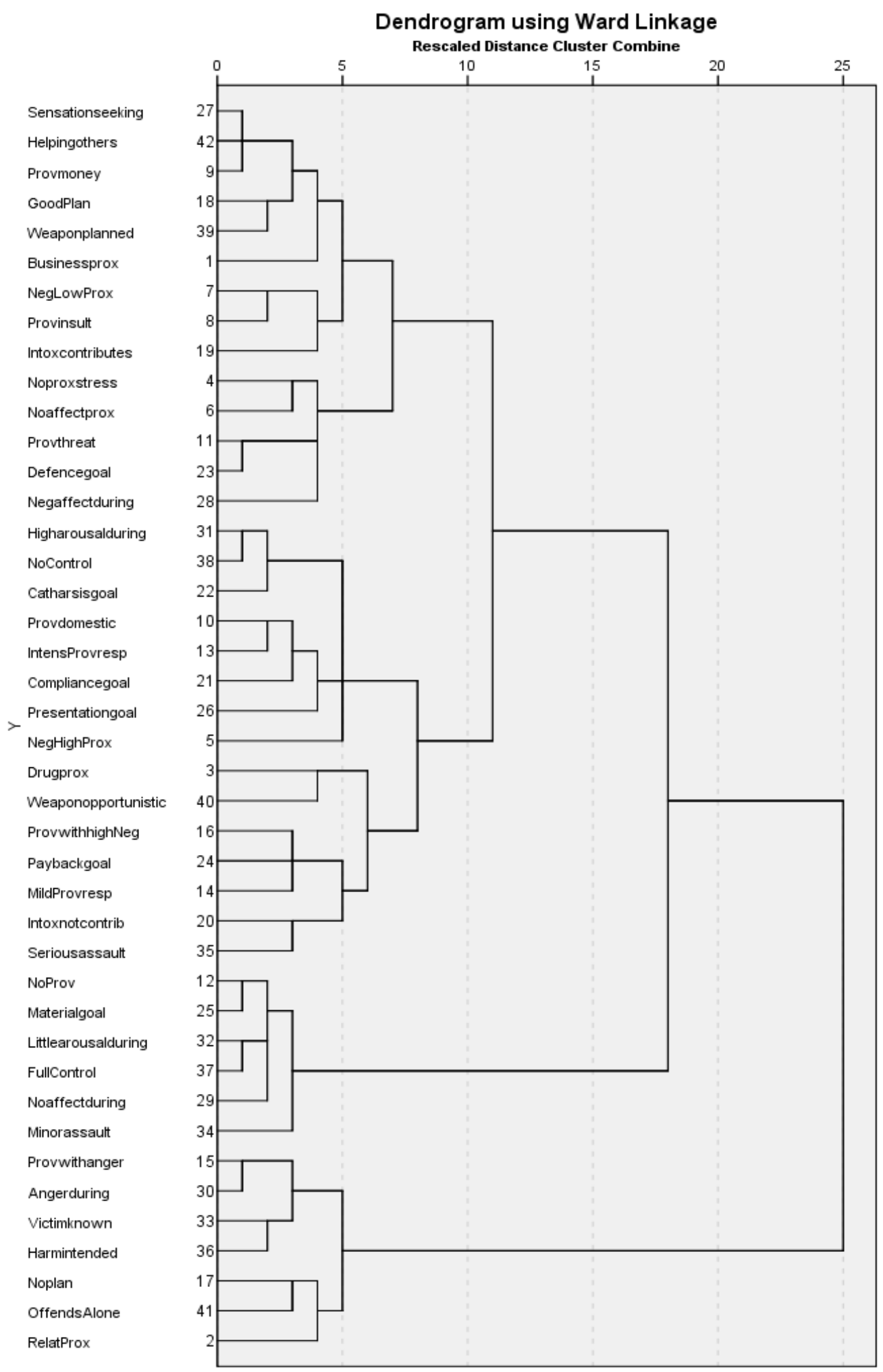

